\title{
BIOORTHOGONAL FLUORESCENT LABELS: A REVIEW ON COMBINED FORCES
}

\author{
Gergely B. Cserép, András Herner and Péter Kele*
}

Address: Chemical Biology Research Group, Hungarian Academy of Sciences, Research Centre for Natural Sciences, Institute of Organic Chemistry. H-1117 Magyar tudósok krt. 2, Budapest, Hungary

e-mail:kele.peter@ttk.mta.hu

\begin{abstract}
This review ventures upon to summarize the latest developments in bioorthogonal fluorescent imaging labels with a special focus on bioimaging applications. We briefly summarize the most preferred means of bioorthogonal tagging schemes for the labeling of specific biomolecular structures. The review is structured by the type of the fluorescent labels that can address the problems that most commonly compromise fluorescent imaging techniques i.e. autofluorescence of biomolecules, background fluorescence of unreacted reagents and photobleaching. Thus we present i) far-red / near-infra-red emitting dyes, ii) fluorogenic scaffolds and iii) nanoparticle based signaling platforms.
\end{abstract}

\section{Introduction}

In line with the growing needs of chemical biology, progress in bioorthogonal chemistry has brought great advances in bioconjugation related techniques. Since Bertozzi and Saxon has formulated the postulates for bioorthogonality in 2002 a set of bioorthogonal reactions was delineated.[1] Covalent modification of biomolecules by means of bioorthogonal reactions rely on the ready and selective (orthogonal) reactions of biocompatible, non-natural cognate functions inside living systems while they do not interfere with the multitude of endogenous groups (e.g. thiols, amines) present in biomolecules.[2,3,4,5,6,7] Most bioorthogonal tagging reactions follow a two-step manipulation scheme. First, the biomolecule of interest is modified with one of the bioorthogonal functions (chemical reporter) by means of chemical, enzymatic, metabolic incorporation or protein engineering. Then the bioorthogonalized system can be selectively targeted with a secondary reagent (marker, affinity label etc.) harboring the 
complementary bioorthogonal function.[1-7] These lately developed reactions enable controlled and exquisite manipulation of biomolecules. Such manipulated systems then can be used to interrogate biological systems in order to get deeper insight into biomolecular processes. Since fluorescent microscopy techniques offer excellent temporal and spatial resolution for the monitoring of these in vivo processes, most bioorthogonal tagging schemes involve fluorescent modulation of the biomolecule of interest.[8]

In this review we discuss the latest developments in bioorthogonal fluorescent labeling techniques with a special focus on bioimaging applications using different fluorescent species. We briefly summarize the most preferred bioorthogonal tagging schemes together with the possible means for the bioorthogonalization of biomolecular structures. At the end we attempt to give some insights into the future challenges of the field.

\section{Bioorthogonal reactions}

The early 2000s resulted in the delineation of a set of reactions with the potential to be applicable in living systems. Several, related and recent reviews list all these chemistries in details.[1-7] Although wider selections of bioorthogonal reactions list more chemical transformations e.g. aldehyde/ketone-amine ligations, herein we restrict our discussion to chemistries that either use purely non-natural functions or non-natural combinations of natural functions (e.g. Cys4-tag) to ensure selective ligation (Figure 1).

\subsection{Staudinger-(Bertozzi) ligation}

Triaryl-phosphanes harboring an ester function as an electrophilic trap together with organic azides are moieties that are stable in biological media and indifferent to the presence of natural functions react readily with each other resulting in the formation of a stable amide bond.[1,9,10,11] Though this transformation is quite slow (Figure 1) and some of the reagents is lost due to spontaneous oxidation of the phosphanes, it still remains popular for its full biocompatibility, selectivity and its potential to construct fluorogenic probes.

\subsection{Photoclick recation}

The reaction developed by Lin et al. generates nitrile imine intermediates from tetrazoles following a short pulse of UV irradiation.[12,13,14,15,16] The reactive dipolar species undergo rapid cycloaddition with olefins affording fluorescent pyrazoline derivatives

(Figure 1). In spite of its need for UV irradiation the inherent fluorogenicity and photo- 
controllability, which enables spatial and temporal control makes this transformation quite appealing.

\subsection{Azide-alkyne cycloadditions}

Similarly to the Staudinger-ligation the copper catalyzed azide-alkyne 1,3-dipolar cycloaddition (CuAAC) also makes use of the small, stable, yet highly energetic azide group.[17] This highly valuable regioselective reaction between organic azides and terminal alkynes in the presence of $\mathrm{Cu}(\mathrm{I})$ catalyst gives rise to the formation of a stable, covalent 1,4disubstituted triazole-linkage.[18,19,20] The need for copper catalyst, however, limits the in cell or in vivo applicability of this reaction, although recent developments addressed the metaltoxicity issue by applying appropriate ligand additives to mask the toxic transition metal.[21] Besides the biocompatibility concerns, copper can also affect fluorescence of certain signaling species and irreversibly quench the fluorescence of e.g. GFPs or quantum dots. An alternative approach that eliminates the need for toxic copper catalyst was introduced by Bertozzi and coworkers.[22,23] In their respective works they demonstrated that introduction of strain into the alkyne reactant efficiently promotes the reaction to proceed at room temperature without any catalyst. Leaving the copper catalyst out had some consequences though: besides loosing regioselectivity, the strain promoted azide-alkyne cycloaddition (SPAAC) proceeds at slower rates than the copper catalyzed reaction. This latter issue was addressed by many laboratories by developing more reactive cyclooctynes derivatives (Figure 1).[24,25,26,27,28]

\subsection{Inverse electron demand Diels-Alder reactions}

A breakthrough was achieved in catalyst-free bioorthogonal ligations with the use of tetrazines and respective strained dienophiles.[22] The strain promoted inverse electron demand Diels-Alder cycloaddition (SPIEDAC) reaction between these reactants really meets the need for demanding biological applications.[29,30,31] Although the synthesis of the reagents often require laborious synthetic work, tetrazines in combination with various strained dienophiles such as norbornenes, cyclooctynes, trans-cyclooctenes display the fastest reaction rates, in general, of all bioorthogonal reactions (Figure 1). The reactivity of the tetrazines could be tuned either by reducing the bulk [32] or increasing the electron withdrawing nature of substituents, however, for biological applications a trade-off should be made between reactivity and stability.[29]

Finally, it should be noted that some bioorthogonal transformations are also orthogonal to each other. For example, appropriately selected reactants enable orthogonal SPAAC and 
SPIEDAC ligations.[33] Other examples report on the orthogonal use of two SPIEDAC reactions where appropriately selected tetrazines and dienophiles allowed selective modulation schemes.[34]

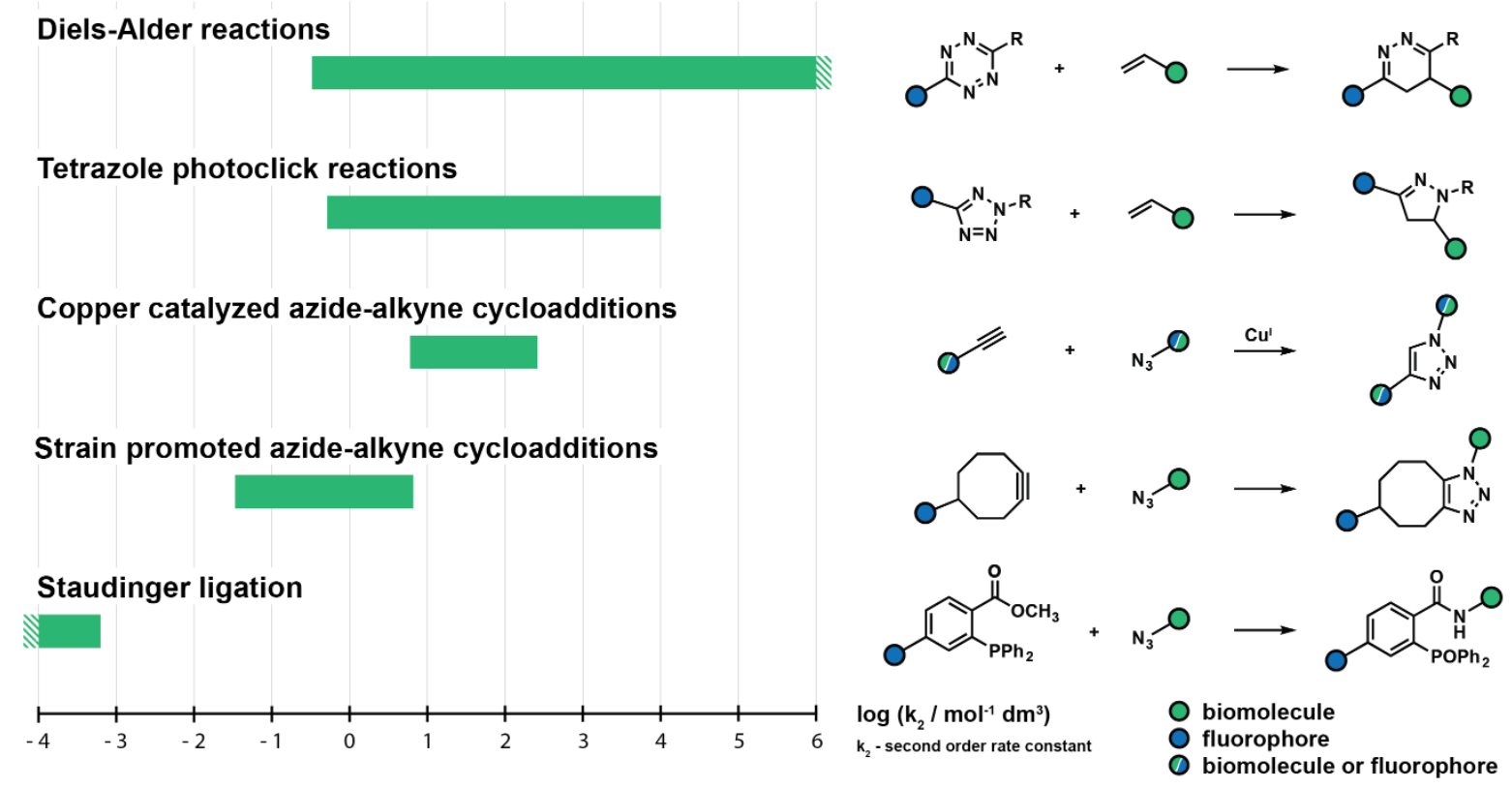

Figure 1. Comparison of reaction rates of the most used bioorthogonal reactions.

\subsection{Installation of bioorthogonality}

Bioorthogonal labeling strategies mostly rely on a sequential two-step modification scheme.[2-4,35] At first installation of the bioorthogonal moiety into the biomolecule of interest by means of chemical reporters is required. This step is followed by a selective modification of this chemical reporter through its bioorthogonal motif with a fluorescent marker harboring the complementary bioorthogonal function. For the incorporation of the chemical reporter tag, several options exist, however, for proteins, most methods are restricted to $\mathrm{N}$ - or C-terminal modifications. For instance, proteins can be manipulated selectively through their C- or Ntermini using mild chemistries.[2,36,37,38,39] Other methods to affix bioorthogonal moieties onto proteins include selective derivatization through rare building blocks e.g. Cys or Tyr residues.[40,41,42,43] Installation of chemical reporter tags is also possible e.g. by means of enzymatic tagging platforms.[44] Truly site-specific decoration of the protein of interest with bioorthogonal function is enabled by means of amino acid mutagenesis using orthogonal AARS/tRNA pairs.[45,46,47]

Fewer methods exist for the bioorthogonalization of non-proteinaceous species (lipids, sugars, nucleic acids).[48] Examples for the use of direct chemical modification or mutant enzymes of such scaffolds exist, however mostly limited to in vitro use. For in vivo 
derivatization of non-proteinaceous species the trick can be done by taking advantage of the biosynthetic apparatus of the organisms using modified metabolic precursors. $[49,50,51,52]$ This latter approach, however, is limited to the introduction of metabolically tolerable, small bioorthogonal motifs (e.g. azide, acetylene).

\section{Imaging with bioorthogonalized light emitting markers}

Species capable of releasing photons upon various means of excitation can be very different by nature. Fluorescent species that emit photons upon photoexcitation can be natural or synthetic by origin. This latter group can be further divided to organic and inorganic subcategories according to the composition of the labels. One advantage of applying synthetic probes is that their chemical and photochemical features can be synthetically tailored for the special needs.[53] Inorganic fluorophores on the other hand can be superior from the photostability and brightness point of view. Within this review, we structured our discussion by listing the groups of fluorescent markers that offer solutions to either of the obstacles faced in fluorescent bioimaging applications (i.e. autofluorescence, background fluorescence, photobleaching and brightness). Therefore we discuss NIR emitting, fluorogenic and nanoparticulate species that can be installed onto the biomolecule of interest by bioorthogonal modulation schemes. The list presented here is far from comprehensive and the readers interested in more details e.g. on nanoparticles can find excellent reviews on recent developments.[54]

\subsection{Bioorthogonally applicable small, green, red and NIR emitting organic fluorophores}

In general, fluorescent imaging of biological samples prefer light emitting markers with signals, clearly distinguishable from fluorescence of naturally occurring fluorophores (aromatic amino acids, DNA bases etc.). Such autofluorescence interferes the specific signals of synthetic dyes especially when their luminescence is dim. To reduce autofluorescence, therefore increase signal-to-noise ratio, several techniques emerged (e.g. time-resolved techniques). Other approaches utilize labels with large Stokes-shifts in combination with certain filters, or fluorophores that are excitable and emit at wavelengths (red, far-red, NIR regime), where natural fluorophores are not absorbing and emit photons. Visible - NIR labels are therefore the most common markers in bioorthogonal labeling schemes.

One of the very first examples for bioorthogonalized small organic probes appeared as early as 2003. In their report, Cravatt and co-workers introduced a rhodamine-alkyne probe suitable for functional proteome analysis. [55] In their activity-based protein profiling scheme a 
sequential approach was followed where an active-site directed chemical modification effected by an azide-derivatized phenyl sulfonate ester $\left(\mathrm{PS}-\mathrm{N}_{3}\right)$ was followed by a click reaction with the rhodamine-alkyne tag. This approach proved to be just as efficient and in some cases superior in terms of labeling efficiency and probe variability to the previously applied tagging schemes e.g. where a rhodamine-tagged phenyl sulfonate probe (PS-Rh) (Figure 2) was applied to tag glutathione S-transferases (GSTO 1-1). Furthermore, the smaller reagents applied in the sequential scheme are less likely affect e.g. the binding affinity of enzymes of interest. The more efficient labeling and thus, the more intense fluorescent signal observed in the case of PS$\mathrm{N}_{3}$ was explained by substitution of the bulky rhodamine tag for the small azide group. An even more important outcome of these experiments was that unlike previous methods, this sequentially driven activity-based protein profiling scheme could detect protein activities even in living organisms. Since then, Cravatt and co-workers have used this strategy to profile breast cancer cells [56] with a similar rhodamine probe and a bisalkynyl-naphthalene probe for tagging cytochromes P450.[57]
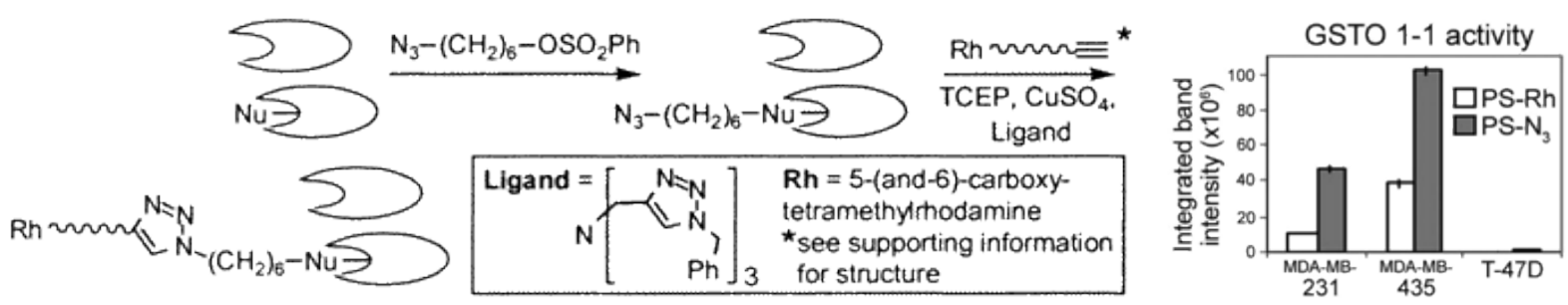

Figure 2. In vitro labeling of enzymes in complex proteomes by PS-Rh or PS-N3 and GSTO 1-1 activity in human breast cancer lines measured by in-gel fluorescence scanning of labeled proteomes. [Reprinted with permission from ref 55. Copyright (2003) American Chemical Society]

In the same year, Ju et al.[58] proved that the azide-alkyne reaction can also be extended to tag oligonucleotides. In their account they addressed the need for the efficient and stable modification of DNA. First, they modified an oligonucleotide with an azide containing tag at the 5'-end, which was subsequentially allowed to react with an alkynyl 6carboxyfluorescein derivative in the presence of copper catalyst. The click reaction successfully demonstrated the ability to synthesize fluorescent oligonucleotides with high selectivity, yield, and stability. Such oligonucleotide constructs could be utilized for DNA analysis without further purification, and can be used directly in DNA sequencing techniques e.g. the Sanger dideoxy chain termination method.

A fluorescein-derived label suitable for the efficient preparation of homogeneous antibody-drug conjugates was introduced recently by the Boons group.[59] By remodeling the oligosaccharides of an anti-CD22 monoclonal antibody using a cytidine-monophosphate-based 
sialic acid derivative, they introduced azide moieties onto the antibodies. To calculate the incorporation efficiency by fluorescence intensity measurements, a cyclooctyne-fluorescein derivative (DIBO-FITC) was used to label the azide groups by means of strain-promoted azidealkyne cycloaddition.

Compared to commonly utilized dyes with blue-green emission, fluorophores emitting in the red or near infrared (NIR) region are more suitable for biological (in vitro and in vivo) applications as there is little or no interference from biological luminescence (autofluorescence). At the same time they enable deeper tissue imaging due to improved photon penetration distance in this portion of the spectrum (the so called 'water-window'). The earliest examples for such NIR labels belonged to the cyanine family and are still widely used. For example, Hilderbrand et al.[60] used the $\mathrm{Cy} 5$ core and decorated it with $\mathrm{SO}_{3}{ }^{-}$groups on the one hand, to improve water solubility and an azide or alkyne motif on the other hand through a pendant linker of the polymethyne chain. Similarly to others, the suitability of this probe was tested on metabolically modulated azide-decorated glycans a method developed by Wong et al.[61] and Bertozzi et al.[22]

Hang and co-workers designed alkyne and azide functionalized photostable 2dicyanomethylene-3-cyano-2,5-dihydrofuran frameworks with red-shifted emission (alkCyFur and az-Cyfur) [62] to study the incorporation of azido- and alkynyl-fatty acid chemical reporters into N-myristoylated and S-palmitoylated proteins. The azido-fatty acid modulated Jurkat $\mathrm{T}$ cell lysates were allowed to react with alk-CyFur or alk-Rho (an alkyne-derivatized Rhodamine) under CuAAC conditions. The proteins were then visualized by in-gel fluorescence imaging. Due to the distinct spectral properties of Rho and CyFur, scanning at various excitation/emission channels allowed selective detection of the fluorophores. Moreover, the different linkages used to harbor the azide and alkyne moieties resulted in different spectral properties. For example, the ether-linked alk-CyFur showed considerably red shifted emission with a slightly higher quantum yield compared to its congener az-CyFur, where azide was linked through a carbamate. These distinct spectral properties allowed efficient Förster-type resonance energy transfer (FRET) to occur when the two CyFur probes were brought into close proximity. The FRET system showed remarkable pseudo Stokes-shift allowing far-red signal detection holding great promise in biological applications. 

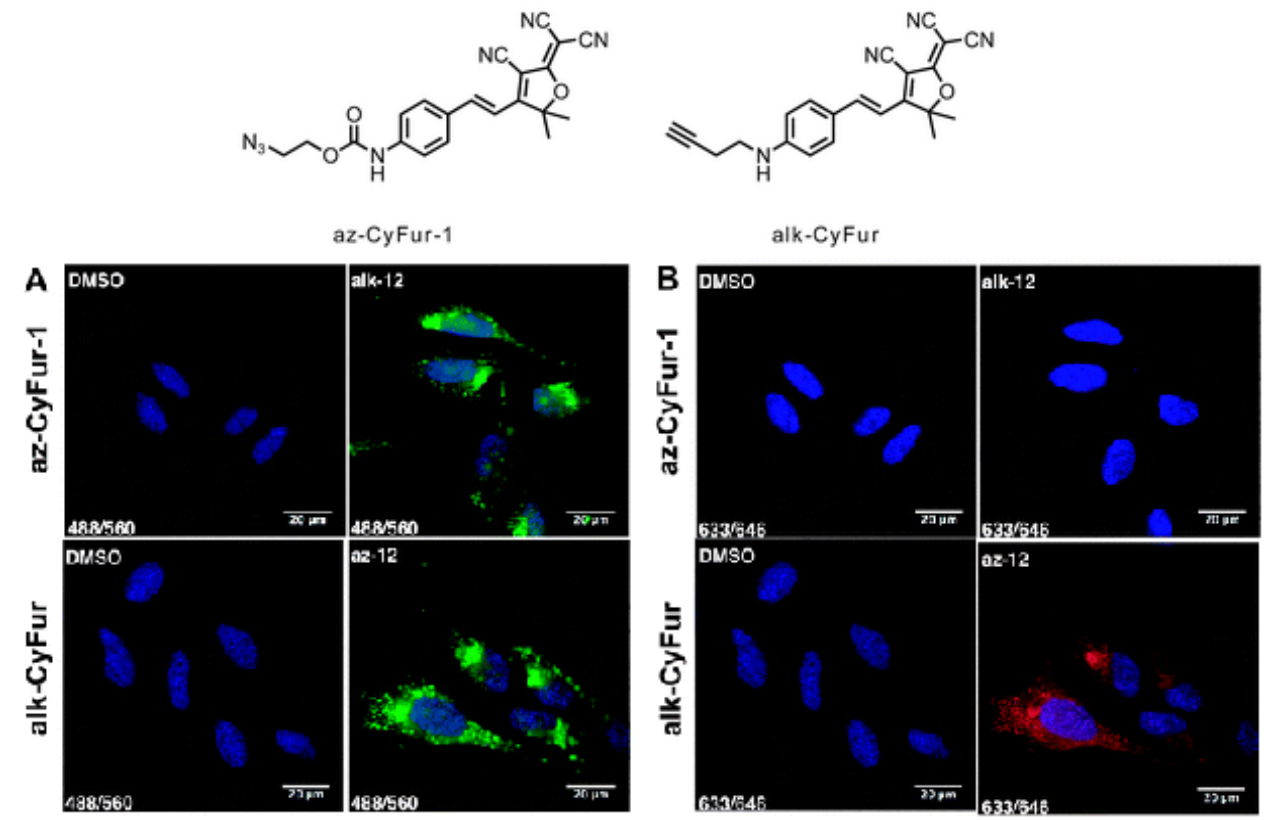

Figure 3. Top: Structures of az-CyFur-1 and alk-CyFur. Bottom: Fluorescence microscopy of azido (az-12)- and alkynyl (alk-12)-fatty acid labeled HeLa cells after bioorthogonal ligation with clickable dyes. (A) Imaging with $488 \mathrm{~nm}$ excitation and $560 \mathrm{~nm}$ emission long-pass filter. Top panel: az-CyFur1-labeled proteins. Bottom panel: alk-CyFur-labeled proteins. (B) Imaging with $633 \mathrm{~nm}$ excitation and 646-753 nm emission filter. Top panel: az-CyFur-1-labeled proteins. Bottom panel: alk-CyFur-labeled proteins. [Reproduced in part from Ref. 62 with permission of the Royal Society of Chemistry (RSC)]

The multi-channel, cross-talk free imaging capability of the two CyFur probes was demonstrated on HeLa cells metabolically modified with azide- and alkyne-fatty acids on their surface glycolipids (Figure 3).

The Lemke group used Cy5 and Atto532 cores both suitable for localization-based SRM techniques to construct tetrazine conjugates for dual-color pulse-chase imaging of surface insulin receptors (IR) expressed at different times.[34] They examined the reactivities of different dienophiles (simple-cyclooctyne, SCO, reactive cyclooctynes, $\mathrm{BCN}$ and highly reactive trans-cyclooctene, $\mathrm{TCO}^{*}$ ) with $\mathrm{Me}$ - and $\mathrm{H}$ - substituted tetrazines and found that appropriately chosen tetrazine-dienophile pairs can afford orthogonal tagging reactions (Figure 4). Their approach, dubbed selectivity-enhanced strain promoted inverse-electron- $\underline{\text { demand }}$ Diels-Alder cycloaddition (seSPIEDAC) relied on the different reactivities of simple SCO and TCO* towards the differently substituted tetrazines. The H-substituted tetrazine (H-Tet) showed high reactivity towards both dienophiles. In contrast, the Me-substituted tetrazine (MeTet) showed appreciable reactivity only towards the highly strained TCO* motif. To demonstrate the versatility of such orthogonal tagging schemes, insulin receptors of HEK293T cells were site-specifically modified with SCO and TCO* bearing lysine using a promiscuous orthogonal tRNA-RNA synthase (tRNA/RS) pair. 


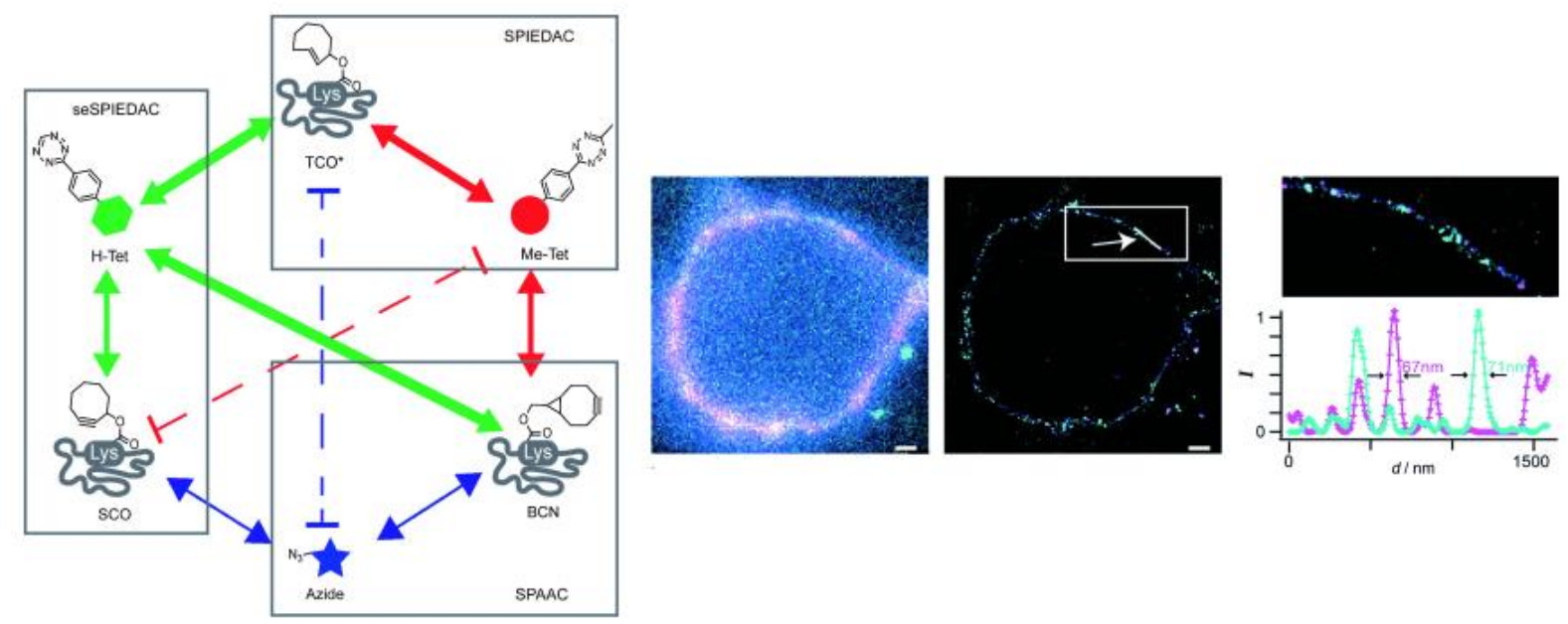

Figure 4. Left: Reactivities of TCO*, SCO, and BCN with azide (blue), H-Tet (green), and Me-Tet (red) in SPAAC, SPIEDAC, and seSPIEDAC reactions. The thickness of arrows correlates with reaction rate. Dashed lines highlight reactants that do not react with each other under the tested conditions. Right: SRM images of cells expressing IRs after seSPIEDAC labeling. Widefield (left) and SRM (middle) images of labeled IR (Att0532 in magenta, Cy5 in cyan). Right: inset from the middle panel and a line plot (across the line shown in middle panel, which is highlighted by an arrow). [Reproduced in part from Ref. 34 with permission of John Wiley \& Sons, Inc. Copyright (C) 2014 by John Wiley Sons, Inc.]

To achieve dual-color labeling of live cells, SCO- and TCO*-modified unnatural amino acids (UAAs) were genetically encoded and incorporated into IRs by pulse-chase experiment (Figure 4) where the growth medium was first pulsed with the first UAA (TCO*-Lys) that was chased with incubation with the second UAA (SCO-Lys). The IRs were then allowed to react first with Me-Tet-Cy5 to tag TCO* moieties. Provided that all TCO* was consumed, a second labeling reaction using highly reactive $\mathrm{H}-\mathrm{TetTet}$-Atto532 probe allowed selective tagging of SCO modified IRs only (Figure 4). Dual-color localization-based super resolution microscopy (SMR) imaging of the cells revealed heterogeneous distribution of insulin receptors clusters at the membrane.[34]

Hildebrand and co-workers [31] took advantage of the orthogonality of the SPIEDAC and SPAAC reactions for selective multi-target imaging scheme (Figure 5). In their experiment two different cell types were labeled in a simultaneous double-click test. Two cancer cell line (SKBR-3 and A431, expressing different receptors) antibodies were labelled with AF567 and AF488 fluorophores on the one hand, and modified genetically either with trans-cyclooctene TCO or cyclooctyne DBCO, respectively on the other hand. In the next step, the co-cultured cells were first incubated with the mixtures of the antibodies, then with AF750-Tetrazine and AF647-azide probes, simultaneously. The images revealed (Figure 5) that AF750-Tetrazine and AF647-azide allowed rapid and selective labeling of TCO and DBCO modified cells, respectively (Figure 5). 
a)

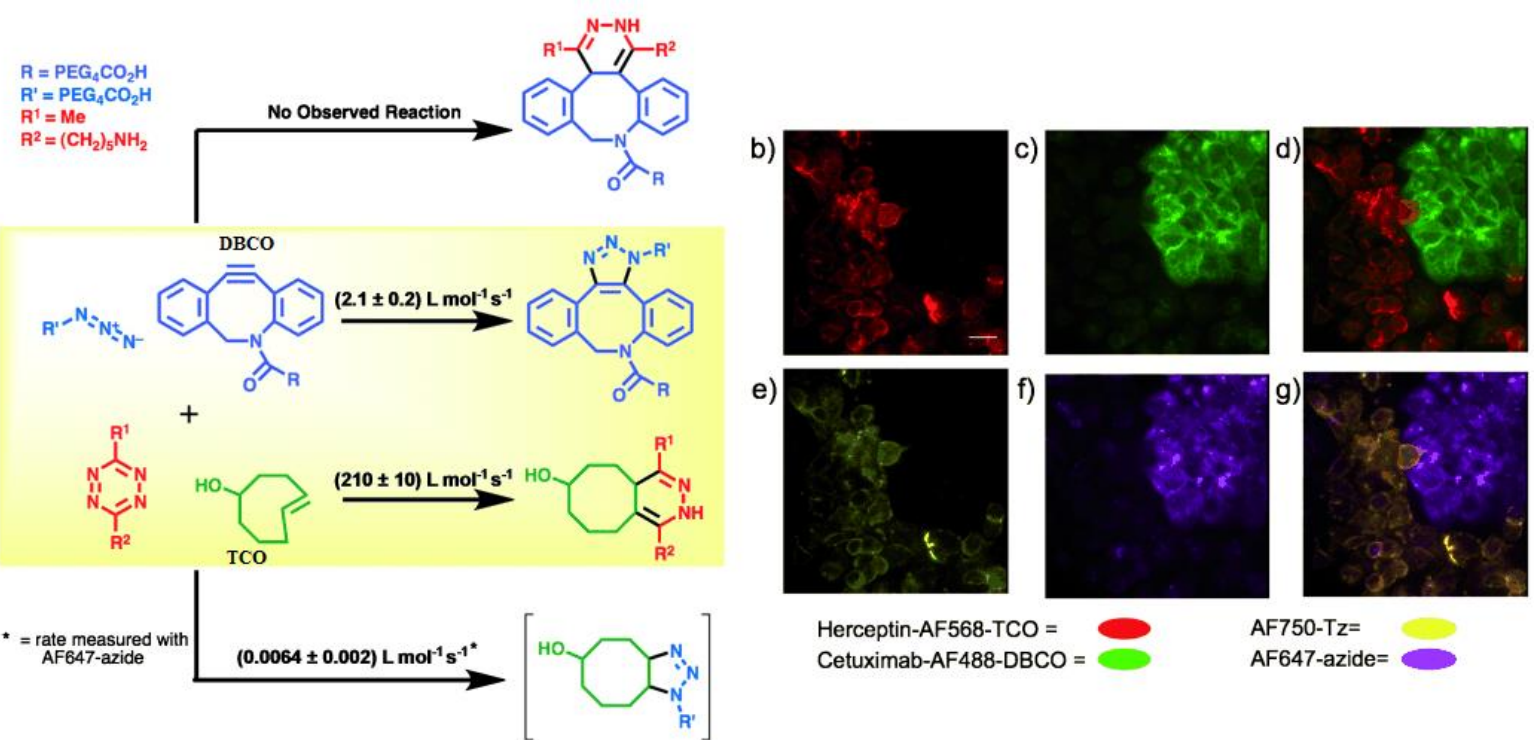

Figure 5. a) The four cycloaddition reactants and representative cycloaddition products/potential products. Second-order rate constants listed are from incubations of the two individual reactants in phosphate-buffered saline (PBS), pH 7.4 at $37^{\circ} \mathrm{C}$. The desired azide-DBCO and tetrazine-TCO-OH cycloadditions are highlighted in yellow. b)-g) fluorescence microscopy images of co-cultured A431 (EGFR+) and SKBR-3 (HER2/neu+) cells. Cells were treated with Cetuximab-AF488-DBCO and Herceptin-AF568-TCO, followed by AF647-azide and AF750-tetrazine concurrently. Shown: fluorescence from b) AF568, c) AF488, d) AF488/AF568 merge, e) AF750, f) AF647, g) AF647/AF750 merge. Scale bar in (b): $50 \mu \mathrm{m}$. Panels (e) and (f) show the selective covalent labeling by AF647-azide and AF750-tetrazine of Cetuximab-AF488-DBCO bound to the EGFR receptors and Herceptin-AF568TCO bound to the SKBR-3 cells, respectively. [Reproduced in part from Ref. 33 with permission of John Wiley \& Sons, Inc. Copyright (C) 2011 by John Wiley Sons, Inc.]

Apart from the emission wavelength, the brightness and cell-permeability are also important features of fluorescent probes. The usually low quantum yields of small organic NIR fluorophores can often be a drawback when working at low concentrations. The Johnsson group addressed this problem by designing a new near-infrared silicon-rhodamine probe (SiRtetrazine) that can be conjugated to TCO modified proteins via the SPIEDAC reaction.[63] Green fluorescent proteins expressed in E. coli were modified genetically with TCO- or SCOLys through amber (TAG) stop-codon suppression technique. TCO permits fast labelling with probes bearing tetrazines while SCO derivative was expected to be unreactive towards the particular tetrazine motif and served as a control. As supposed, successful labelling of intact $E$. coli cells was obtained exclusively for TCO, but not for SCO or wild-type GFPs. and any other protein in the $E$. coli cells did not show a red fluorescence. Moreover, due formation of a nonfluorescent lactone form in non-polar media, the SiR probe gives reduced non-specific signal that might originate from sticking to hydrophobic surfaces. These combined features make this probe ideally suited for live-cell super-resolution microscopy (Figure 6). 


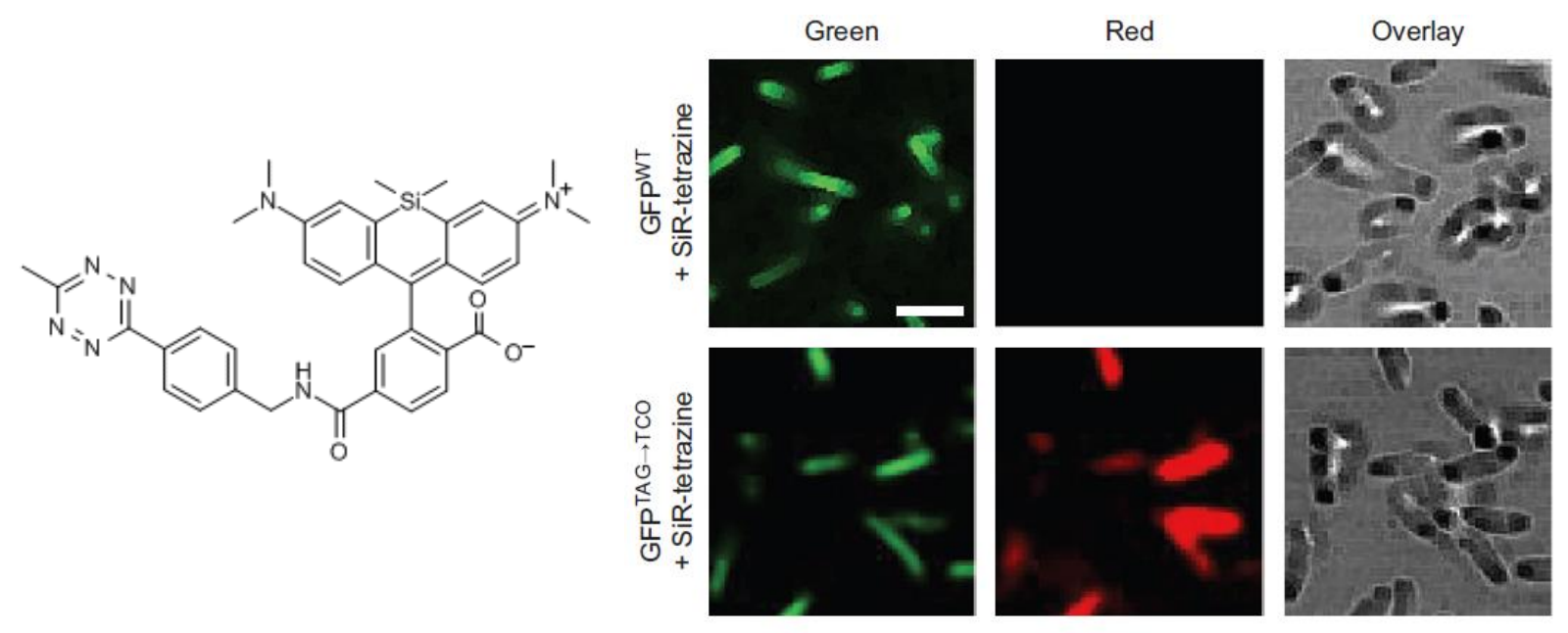

Figure 6. Left: silicon-rhodamine-tetrazine probe. Right: Live E. coli cells expressing GFPWT (upper row) and GFPTCO (lower row) were incubated with SiR-tetrazine. The cells were imaged for green or red fluorescence (third column shows the overlay). [Reprinted from Ref. 63 by permission from Macmillan Publishers Ltd: Nature Chemistry]

Cell-permeability became a profound issue of the Weissleder group during the imaging studies of Aurora Kinase A (AKA) in live cells.[64] In their initial approach, the small molecule AKA-specific inhibitor MLN8054 was decorated with a trans-cyclooctene (TCO) moiety, which can be visualized by a tetrazine-conjugated dye using standard, bioorthogonal two-step labeling method. In vitro studies using a Texas-Red-tetrazine conjugate (TR-Tz) confirmed, that the applied two-step labeling method (labeling with MLN8054-TCO and imaging with TR$\mathrm{Tz}$ ) is more efficient compared to direct labeling with fluorescent MLN8054-TR conjugate (IC50 value of $61.8 \mathrm{~nm}$ versus $437.3 \mathrm{~nm}$, respectively). However, TR-Tz appeared to enter cells through endocytosis, and this resulted in bright, punctate staining, which masked the localization of TR-Tz to MLN8054-TCO (13)/AKA. 

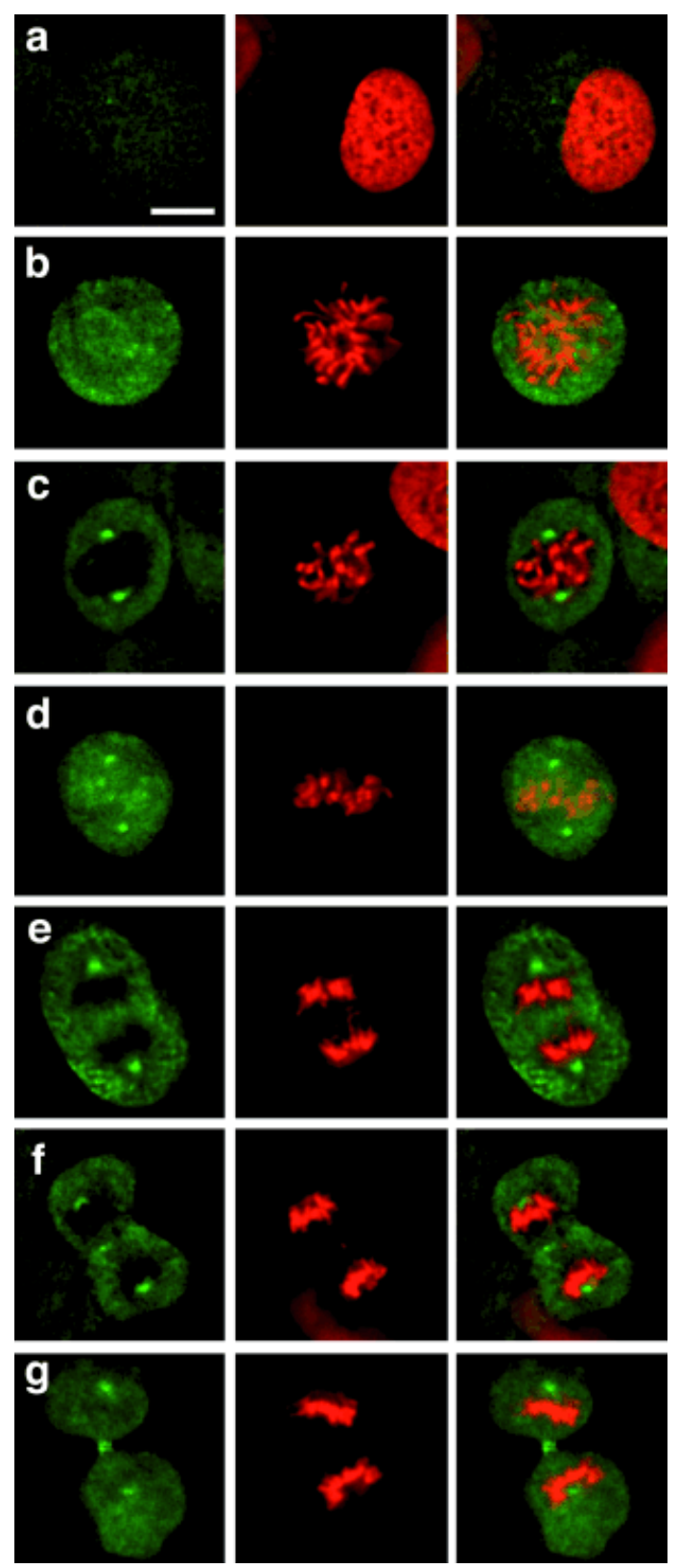

Figure 7. Localization of MLN8054-TCO (13)/CFDA-Tz in dividing HT1080 H2B-Apple cells. HT1080 cells were incubated for 30 min with $125 \mathrm{~nm}$ MLN8054-TCO (13), washed and incubated for 30 min with $1 \mu \mathrm{m}$ CFDA-Tz for bioorthogonal reaction inside living cells. Following $2 \mathrm{~h}$ of washing, live cells at different stages of mitosis were imaged at $40 \times$ with 1.6 zoom by deconvolution microscopy. Left column: MLN8054-TCO (13)/CFDA-Tz, Middle column: H2B-Apple, Right column: merge. a) Interphase, b) Prophase, c) Prometaphase, d) Metaphase, e) Anaphase, f) Telophase, g) Cytokinesis. Scale bar: $10 \mu \mathrm{m}$. [Reproduced from Ref. 64 with permission of John Wiley \& Sons, Inc. Copyright $\mathbb{C}$ 2012 by John Wiley Sons, Inc.]

To overcome this limitation, the group screened a library of various $\mathrm{Tz}$ modified fluorophores to identify a probe capable of diffusion-mediated cellular uptake. For this screening process a modified PANC-1 cell-line expressing mCherry-AKA (RFP-AKA) was used as probe target. The best candidate proved to be carboxyfluorescein diacetate-Tz (CFDA$\mathrm{Tz}$ ), which was further investigated in the two-step labeling procedure, using the same RFP- 
AKA expressing PANC-1 cell-line. Final in vivo experiments on live, actively dividing cells were performed using an HT1080 fibrosarcoma cell-line stably transfected with H2B-Apple (a red fluorescent protein). Labeling of the endogenous AKA during different stages of the G2/M phase with MLN8054-TCO / CFDA-Tz showed very good correlation with the expected localization of AKA during mitosis (Figure 7).

Compared to the traditional dyes, the decreasing quantum yield in the NIR region also poses a challenge. Zumbusch et al.[65] examined this problem and synthesized a new family of Pyrrolopyrrole Cyanines (PPCy) dyes with extremely narrow NIR absorption and emission bands with excellent quantum yields (Figure 8). Achilefu and co-workers [66] incorporated two alkyne moieties into the same core. Alk-PPCy showed similar characteristics and its azideclicked triazole derivative showed large extinction coefficients $\left(\varepsilon=138000 \mathrm{M}^{-1} \mathrm{~cm}^{-1}\right)$ and quantum yields ( $\phi=37 \%$ relative to ICG in DMSO). They also examined the photostability of the PPCy dyes and found that it can withstand the intense light used in microscopy. In contrast, most NIR carbocyanine dyes rapidly bleach under these conditions, which prevents their use in time-lapse microscopy (Figure 8).
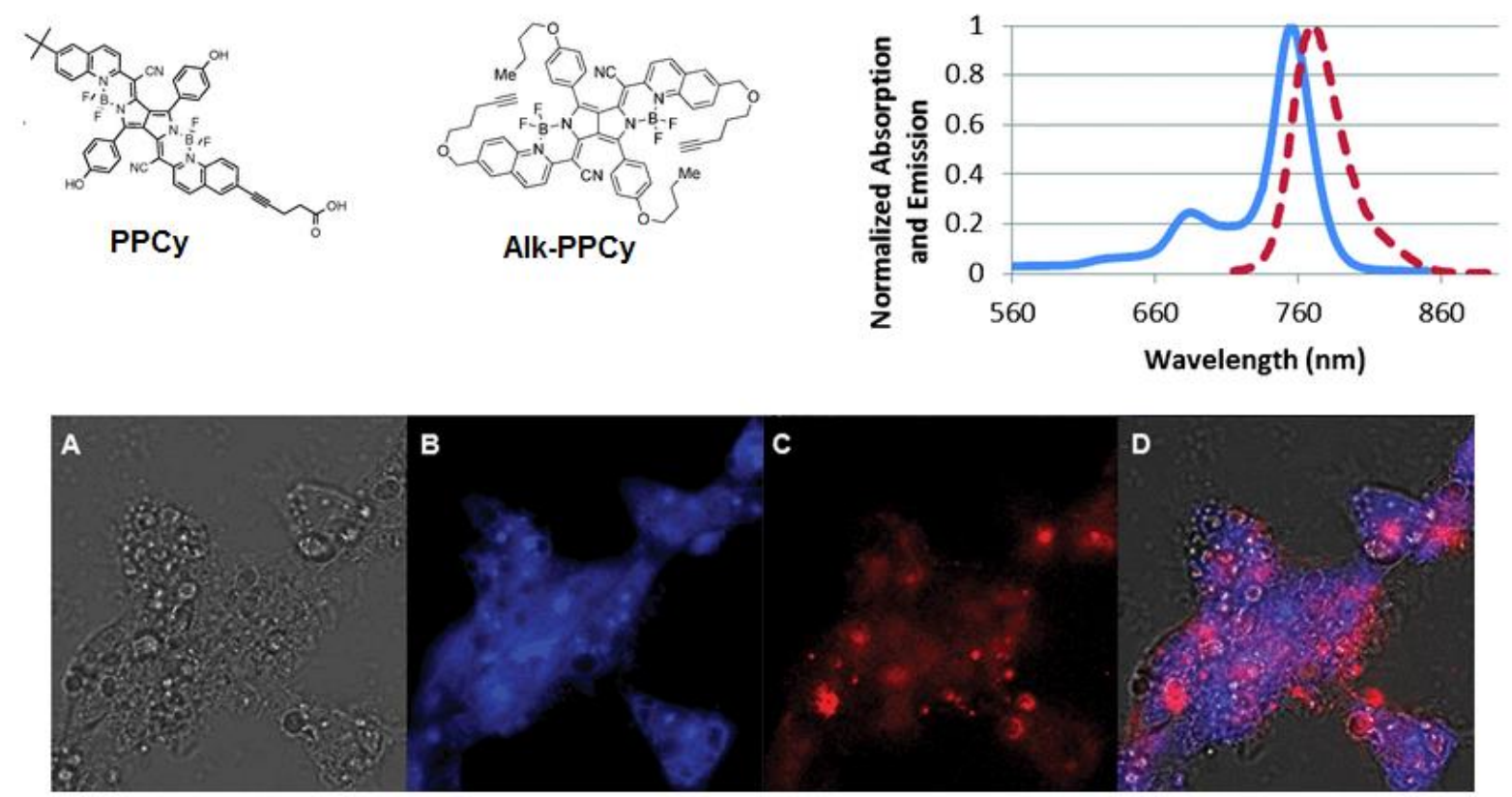

B

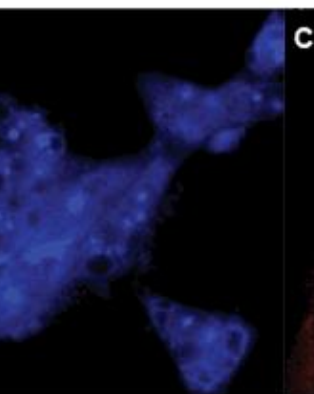

C

D

Figure 8. Top: Structure of PPCy dye and its bioorthogonalized Alk-PPCy derivative with normalized absorption and emission spectra. Bottom: Live cell imaging using Alk-PPCy. MCF-7 cells were incubated with Alk-PPCy $(5 \mu \mathrm{M})$ in DMEM containing 0.03\% DMSO, $0.3 \%$ Tween80 and GeneJuice $(5 \mu \mathrm{M})$ at $37{ }^{\circ} \mathrm{C}$ for 18 h. (A): Bright field; (B): TOTO1 stained cell nuclei; (C): Alk-PPCy stained cell; (D): composite image of the cells with TOTO1 and Alk-PPCy staining. [Reproduced in part from Refs. 65 and 66 with permission of The Royal Society of Chemistry (RSC)]

Another common issue in fluorescent imaging techniques, especially in FRET applications is the small Stokes-shift of the probes. Kele and co-workers $[67,68]$ synthesized a 
series of dyes with large Stokes-shifts based on a stilbene motif (Figure 9). The labels were furnished with alkyne and/or azide as a bioorthogonal functionality and their emission ranged from $630 \mathrm{~nm}$ to $805 \mathrm{~nm}$, covering the spectra from the red to the NIR regime. The dyes were tested in similar conditions mentioned previously, i.e. in the labeling scheme of azido-mannose modified surface glycans of CHO cells.

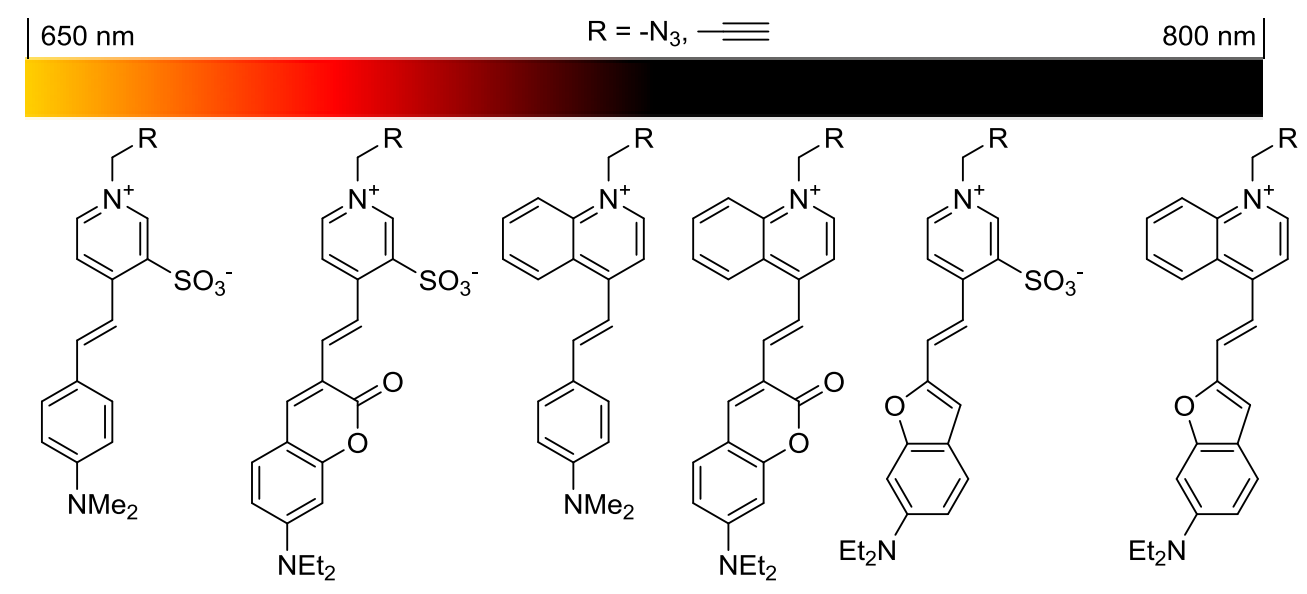

Figure 9. Structure of the "clickable" dyes with large Stokes-shifts.

Fluorophores exhibiting large Stokes shifts make these dyes ideal candidates for Förster-type Resonance Energy Transfer (FRET) applications, since direct excitation of acceptor emission by the light used to excite the donor is an often encountered problem in FRET assays. The possibility to use a NIR fluorescent probe to monitor the release of Daunomycin (Dau), a fluorescent anticancer drug was also demonstrated by the Kele group, [68] on a dually labeled, model peptide motif, that could be cleaved by an enzyme. The experiments showed that the fluorescence of Dau was efficiently quenched by an appropriately chosen dye, and the fluorescence of Dau could be fully reinstated upon hydrolysis of the dually labeled tetrapeptidebased enzyme substrate. In another study [69], the emission intensity of these dyes showed remarkable dependence on local polarity and showed large fluorescence increase when conjugated to oligonucleotides. Upon hybridization with the respective counterstrands it also became apparent that a special focus must be put on the design and location of the linker between the oligonucleotide and the dye.

\subsection{Bioorthogonal fluorogenic probes}

In bioorthogonal labeling schemes larger or smaller excess of the fluorescent label is needed to facilitate tagging efficiency as the required probe concentration is directly proportional to the reaction rate of the applied bioorthogonal chemistry. For example, relatively 
slow Staudinger ligation schemes require $\mathrm{mM}$ concentration of the label, whilst SPIEDAC reaction allow probe concentration in the nanomolar range. In cases where larger concentration of the probe is applied the excess of the fluorescent label has to be removed via several washing step cycles to minimize background fluorescence of the unreacted probes. Another approach to minimize background fluorescence relies on the use of so-called fluorogenic (also knowns as turn-on, or smart) probes. These fluorogenic labels have the unique feature of becoming fluorescent only upon reaction. Such fluorogenic dyes are extremely advantageous in in vivo labeling schemes where washing steps are undesirable.

Amongst the various fluorogenic probes bioorthogonally applicable scaffolds are of special importance as they can ensure site-specific tagging of the biomolecules of interest. There are two major approaches that rely on the use of bioorthogonal handles. There are instances where the bioorthogonal function is responsible for the quenching effect and upon chemical transformation the fluorescence is enabled. Other approaches use the bioorthogonal transformation to trigger the release of either photocaging or quencher moieties. Whichever mechanism is responsible for the low emission intensity of the quenched forms the outcome after bioorthogonal reaction is the enhancement of fluorescence intensity. Therefore the most important feature of such fluorogenic systems is their enhancement factor $(\mathrm{EF})$, which is given by the ratio of either the intensities, the quantum yields or brightnesses of the product and the starting material, respectively at a given wavelength. Other features such as brightness, excitation and emission maxima in the red-NIR regime, photostability or membrane permeability are also preferred. Within this chapter we will follow a reaction-based discussion to give an insight into the recent developments on bioorthogonally applicable fluorogenic probes.

\subsubsection{Azide-bearing fluorogenic dyes}

Azide modified fluorescent scaffolds are one of the most common and widely used bioorthogonally applicable fluorogenic probes. The azide group is highly energetic, yet very stabile under a variety of conditions. Its selective reactivity towards phosphanes and (cyclo)alkynes makes it exceptionally useful in bioorthogonal labeling applications.[17,70,71] Further advantages are its easy accessibility (e.g. from amines) and relatively small size, which minimally perturbs the biological systems.

There are diverse mechanisms to explain the quenching effect of the azide moiety. In their respective work Wang et al. accuse the electronrich $\alpha$-nitrogen of the azide for the 
quenching.[72] Kele and co-workers used quantum chemical calculations to investigate the quenching effect posed by the azide. They found that the presence of the azide opens alternative, non-radiative relaxation channels.[73] In other instances PET mechanism can be the possible cause for non-radiative relaxation.[74]

One of the very first reports on bioorthogonally applicable small fluorogenic dyes introduced a series of 3-azido-coumarin derivatives (Figure 10, 1), some of which showed remarkable $\mathrm{EF}$ in water/DMSO mixture.[72] Of these azidocoumarins 3-azido-7hydroxicoumarin (AHC), was found to be especially useful and found wide range of fluorogenic tagging applications. It shows 100-fold increase in fluorescence intensity (in ethanol - water). In their work, Zong et al. incorporated the fluorogenic AHC scaffold into a dendrimer.[75] This fluorogenic platform was used to profile cellular proliferation by following the incorporation of 5-ethynyl-2'-deoxyuridine into newly synthesized DNA. Very recently the Dirksen group developed a method for parallel synthesis and fast screening of anti-Angiopoietin-2 peptide antibody conjugates.[76] They used 3-azido-7-hidroxi-coumarin to detect the residual, unreacted scaffolds through SPAAC.

Photoinduced electron transfer based quenching mechanism can be tracked down in the 9-azidomethyl anthracene (Figure 10, 2) scaffold introduced by Wang and co-workers.[77] They reached 75-fold increase in emission intensity (in DMSO), and successfully applied this probe in the labeling of alkyne-derivatized cowpea and tobacco mosaic viruses using CuAAC. Seela and co-workers used the same azido-anthracene scaffold to label oligonucleotides to study duplex formation.[78] The same researchers reached high density functionalization and crosslinkage formation between alkyne functionalized DNA strands, using mono- and bis-azidoanthracenes.[79] Although the probes showed excellent fluorogenic properties its UV excitability limited its use in cellular environments. 
<smiles>Nc1cc2cc[R]cc2oc1=O</smiles><smiles>[R]c1c2ccccc2c(CN)c2ccccc12</smiles>

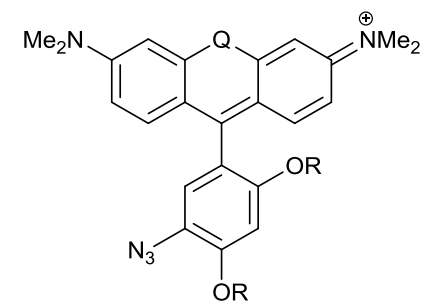

$5 \mathrm{Q}: \mathrm{O} \mathrm{SiMe}_{2}$

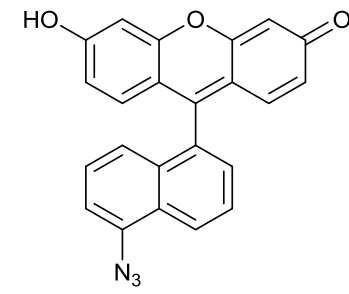

3

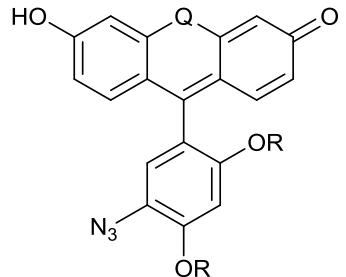

$4 \quad \mathrm{Q}: \mathrm{O}, \mathrm{SiMe}_{2}$

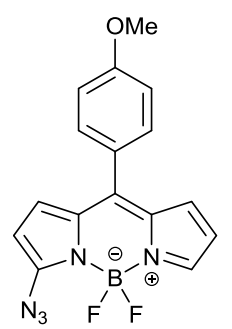

7

Figure 10. Various azide-bearing fluorogenic dyes based on coumarin, anthracene, xanthane and BODIPY cores.

Based on the general consideration and theoretical calculations of Nagano et al. $[74,80]$ the Bertozzi group showed that the PET based quenching mechanism can be harvested in the design of new xanthane smart probes. In their account the newly reported (silica)fluorescein and (silica)rhodamine fluorogenic azides $(3-5)[81,82,83]$ showed 35 - 243-fold increase in $\Phi_{\mathrm{F}}$ (PBS pH 7.4) (Figure 10). They also showed that the possible decomposition of the azide moiety to amine, a common problem in fluorogenic labeling schemes in biological systems,[84] does not contribute to unwanted background fluorescence as the respective amines had lower $\Phi_{\mathrm{F}}$ than the corresponding azides. Moreover, the excitation and emission maxima of these new probes were found to be in the visible region for the fluoresceins $\left(\lambda_{\mathrm{exc}} 500 \mathrm{~nm}, \lambda_{\mathrm{em}} 521 \mathrm{~nm}\right.$, PBS 7.4) and for rhodamines ( $\lambda_{\mathrm{exc}} 561 \mathrm{~nm}, \lambda_{\mathrm{em}} 583 \mathrm{~nm}, \mathrm{PBS} 7.4$ ) and in the far red/near infrared regime for Si-fluoresceins ( $\left.\lambda_{\mathrm{exc}} 591 \mathrm{~nm}, \lambda_{\mathrm{em}} 609 \mathrm{~nm}, \mathrm{PBS} 7.4\right)$ and Si-rhodamines $\left(\lambda_{\mathrm{exc}} 657 \mathrm{~nm}\right.$ and $\lambda_{\mathrm{em}} 674 \mathrm{~nm}$, in PBS $\mathrm{pH}$ 7.4). One of the fluorescein derivatives was successfully tested in the labeling of cell surface glycans of fixed $\mathrm{CHO} \mathrm{K} 1$ cells previously treated with peracetylated $\mathrm{N}$-(4-pentynoyl)-mannosamine (Ac $4 \mathrm{ManNAl}_{4}$, Figure 11). They also highlighted the remarkable resolution that was obtained without any washing step. A Si-rhodamine smart-probe was successfully tested using the previously described $\mathrm{CHO}$ K1 system together with alkyne functionalized HEK $293 \mathrm{~T}$ cells in glycan labeling studies. Furthermore, bacteria (E.coli) expressing alkyne modified peptidoglycans were also labeled using SPAAC chemistry. Besides their glycan labeling properties, a set of these dyes was also tested for DNA or RNA labeling 
capabilities in HEK 293T cells and in E. coli using 5-ethynyl uridine or 5-ethynyl deoxyuridine as chemical reporter units.[84]
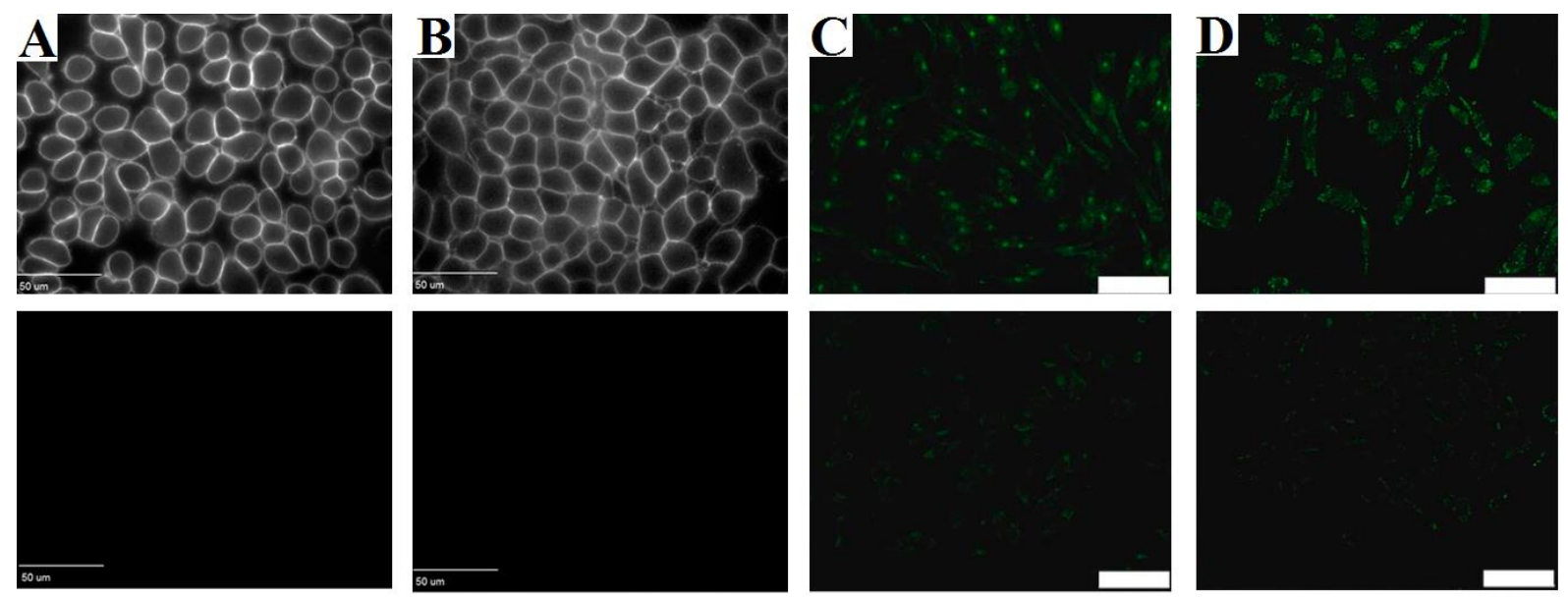

Figure 11. No-wash mammalian cell surface labeling. Upper row: treated with azido-sugars, bottom row: treated without azido-sugars as a control. Fluorescence images of CHO K1 (A) and HEK 293T (B) cells treated with $\mathrm{Ac}_{4} \mathrm{ManNAl}$ and labeled with 4. [[Reprinted with permission from Ref. 82 Copyright (2014) National Academy of Sciences, USA.]

Fluorescence images of CL1-5 cells treated with $\mathrm{Ac}_{4} \mathrm{ManNAl}(\mathrm{C})$ or $\mathrm{Ac}_{4} \mathrm{GlcNAl}$ (D) and labeled with 5.[Reprinted with permission from Ref 85. Copyright (2014) American Chemical Society]

The PET-based quenching mechanism motivated Wong and co-workers to introduce an azide modified BODIPY fluorogenic dye (Figure 10, 6) exhibiting 52-fold EF (in EtOH) upon reaction.[85] The excitation and emission maxima of the BODIPY-fluorogenic label in ethanol were $\lambda_{\text {exc }} 501 \mathrm{~nm}$ and $\lambda_{\mathrm{em}} 515 \mathrm{~nm}$, respectively. They also experienced that the potential byproduct amine derivative is virtually non-fluorescent therefore it has no contribution to the background signal. A selected compound was first evaluated in alkyne-functionalized BSA tagging using CuAAC scheme, then used to label proteoglycans in fixed CL1-5 lung cancer cells, previously incorporated peracetylated alkynyl- $N$-acetylmannosamine ( $\left.\mathrm{Ac}_{4} \mathrm{ManNAl}\right)$ and alkynyl- $N$-acetylgalactosamine ( $\left.\mathrm{Ac}_{4} \mathrm{GalNAl}\right)$ (Figure 11).

Wang and co-workers in 2012 reported another azido-BODIPY derivative (Figure 10, 7), which showed an excellent, 800-fold (although in $\mathrm{CHCl}_{3}$ ) increase in fluorescence intensity upon reaction with alkynes (reaction with different alkynes: $\lambda_{\mathrm{exc}} 514-522, \lambda_{\mathrm{em}} 529-538$, in $\mathrm{MeOH}$ ).[86] $\mathrm{KB}$ cells overexpressing folate receptors were treated with terminal alkyne modified folate. The modified folate receptors were then successfully profiled using the azidoBODIPY derivative. However, they noticed that the negative control also showed fluorescence. The low stability of azido-BODIPY dye under the applied conditions, thus a fluorescent decomposition product was accounted for the high background signal. The authors suspected 
an ICT-based mechanism behind the quenching effect. Later, Talukdar and co-workers published a similar azide modified BODIPY probe (reaction with different alkynes: $\lambda_{\text {exc }} 502-$ 540, $\lambda_{\mathrm{em}}$ 528-650 nm, HEPES pH 7.4), which showed 532-fold fluorescence enhancement (HEPES 7.4) upon CuAAC reaction with alkynes.[87] The authors assumed a PET-based quenching effect responsible for the fluorogenic behavior. They found that a membrane permeable cholesterol modified probe showed exclusive accumulation in the intracellular membranes. This fluorogenic-cholesterol can be used to follow cholesterol trafficking in live cells.

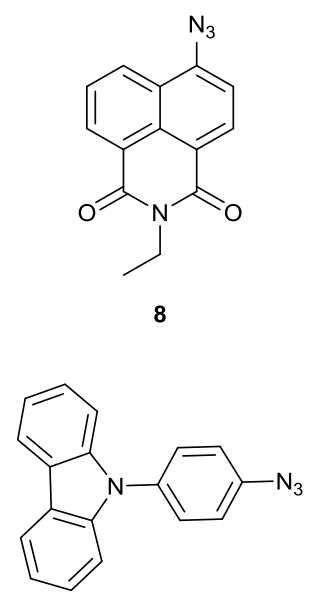

9

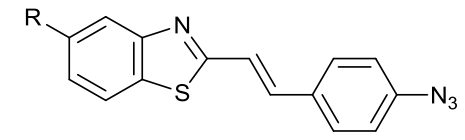

10
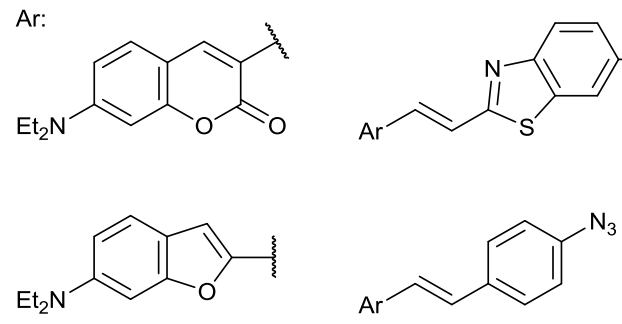

11

Figure 12. Various azide-bearing fluorogenic dyes based on 1,8-naphthalimide, carbazole and stilbene cores.

Most probably not PET based quenching mechanism is responsible for the fluorogenic nature in a 4-azido 1,8-naphthalimide fluorogenic dye (Figure 12, 8) emitting in the blue region ( $\lambda_{\text {exc }} 357, \lambda_{\mathrm{em}} 422 \mathrm{~nm}, \mathrm{PBS} \mathrm{pH}$ 7.2).[61] The authors found that the probe shows excellent fluorogenic properties (about 100-fold EF). Together with other fluorogenic azido-dyes, this azido-naphthtalimide was also successfully applied in the real time activity measurement of aberrantly activated oncogenic Src kinases in the crude lysate of leukemia cells.[88]

Just very recently, an azido-phenyl carbazole (Figure 12, 9) was introduced by Bräse and co-workers.[89] This carbazole derivative was found to be virtually dark, while fluorescent after reaction with alkynes, possessing UV excitability (291-293 nm, various solvents) and visible emission (387-492 nm, various solvents). The triazolic products showed strong $\mathrm{pH}$ dependency both in terms of emission wavelengths and Stokes-shifts. Theoretical calculations and experimental results indicated that a twisted internal charge transfer (TICT) is responsible for the photophysical properties of these new dyes. Two conjugates were further tested in HeLa 
cells as a polarity sensitive probes. It was found that both derivatives were quite stable under live cell conditions and they showed strong preference to the endosomal-lysosomal system. The authors therefore foresee them as promising probes to follow endocytotic uptake processes.

In 2013 Kele and co-workers reported on the design and synthesis of a set of new, azidebearing fluorogenic dyes (Figure 12, 10) based on the stilbene motif.[73] Theoretical investigations suggested that fast rotation and bending of the azide group opens up the possibility of the internal conversion of the two lowest excited states followed by another internal conversion process to the ground state. They used the same calculation model to predict fluorogenicity and designed another set of stilbene type of azide-bearing fluorogenic dyes (Figure 12, 11) with red-shifted excitation and emission properties. [90] The dyes were tested in live E.coli cultures to target genetically encoded cyclooctyne motifs in proteins. The proteins were then successfully profiled in cell-lysates.

\subsection{2. (Cyclo)alkyne fluorogenic dyes}

The presence of an alkyne motif can also function as a quencher although in rarer instances. Since metabolic, or genetic incorporation of azide-modified chemical reporters is well developed, such alkyne-bearing fluorogenic probes would be obvious targets of probe research. However, alkyne-based quenching is less generalizable and rather restricted to a few special cases. Following this pioneering work on terminal alkynes,[91] Bertozzi and co-workers reported on the design and synthesis of a coumarin-fused cyclooctyne derivative (Figure 13, 12).[92] The probe showed moderate, 10 -fold increase in quantum yield upon conjugation $\left(\lambda_{\mathrm{exc}}\right.$ 305, $\lambda_{\mathrm{em}} 438 \mathrm{~nm}$, PBS pH 7.4) with azides. Following this track, Boons and co-workers introduced another fluorogenic cyclooctyne (Figure 13, 13), which shows better EF ratio (60fold for $\Phi_{\mathrm{F}}, 1900$-fold for brightness, $\lambda_{\mathrm{exc}} 362-364, \lambda_{\mathrm{em}} 489-499 \mathrm{~nm}, \mathrm{MeOH}$ ).[93] Moreover, the stability of this latter label under acidic and basic media was found to be remarkable. Theoretical investigations suggest that the difference in emission intensities is due to the substantial differences in oscillator strengths of the $S_{0} \leftrightarrow S_{1}$ transitions in the planar $C_{2 v^{-}}$ symmetric $\mathbf{1 3}$ compared to the symmetry-broken and nonplanar triazolic product.

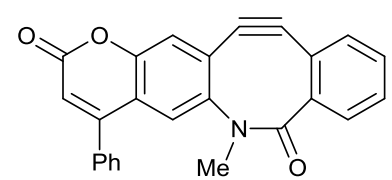

12

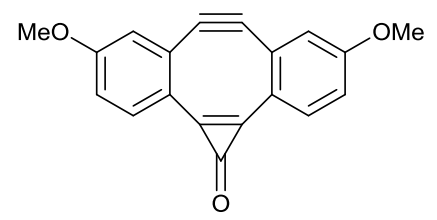

13

Figure 13. Fluorogenic dyes based on cyclooctyne motifs 


\subsubsection{Fluorogenic probes for Staudinger ligation}

As it was outlined in the introduction, during the course of the Staudinger ligation the aza-ylide intermediate formed in the reaction between azides and phosphanes is captured by a neighboring electrophilic trap, mostly an ester group, leading to the overall formation of an amide and a phosphane oxide, while releasing a molecule of alcohol.[1] These characteristics are exploited when fluorogenic Staudinger ligation probes are designed. There are examples where the original phosphane is responsible for the quenching via ICT. Upon oxidation to the phosphane oxide the ICT originating from the phosphorous' lone pair is no longer possible, therefore the fluorescence reinstates. An example for this approach is presented by Bertozzi et al.[94] Their coumarin-modified phosphane (Figure 14, 14) showed 60-fold fluorescence increase upon transformation to 15 ( $\left.\Phi_{\mathrm{F}}, \lambda_{\mathrm{exc}} 443, \lambda_{\mathrm{em}} 495 \mathrm{~nm}, \mathrm{PBS}\right)$ with kinetics, comparable to general Staudinger reaction $\left(k=1.5 \times 10^{-3} \mathrm{M}^{-1} \mathrm{~s}^{-1}\right.$ in water-MeCN 1:1). To demonstrate the versatility of this approach, they used this phosphane dye in combination with recombinant azidohomoalanine containing murine dihydrofolate reductase.

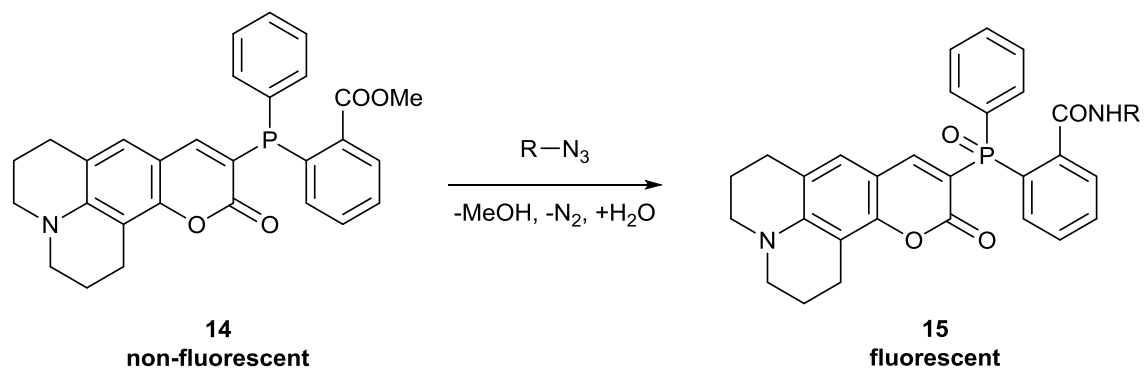

Figure 14. Coumarin based fluorogenic dye activated by Staudinger ligation. [Reprinted with permission from ref 94. Copyright (2003) American Chemical Society]

Unfortunately the phosphanes tend to oxidize spontaneously, which, in this particular case would result in increased background fluorescence. Another approach that eliminates this latter problem relies on the elimination of the alcohol. In such instances the alcohol is part of a quencher that diminishes fluorescence via FRET processes. After the ligation process the quencher is released and the fluorescence of the original fluorophore is restored. 
A
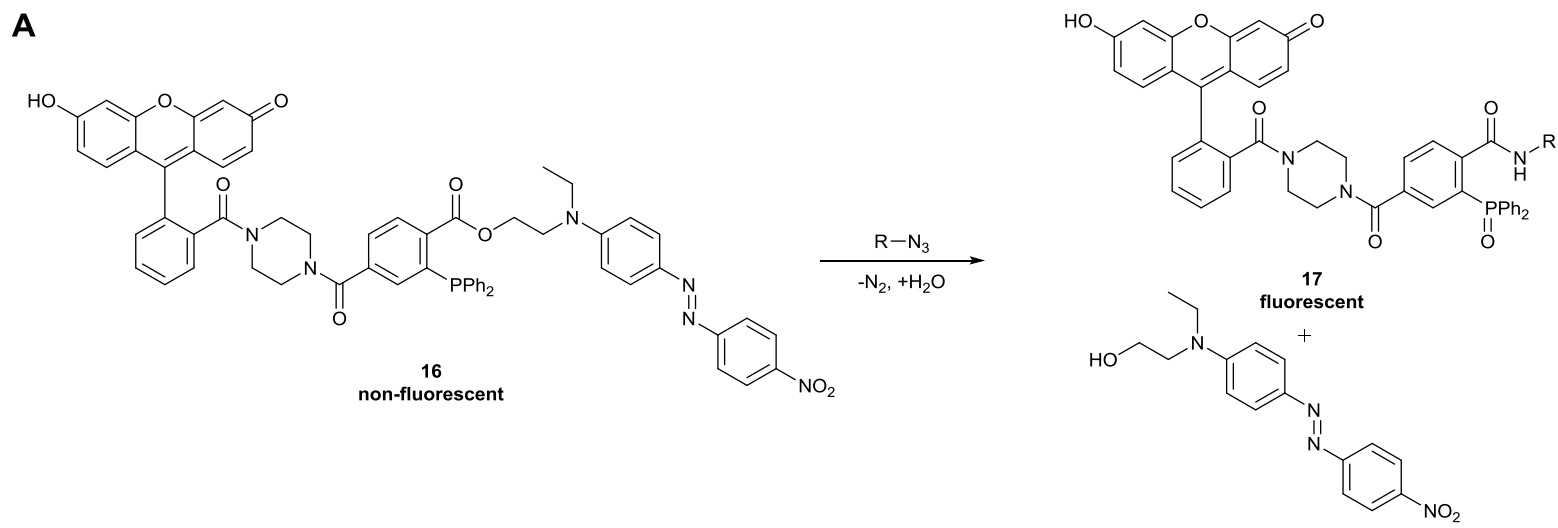

B

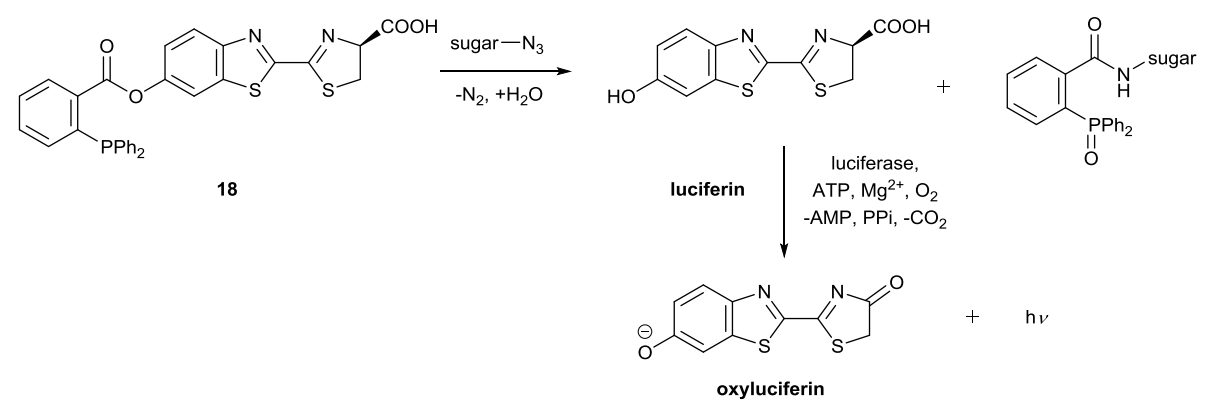

Figure 15. Fluorescence activation through Staudinger ligation. A: release of quencher from fluorescein through ester cleavage. B: release of caged luciferin for luciferase-luciferin reaction.

Not only are bond cleavage based techniques popular design elements in fluorogenic species, but it is also frequently applied in techniques involving controlled drug release.[95] Depending on the nature of the substituent on the electrophilic trap (ester, carbonate or carbamate) the released group can either be an alcohol or an amine.[96,97] Using this approach a fluorescein-Disperse Red system (16) was introduced by the Bertozzi group.[98] Such design afforded 170-fold increase in $\Phi_{\mathrm{F}}$ after release of the quencher (17) (Figure 15A). This probe was tested on the well-established CHO cell-system exposing azidosialate motifs in their cellsurface glycans (Figure 16). Though the probe was quite efficient in the visualization of surface glycans it had decreased permeability, which limits its use in the imaging of intracellular targets. 
a)

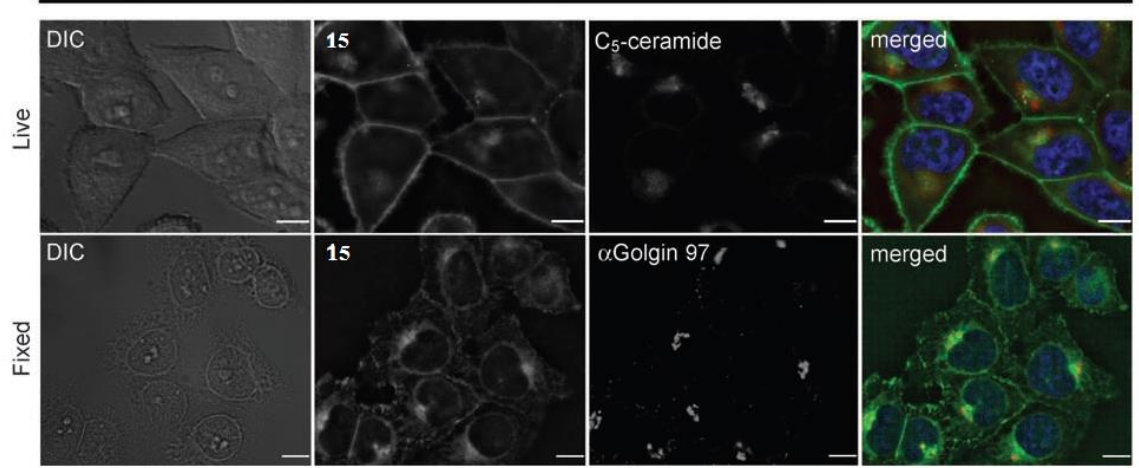

b)

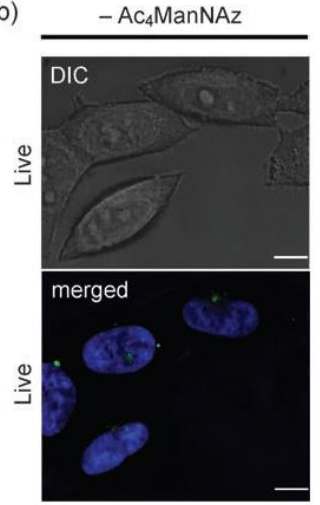

Figure 16. Fluorescence microscopic images of Ac4ManNAz-treated HeLa cells labeled with phosphane 16. a) Top row: Live HeLa cells treated with $\mathrm{Ac}_{4} \mathrm{ManNAz}, 16$ (FITC channel), and the live-cell Golgi marker BODIPY TR C5-ceramide (Cy3 channel); bottom row: HeLa cells treated with Ac4ManNAz, 16, then fixed, permeabilized, and treated with anti-Golgin 97 mouse $\mathrm{mAb}$ and goat anti-mouse IgGAlexa Fluor 647 (Cy5 channel). b) Live HeLa cells treated with 16 only. All cells were treated while alive with nuclear stain Hoechst 33342 (DAPI channel) and viability stain propidium iodide (Cy3 and Cy5 channels). The lack of nuclear fluorescence in $\mathrm{Cy} 3$ and $\mathrm{Cy} 5$ channels indicates propidium iodide exclusion from cells. The scale bars represent $10 \mu \mathrm{m}$. [Reprinted with permission from Ref. 98 Copyright: John Wiley and Sons]

A unique combination of Staudinger ligation and bioluminescence was reported by the same group by the introduction of a phosphane caged luciferin (Figure 15B, 18).[99] Upon reaction with surface glycan azides a luciferin is decaged from the probe, and becomes accessible for co-expressed luciferase to produce bioluminescent signal. The method does not require external irradiation due to enzymatic activation (bioluminescence), making it a powerful imaging tool with exclusive signal-to-noise ratio. 
A.

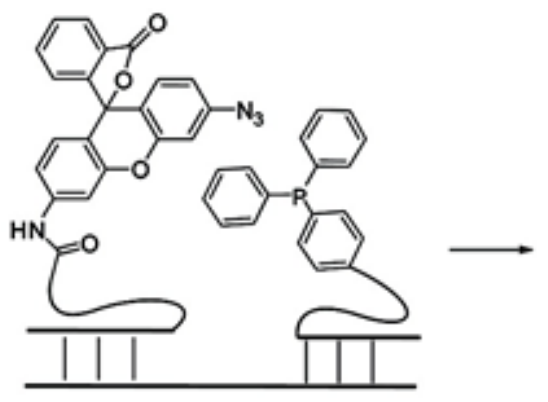

18

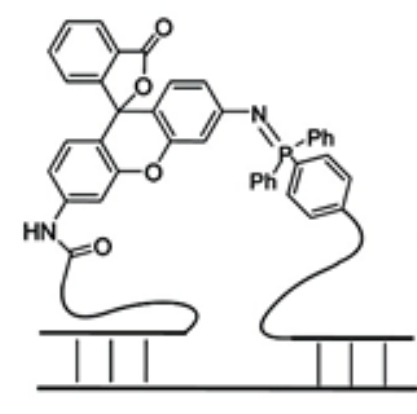

aza-ylide intermediate

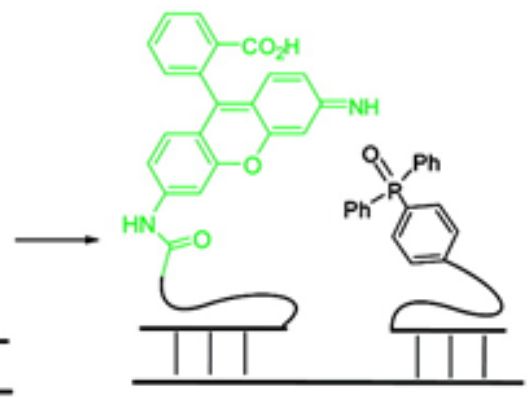

20

B.

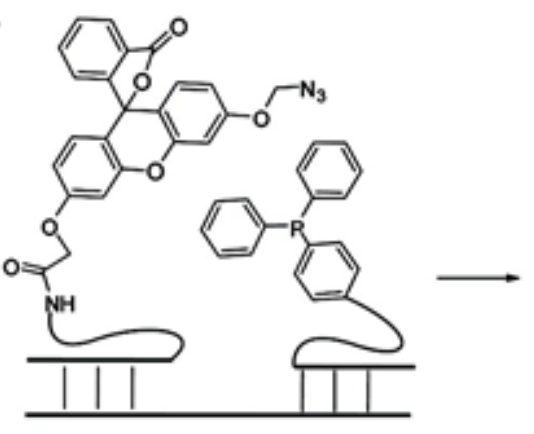

19

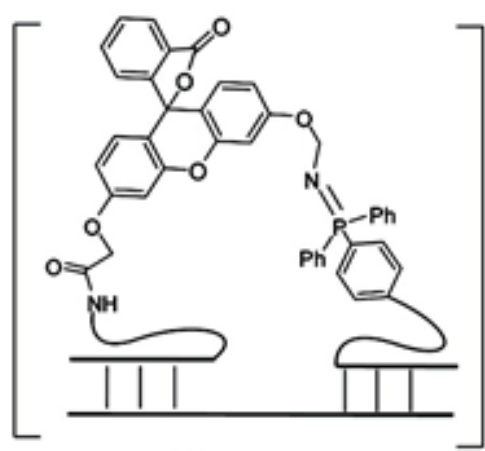

aza-ylide intermediate

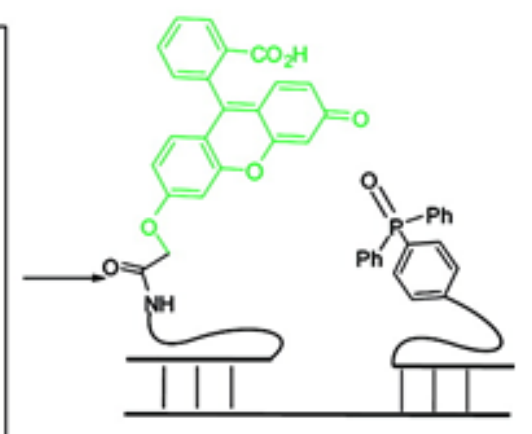

21

Figure 17. Fluorescence turn-on of RNA-bound azide quenched xanthanes through Staudinger reaction. [Reprinted with permission from Ref. 100 Copyright (2009) American Chemical Society]

Other approaches also harvested the potential of the original Staudinger reduction. In one of such examples the azide served as a quencher of different fluorescent xanthane cores. Upon phosphane mediated reduction of the azide moiety in constructs $\mathbf{1 9}$ and $\mathbf{2 0}$ to amines $\mathbf{2 1}$, 22, the fluorescence intensities increased considerably (Figure 17). The technique was applied to the detection of endogenous RNAs in living human cells.[100,101] In their approach two oligonucleotide templates labeled with azido-xanthane and phosphane, respectively were allowed to anneal with target RNA. Upon matched hybridization the azide and the phosphane tagged strands were brought into close proximity therefore Staudinger reduction could take place leading to strongly fluorescent products (Figure 17).

\subsubsection{Photoinduced reaction of tetrazoles}

The reaction originally described by Huisgen and co-workers in 1967 between 2,5diphenyltetrazole and methyl crotonate,[102] was found to be quite useful in bioorthogonal schemes and triggered the development of a series of new tetrazoles (23) for bioconjugation and fluorescence imaging applications.[14] The inherent fluorogenic nature of this reaction makes this transformation quite attractive. In their very first reports Lin et al. used UV light $(305 \mathrm{~nm})$ to induce photorelease of nitrogen and formation of the reactive dipolar nitrile imine 
species (Figure 18, 24). Subsequent efforts shifted the wavelength of photoreaction together with the excitation and emission maxima of the pyrazoline (25) products towards the visible region through 'scaffold hopping' strategy (Figure 18).[12,13,16,103] These efforts resulted in photoinduction of tetrazoles in near UV and far red region (up to $390 \mathrm{~nm}$ and $700 \mathrm{~nm}$ using two-photon absorption) and the corresponding pyrazoline derivatives showed fluorescence upon visible excitation in the orange-red region ( $\lambda_{\mathrm{exc}} 402-437, \lambda_{\mathrm{em}} 575-644 \mathrm{~nm}$, MeCN-PBS 1:1 v/v).[103] Reactions using cyclopropene as dipolarophile were carried out on genetically modified mammalian cells to prove the excellent efficiency and spatiotemporal control of this labeling scheme.[104] A unique framework (Figure 18, 26) allowing intramolecular photo-click reaction was also developed and conjugated to a microtubule-binding taxoid core. This construct was applied in fluorogenic visualization of microtubules in live $\mathrm{CHO}$ cells (Figure 19, $\lambda_{\mathrm{exc}} 330-358, \lambda_{\mathrm{em}} 528-617 \mathrm{~nm}, 21-112$-fold increase in fluorescence emission, MeCN-PBS $1: 1 \mathrm{v} / \mathrm{v}) \cdot[105]$

A

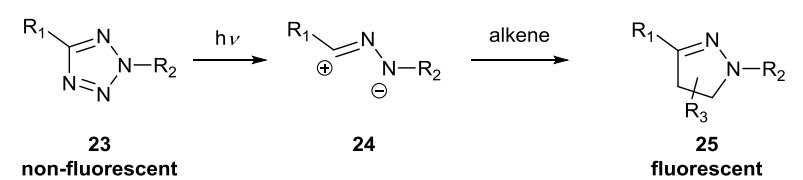

$R_{1}$ :<smiles>[R]NC(=O)C(C)C</smiles><smiles>[R]CI(I)c1ccccc1I</smiles><smiles>Ic1ccc(-c2cccs2)s1</smiles><smiles>[Y]C(C)c1c[R]ccc1</smiles><smiles>CC(C)c1ccc2ccccc2c1</smiles><smiles>Ic1ccc2ccccc2c1</smiles><smiles>Cc1cc(=O)oc2cc(I)ccc12</smiles><smiles>O=C(O)OCCOCCOCCO</smiles><smiles>[R]OCC=C</smiles><smiles>C=CNC(=O)OCC1C=C1</smiles>

C<smiles>CC1=CC(C)CC(C)=C1</smiles><smiles>Ic1ccc(C#Cc2ccccc2)cc1</smiles>
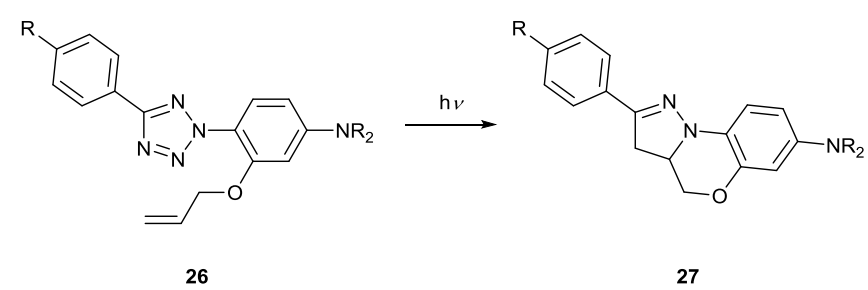

$\stackrel{26}{\text { non-fluorescent }}$ $\stackrel{27}{\text { fluorescent }}$

Figure 18. Tetrazole based fluorogenic dyes. A: Various dyes for photoinduced reaction. B: Commonly used alkene partners for cycloaddition. C: Reagent for intramolecular photoclick reaction. 

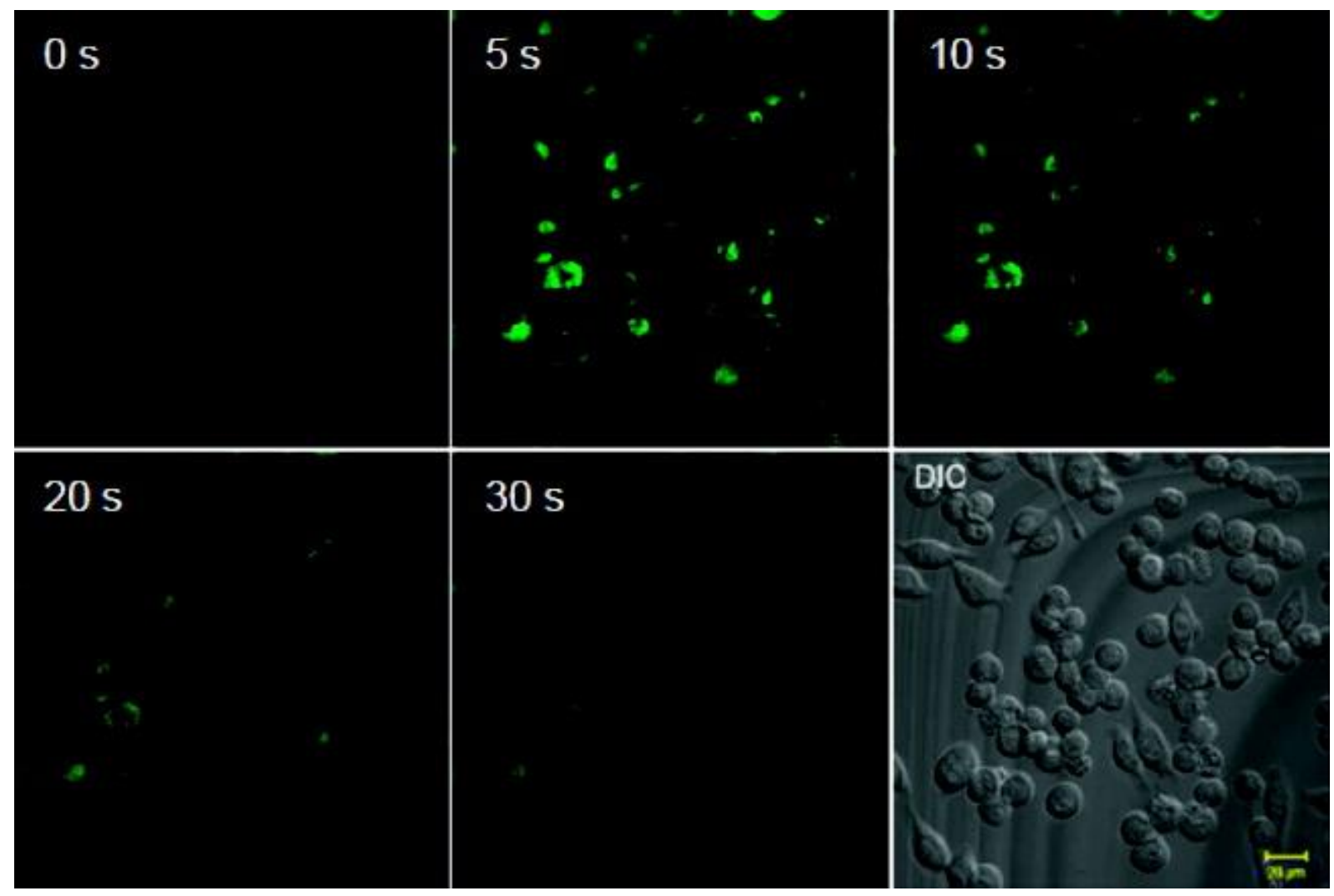

Figure 19. Time course of the photoactivation of taxoid conjugated with tetrazole $\mathbf{2 6}$ in live CHO cells. (a) Time-lapsed confocal micrographs of tetrazole-treated $\mathrm{CHO}$ cells after photoillumination, scale bar $=20 \mu \mathrm{m}$. Cells were treated with $1 \mu \mathrm{M}$ of taxoid-tetrazole for $30 \mathrm{~min}$ before photoillumination. ZEISS filter set \#49 was used for incident light filtering; for fluorescence, $\lambda_{\mathrm{ex}}=405 \mathrm{~nm}$. [Reprinted with permission from Ref. 105 Copyright (2011) American Chemical Society]

\subsubsection{Inverse electron demand Diels-Alder reaction of tetrazines}

As described earlier, the tetrazine moiety can participate in fast and efficient strain promoted inverse electron demand Diels-Alder cycloaddition (SPIEDAC) based ligation schemes with various dienophiles. Only very recently was the quenching ability of tetrazine scaffolds harvested in fluorogenic probe designs.[106] Tetrazines can quench the fluorescence of fluorescent scaffolds with matching emission bands by traditional FRET mechanisms. Most tetrazines absorb light at around $520 \mathrm{~nm}$, so virtually any fluorescent scaffolds with overlapping emission bands are suitable energy donors. Weissleder and co-workers demonstrated this using a series of green to red emitting BODIPY (28) and xanthane (Oregon Green) (29) derivatives (Figure 20). Reaction with trans-cyclooctene (TCO) resulted in $1.0-20$ fold EF in PBS. To evaluate the performance of these fluorogenic dyes in more challenging media they were tested in the labeling of the microtubular network of PtK2 cells using a microtubule binding TCOmodified taxol derivative. Successful imaging of the microtubular network revealed the suitability of this approach in in vivo imaging schemes (Figure 21). Other research groups 
developed Oregon Green and BODIPY tetrazine conjugates (Figure 20, 30,31), and examined their applicability and characteristics (e.g. permeability, stability) in the labeling of RNA,[107,108,109] proteins,[110,111,112] and phospholipids[113] in details.

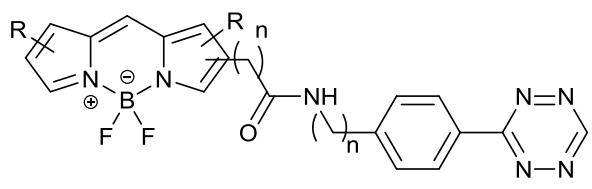

28<smiles>Cc1nnc(-c2ccc(CNC(=O)c3ccc(-c4c5ccc(=O)cc-5oc5cc(O)ccc45)c(C(=O)O)c3)cc2)nn1</smiles>

30<smiles>O=C(NCc1ccc(-c2nncnn2)cc1)c1ccc(-c2c3cc(F)c(=O)cc-3oc3cc(O)c(F)cc23)c(C(=O)O)c1</smiles><smiles>CN(C)c1ccc2c(c1)Oc1cc([N+](C)C)ccc1-c1ccc(C(=O)NCc3ccc(-c4nncnn4)cc3)cc1C2=O</smiles>

31

Figure 20. FRET-based tetrazine quenched fluorogenic dyes with flexible linkers.

a)
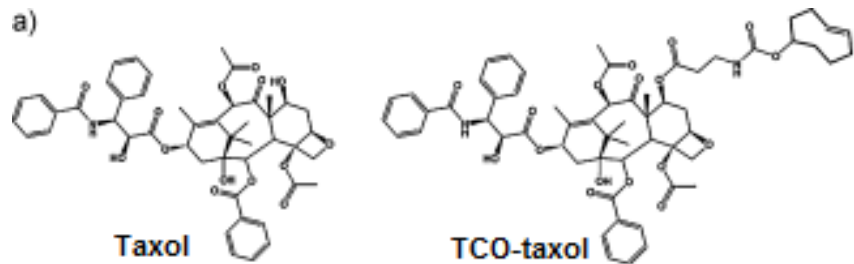

b)

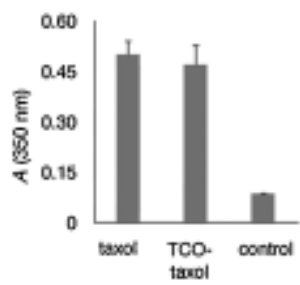

c)

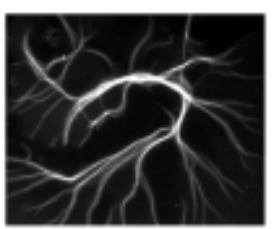

Figure 21. a) Structure of taxol and trans-cyclooctene-modified taxol (TCO-taxol). b) Comparison of the ability of $10 \mu \mathrm{M}$ taxol, trans-cyclooctene taxol, and a DMSO control to polymerize tubulin in the absence of GTP (polymerization assayed through absorbance at $350 \mathrm{~nm}$ ). Note that trans-cyclooctene taxol promotes polymerization similar to taxol and significantly better than a DMSO control. c) Microtubule bundles formed in the presence of trans-cyclooctene taxol treated with tetrazine-BODIPY FL (28) and visualized by fluorescence microscopy. [Reprinted with permission from Ref. 106 Copyright: John Wiley and Sons] 
There is an alternative quenching mechanism called through-bond-energy-transfer (TBET). Unlike traditional FRET, TBET quenching does not require overlapping emission and absorption bands of fluorophores and tetrazines, respectively. In TBET frameworks the fluorophore and the quencher are linked together with a twisted, but otherwise conjugated linker.[114,115] Weissleder and Hilderbrand have studied a set of fluorophore-tetrazine TBET (Figure 22, 32, 33) scaffolds to evaluate their fluorogenic nature.[116] Experimental results showed that the orientation of the emission and absorption transition dipoles of the fluorophore and the tetrazine, respectively together with their orientation with respect to the linker that governs the efficiency of TBET quenching. In their particular examples they found the highest EF (900-1600-fold, water) when the fluorescent core and the quenching tetrazine were in metaposition on the benzene ring. This was in good accordance with theoretical predictions. The excellent fluorogenicity was further proven in bioimaging studies using TCO-tagged extra- and intracellular targets. The remarkable EF values allowed imaging with outstanding sensitivity and very low background signal without washing steps.

Prompted by this idea the Wombacher group accounted on the synthesis of rigid BODIPY- and fluorescein-tetrazines $(\mathbf{3 4}, \mathbf{3 5})$.[117] These probes allowed excitation in the visible region ( $\lambda_{\mathrm{exc}} 494-505, \lambda_{\mathrm{em}} 515-524 \mathrm{~nm}$, phosphate buffer $\mathrm{pH} 7.2$ ) but moderate EF values (4.5-23.4-fold $\Phi_{\mathrm{F}}$ enhancements). Their suitability in imaging applications was shown in fluorogenic labeling of TCO modified dihydrofolate reductase. Another set of tetrazineBODIPY (36) [118] and xanthane dyes $(37,38)$ [119] was introduced by Devaraj and coworkers (Figure 22). The BODIPY probes were specifically developed to detect DNA and microRNA templates in picomolar concentrations. Most recently, Weissleder and co-workers constructed a series of coumarin-tetrazine TBET probes (39) that showed outstanding EF values (Figure 22).[120] Fluorescence of the coumarin cores were efficiently quenched by tetrazines and restored upon reaction with TCOs. Though the excitation wavelengths were in the less favorable far UV region ( $\left.\lambda_{\mathrm{exc}} 347-400, \lambda_{\mathrm{em}} 455-502, \mathrm{PBS} \mathrm{pH} 7.4\right)$ changes in $\Phi_{\mathrm{F}}$ justified to call these probes as "HELIOS-probes" for their $\underline{H}$ ypEremissive Ligation-Initiated $\underline{\text { Orthogonal }}$ Sensing capabilities. Upon reaction with TCO 2500-11,000-fold increase in quantum yields were observed. The authors chose epidermal growth factor receptor (EGFR) on the surface of cancer cells as a model system to test the performance of these probes. Images were generated within seconds and exhibited virtually zero nonspecific signal according to the control experiments. Moreover, intracellular imaging of mitochondria and actin network was also accomplished to show the intracellular applicability of these dyes (Figure 23). 
<smiles></smiles>

32

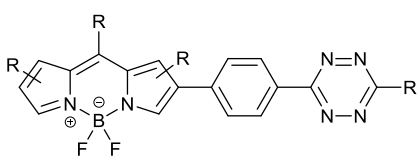

33

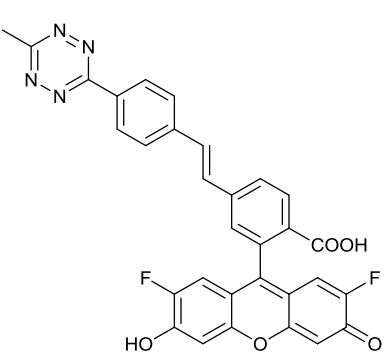

37

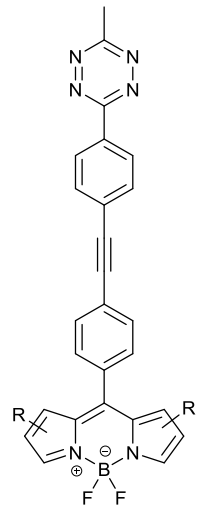

34

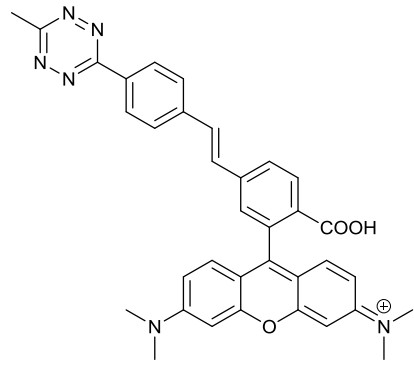

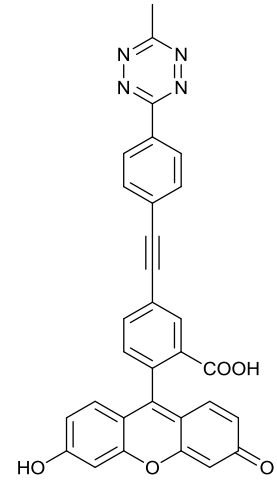

35

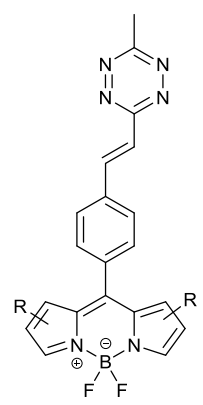

36

Figure 22. TBET-based tetrazine quenched fluorogenic BODIPY $(\mathbf{3 2}, \mathbf{3 3}, \mathbf{3 4}, \mathbf{3 6})$, xanthane $(\mathbf{3 5}, \mathbf{3 7}, \mathbf{3 8})$ and coumarin (39) dyes with rigid linkers.

a)

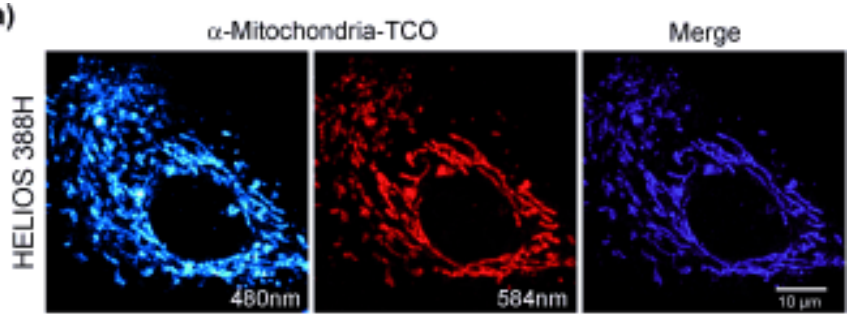

b)

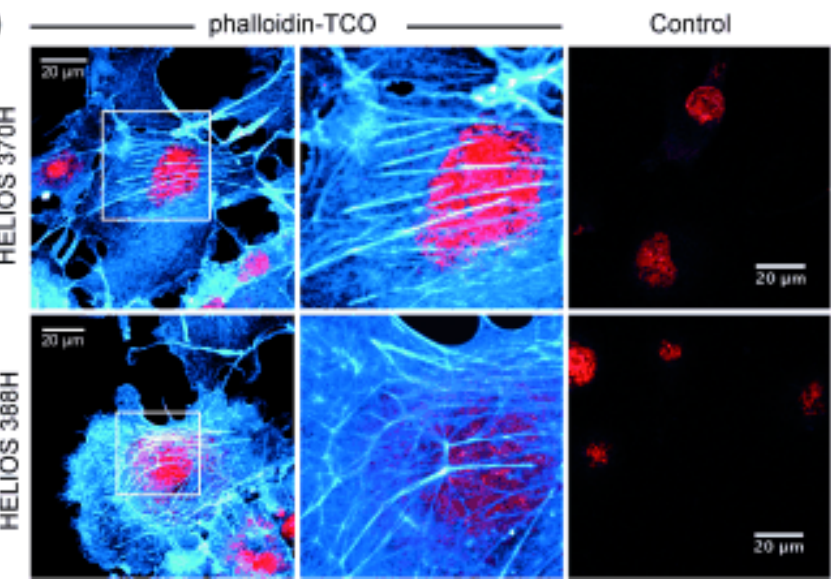

Figure 23. No-wash fluorogenic imaging of intracellular targets. a) Mitochondrial imaging: OVCA-429 cells with RFP-tagged mitochondria were incubated with an anti-mitochondria-TCO antibody, rinsed briefly, and then imaged after addition of $100 \mathrm{nM}$ HELIOS 388H in PBS. Colocalization analysis in ImageJ (Costes auto-threshold) was used to generate the merged image in the right-hand panel (scale 
bar=10 $\mu \mathrm{m})$. b) Actin imaging: COS-1 cells were incubated with phalloidin-TCO $\left(1 \mu \mathrm{g} \mathrm{mL} \mathrm{L}^{-1}\right)$ and DRAQ5 nuclear counterstain ( $1 \mu \mathrm{M}$, BioStatus), rinsed briefly, and then imaged upon addition of the indicated HELIOS probe at $100 \mathrm{nM}$. Control images were collected at matched dye concentrations in the absence of phalloidin-TCO (scale bars $=20 \mu \mathrm{m}$ ). [Reprinted with permission from Ref. 120 Copyright: John Wiley and Sons]

\subsubsection{Other fluorogenic tagging schemes}

Although bioorthogonal postulates suggest the use of non-endogenous functions to ensure orthogonal transformations in the presence of a vast number of naturally occurring functions there are few exceptions to these rules. Non-natural arrangement of natural functions can also be used in bioorthogonal tagging schemes. The best examples for this approach are genetically encoded small proteins or peptide tags with unique enzymatic functions (e.g. HaloTag, SNAP-Tag etc.) or tetra-cysteine $\left(\mathrm{Cys}_{4}\right)$ self-labeling tags, respectively. Within the context of this review only the latter group will be discussed.<smiles>O=C(O)c1ccccc1-c1c2ccc(=O)c([As]3SCCS3)c-2oc2c([As]3SCCS3)c(O)ccc12</smiles>

40

non-fluorescent<smiles>O=c1ccc2nc3ccc(O)c([As]4SCCS4)c3oc-2c1[As]1SCCS1</smiles>

41
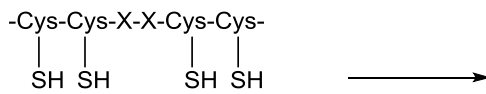

$\overbrace{S-A s}^{\prime}$

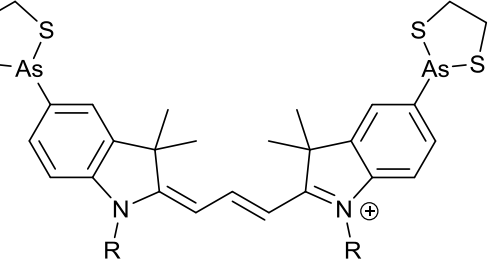

42

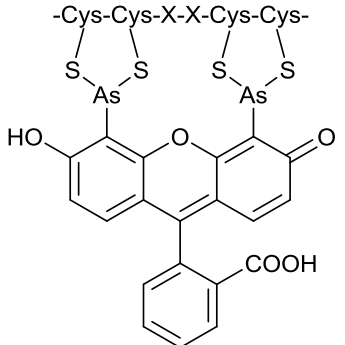

fluorescent complex<smiles>O=C(O)c1ccccc1CN=c1ccc2c(-c3ccccc3[R5](O)(O)O)c3ccc(NCc4ccccc4[15OH])cc3oc-2c1</smiles>

43

Figure 24. Fluorogenic biarsenical probes and its complex with tetracysteine-containing peptide or protein domain.

Tsien and colleagues introduced the concept by the development of fluorogenic biarsenical probes. Although the initial helix model was revised to be a hairpin structure,[121] the most renown biarsenical probe is still dubbed as Fluorescein $\underline{\text { Arsenical }}$ Helix binder (FlAsH) (Figure 24, 40) referring to the original binding structure. FlAsH was able to selectively react with a short 15 amino acid polypeptide tag containing a tetracysteine motif (CCXXCC).[122] Vibrational deactivation or PET by the As-1,2-ethanedithiol groups are supposed to be 
responsible for the quenched state of the FlAsH probe. Reaction with target $\mathrm{Cys}_{4}$ tags creates a more constrained structure, which prevents conjugation of the arsenic lone pair electrons with the molecular orbitals of fluorescein. The attained fluorescence enhancement is about 1000fold $\left(\lambda_{\mathrm{exc}} 508, \lambda_{\mathrm{em}} 528 \mathrm{~nm}\right)$ in aqueous media. The resulting FlAsH-peptide conjugate was found to be stable for weeks even in the presence of excess EtSH. Moreover, the FlAsH probe is cell permeable and allowed intracellular imaging of HeLa cells expressing a recombinant CFP. The authors later applied FRET technology to image the cytosol and nuclei of HeLa cells expressing mutant calmodulin. Later, the same group developed further biarsenical reagents with different cores (e.g. resorufinol, ReAsH, 41), which show red-shifted emission ( $\lambda_{\mathrm{exc}} 593, \lambda_{\mathrm{em}} 608 \mathrm{~nm}$ ) relative to FlAsH.[123] Limitations of these biarsenical probes are the potential toxicity of the arsenic and the competing interaction with non-specific thiols leading to considerable background fluorescence. The need for reducing agents such as DTT or TCEP to prevent the oxidation of $\mathrm{SH}$-groups further limit their use, not to mention that self-labeling peptide tag installation is restricted mostly to the $\mathrm{N}$ - or C-termini of the protein of interest with very few examples for internal protein labeling.[124]

The quenching effect of biarsenic motif was applied by Mayer and co-workers in a cyanine biarsenical dye $(\mathrm{AsCy} 3,42)$. They found moderate, 6 -fold enhancement $\left(\lambda_{\mathrm{exc}} 560, \lambda_{\mathrm{em}}\right.$ $576 \mathrm{~nm}$ ) in aqueous media.[125] It should be noted that AsCy3 was transformed into a membrane-permeable dye suitable for super-resolution imaging.[126] Most recently, Schepartz and co-workers studied the peptide length dependence of an AsCy3 based fluorogenic dye.[127] They found that at least 8 amino acids are needed between the Cys-Cys pairs to reach maximum affinity towards target Cys4 motif and suppress side reaction with non-specific thiols. They, however, only reached a 3.2-fold increase in fluorescence (with 11 amino acids) upon specific binding. Similar to biarsenicals, bis-boronic acid based fluorogenic labels (RhoBo, 43) are useful in specific labeling schemes by targeting tetraserine motifs.[128] The specificity of RhoBo was tested on saccharide-rich (HeLa) cell surfaces to image tetraserine-tagged proteins in the cytosol.

Keillor and co-workers took advantage of the quenching effects of a dimaleimide scaffold to design fluorogenic probes. Examples for this setup are naphthalimide (44),[129] dansyl (45),[130]or coumarin (46-48),[131] based bis-maleimides (Figure 25). The PET process accused with the quenching phenomenon allows 7-350-fold enhancement upon Michael addition with Cys2 motifs. The authors engineered a short alpha-helix sequence (dC10 $\alpha$ (Cys-AA10-Cys) that can be fused to protein of interest.[130] 
A

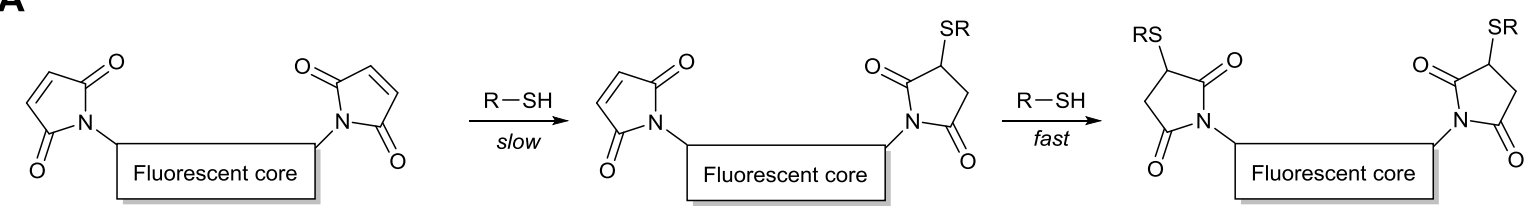

B<smiles>CC(=O)CC(C(C)=O)N1C(=O)c2cc(N3C(=O)C=CC3=O)cc3cc(N4C(=O)C=CC4=O)cc(c23)C1=O</smiles><smiles>CN(C)c1cccc2c(S(=O)(=O)NNNC(=O)c3cc(N4C(=O)C=CC4=O)cc(N4C(=O)C=CC4=O)c3)cccc12</smiles><smiles>[R]C1=CC(=O)N(c2ccc3oc(=O)c(N4C(=O)C=C([R])C4=O)cc3c2)C1=O</smiles>

46

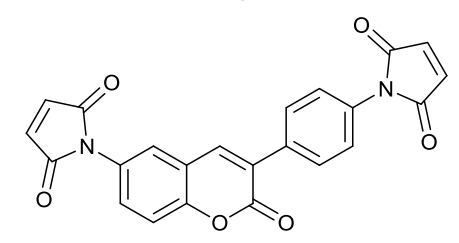<smiles>CCN(CC)c1ccc2cc(C(=O)Nc3cc(N4C(=O)C=C(OC)C4=O)cc(N4C(=O)C=C(OC)C4=O)c3)c(=O)oc2c1</smiles>

48

47

Figure 25. Fluorogenic bis-maleimide probes. A: The general reaction scheme of the double thiol addition. B: 1,8-naphthalimide (44), dansyl (45) and coumarin (46-48) fluorogenics quenched by two maleimide groups.

They found that dimethoxymaleimide probes with attenuated electrophilicity reacted quite specific with target bis-thiols and their reaction with non-specific biothiols (GSH) was completely suppressed. The good membrane permeability of these bis-maleimides was demonstrated in the intracellular labelling studies of recombinant histone $\mathrm{H} 2 \mathrm{~B}-\mathrm{dC} 10 \alpha$, and $\mathrm{dC} 10 \alpha$-actin. These tagged proteins were successfully tagged and imaged in the cytosol and nuclei of HEK293T cells using fluorescence microscopy, without any washing steps.[130]

\subsection{Bioorthogonalized luminescent nanocomposites}

With the development of bioorthogonal chemistries nanocomposites benefited significantly in terms of conjugation capabilities. Owing to their unique properties, nanomaterials are attractive targets for bioconjugation.[132] Besides their genuine attributes such as being protective nanocarriers with high cargo capacity of e.g. drugs with high load capacities and potential for controlled release, many nanocrystalline material exhibit remarkable physical properties.[54,132] Among these features, nanoparticles with the potential for light emission are the most relevant to this review.[54] From the photochemical point of view it can generally be stated that NPs being either intrinsically luminescent or due to dopants exhibit bright photoluminescence with quantum yields close to unity and their photostability is 
far better than those of small synthetic dyes. It should also be mentioned that most NPs are not toxic and do not suffer from non-specific binding to e.g. cellular proteins.[54,132]

Nanoparticles have their characteristic intrinsic properties, however, it is usually necessary for biological applications that they are covered with a translucent shell that on the one hand does not affect luminescent properties and on the other hand can be further functionalized e.g. with bioorthogonal functions. Bioorthogonal modification schemes offer clean, efficient and controllable derivatization of nanoparticles. There are two main reasons that NPs are rendered bioorthogonal: i) to use them in targeted tagging schemes and ii) to display other elements on their surface (e.g. drugs, other signaling modules or recognition elements) using efficient chemistries resulting in high coverage. The most common nanoparticles are either synthetic colloids composed of metals, alloys, semiconductors, carbon allotropes or (bio)polymers. Within this chapter we cover examples for different bioorthogonalized NPs and their usage in bioimaging applications. Surprisingly, relatively few types of luminescent nanoparticles are reported in the literature in the context of bioorthogonality and bioimaging.

\subsubsection{Semiconductor quantum dots (QDs)}

Quantum dots are nanocrystalline particles with typical size between $2-10 \mathrm{~nm}$ are composed of semiconducting materials. The emission properties of QDs can be fine-tuned synthetically by varying their size and composition.[133] Their wide UV absorption band and narrow photoluminescent band make them ideal for multi-color imaging applications. These features are accompanied with high QYs and photostability. Besides rendering them multifunctional in order to enable further - bioorthogonal - functionalization, biocompatible coating of QDs is also necessary to diminish their inherent cytotoxicity.[134] As mentioned earlier the use of CuAAC chemistry is not amenable for QDs as their emission properties are heavily affected by the presence of the transition metal. In order to avoid the unwanted effects of the metal copper-free bioorthogonal chemistries are applied.

Texier et al. conducted a detailed study to assess the effects of copper on the luminescent properties of quantum dots.[135] They incubated commercially available CdSe/ZnS/PEG $2000^{-}$ $\mathrm{NH}_{2}$ QDs in the presence of $\mathrm{CuSO}_{4} /$ sodium-ascorbate a standard resource of $\mathrm{Cu}(\mathrm{I})$ catalyst in azide-alkyne click reactions. They observed that the presence of copper irreversibly decreased the luminescence of the particles. Thus they have used copper-free azide-alkyne chemistry in future applications. The same amine modified $\mathrm{CdSe} / \mathrm{ZnS} / \mathrm{PEG}_{2000}-\mathrm{NH}_{2}$ particles were reacted with a NHS activated cyclooctynes derivative. These bioorthogonalized QDs with an average hydrodynamic size of $\sim 10 \mathrm{~nm}$ and emission peak at around $552 \mathrm{~nm}$ were applied on Chinese 
Hamster Ovary (CHO) cells to image their cell surface glycans. Prior to labeling the CHO cells were treated with azido-tagged mannosamine (ManNAz). The cells incorporated the ManNAz into their cell-surface glycan structure via the metabolic savage pathway. Bioorthogonalized $\mathrm{CHO}$ cell surface then was successfully imaged using the QDs harboring the complementary bioorthogonal function (Figure 26).

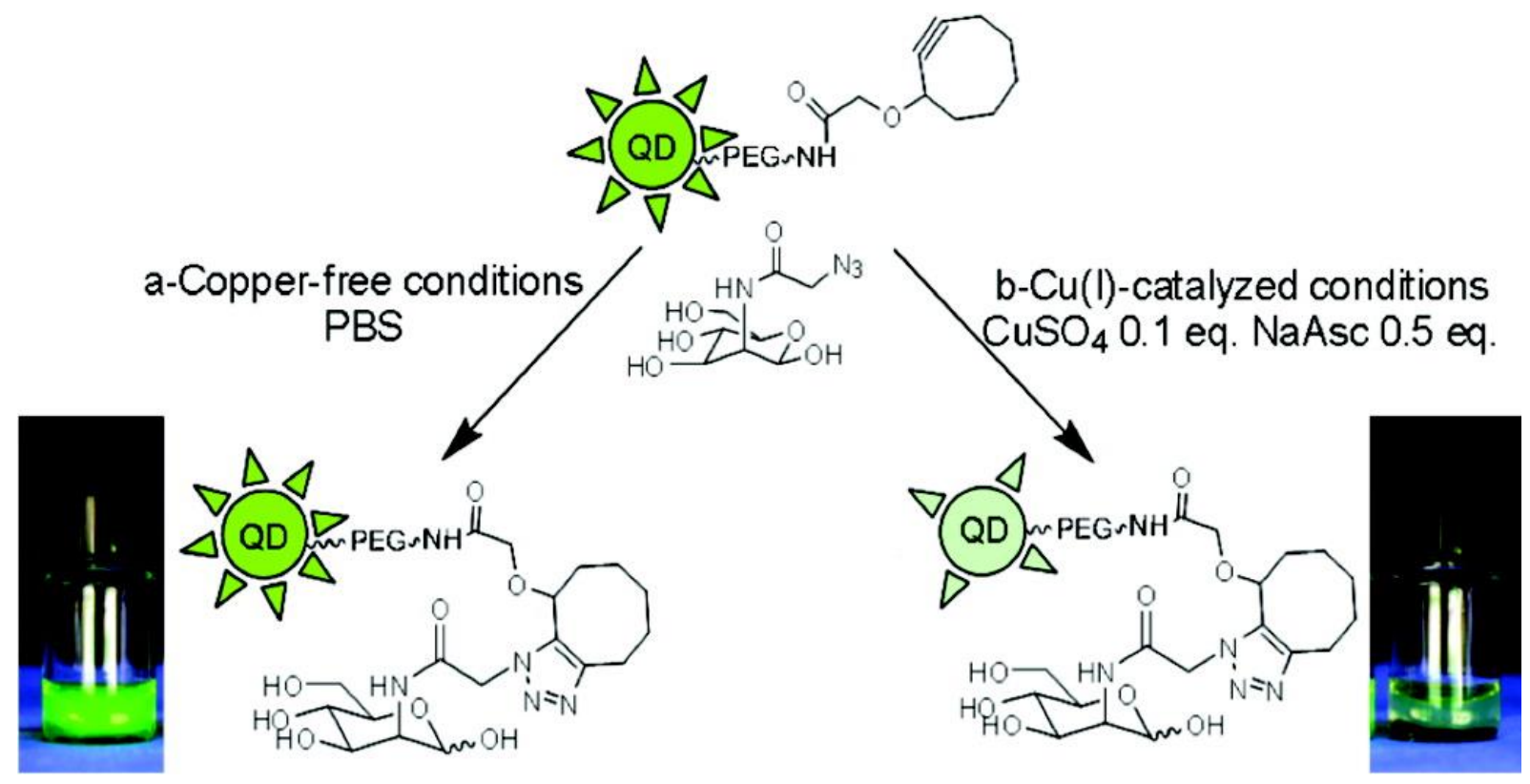

Figure 26. The effect of copper catalyst on the fluorescence properties of "click-functionalized" quantum dots. [Reprinted with permission from Ref. 135 Copyright (2010) American Chemical Society]

In their joint work, the groups of Bawendi and Weissleder devised a biocompatible coating for QDs that was further functionalized with norbornene units to display bioorthogonally applicable moieties on the particles.[136] They have used polymeric imidazole ligands (PILs), random copolymers of poly(ethylene glycol), amino-PEG $\mathrm{P}_{11}$ and imidazole, which ensure water solubility, further functionalization and QD-binding, respectively. These PILs were modified with norbornenyl acetic acid succinimide ester via amide bond formation. The as-modified norbornene-PILs (NBPILs) were used to modify the natively capped QDs by ligand exchange. To demonstrate the versatility of this capping method the authors applied a tetrazine-modified Alexa dye on the norbornene decorated QDs to promote inverse electron demand Diels-Alder reaction. According to the molar absorptivities of the Alexa dye and QDs the modification ratio was determined as 16-dye molecule / QD particle, which also represents the number of norbornene units per particle. The developed NBPILs allow high loading of the particles with reactive bioorthogonal motifs while maintaining the neutral charge. In contrast, former amine or carboxylic acid containing coatings resulted in unwanted non-specific binding to cells or biomolecules due to their charge. 
In their recent work the same authors aimed at developing QD based luminescent probes for in vivo cytometric imaging of rare cells in unmanipulated mice using the same NBPIL capped QDs.[137] They prepared a diverse combination of norbornene decorated QDs composed of different materials e.g.. CdSe/CdZnS, CdSe/CdS and InAs/CdZnS with emission peaks at around 612, 570 and $800 \mathrm{~nm}$, respectively (QD $\left.612, \mathrm{QD}_{570}, \mathrm{QD}_{800}\right)$ and tetrazine modified antibodies (anti-mouse CD31, CD45, c-kit, and Sca-1). They have studied the hydrodynamic size of the Ab conjugated QDs as this parameter influences a lot of biologically relevant parameters such as accessibility, distribution and clearance not to mention the motion of the targeted species. Since NBPILs coordinate directly to the surface of the particles via their imidazole units smaller hydrodynamic size can be achieved compared to e.g. commercially available water-soluble QDs covered by amphiphilic polymers. In this experiment the average hydrodynamic size around the $\sim 5.8 \mathrm{~nm}$ inorganic cores was $\sim 15 \mathrm{~nm}$ (for $\mathrm{QD}_{612}$ ). The NBPIL modified QD-antibody conjugates possessed moderately negative surfaces as indicated by zetapotential measurements. Compared to commercially available hydrophilic QDs the hydrodynamic size of NBPIL-covered QDs did not change after incubation in serum indicating minimal non-specific binding of proteins. With these QD immunoconstruct in vivo single cell labeling of rare populations of hematopoietic and progenitor cells was successfully achieved and visualization of targeted cells in their native environment in live animals became possible. Moreover, the applied multiphoton microscopy enabled deeper tissue penetration and lower autofluorescence (Figure 27).

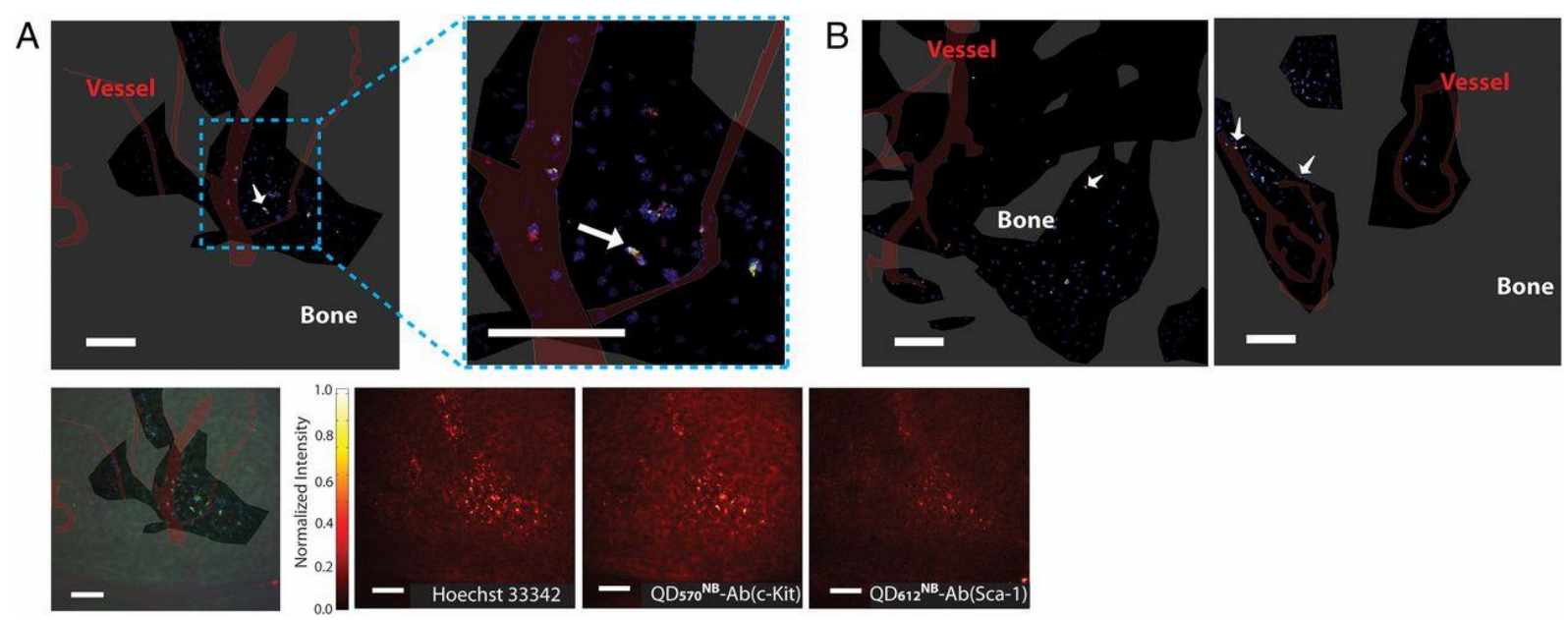

Figure 27. In vivo imaging of single endogenous Sca- $1^{+} \mathrm{c}-\mathrm{Kit}^{+}$cells in the intact bone marrow using $\mathrm{QD}^{\mathrm{NB}}{ }_{-}^{\mathrm{T}} \mathrm{Ab}$. (A, Upper) A representative multiphoton microscopy image of a bone marrow cavity shown after removing the signal from the QD/Ab channels outside of the cells, which were segmented from Hoechst 33342 signal. Yellow cells (arrows) represent single Sca- $1^{+} \mathrm{c}-\mathrm{Kit}^{+}$cells. Red and green cells represent Sca- $1^{+}$and c-Kit ${ }^{+}$cells, respectively. An area containing an $\mathrm{Sca}-1^{+} \mathrm{c}-\mathrm{Kit}^{+}$cell is magnified in Upper Right. Translucent red and gray areas represent vessels and the bone, respectively. Lower Left shows the unmodified maximum intensity projection $(\sim 10 \mu \mathrm{m}$ in the $z$ direction). Lower Right shows 
the maximum intensity projections of each channel individually. (B) Additional images of bone marrow cavities containing Sca- $1^{+} \mathrm{c}-\mathrm{Kit}^{+}$cells. Signals outside of the Hoechst $33342^{+}$cells were discarded in these images, e.g., in A, Upper. (Scale bars: $100 \mu \mathrm{m}$. [Reprinted with permission from Ref. 137 Copyright (2015) National Academy of Sciences, USA.]

In another recent contribution by the Ma and Cai groups the noninvasive visualization of viral infection was accomplished by bioorthogonalized quantum dots.[138] In their report they used $\mathrm{CdSeTe} / \mathrm{ZnS}$ quantum dots that were coated with azide-modified multidentate polymeric ligands bearing imidazole as coordinating group. These azide functionalized NIR emitting $\left(\lambda_{\mathrm{em}}=750 \mathrm{~nm}\right)$ particles with a hydrodynamic diameter of $\sim 13 \mathrm{~nm}$ were conjugated to cyclooctynes derivatized avian influenza H5N1 pseudotype (H5N1p) viruses via strain promoted azide-alkyne cycloaddition to afford luminescent virus constructs (QD-H5N1p). The infectivity of the NIR emitting viruses were found to be unaffected by the QD modification. Mice infected intranasally with live or heat inactivated QD-H5N1p constructs and imaged through the NIR channel. In case of active viruses a bright and sustained fluorescent signal was observed in the lungs, while inactivated viruses displayed distinctly decreased signal. The same active QD-H5N1 construct was used to test the effects of anti-viral drugs (Figure 28). Drug treatment resulted in decrease of signal accumulation in lungs indicating the effects of antiviral treatment. Such bioorthogonally modified systems therefore are promising applicants for the development of antiviral drug screening systems. 
(a)

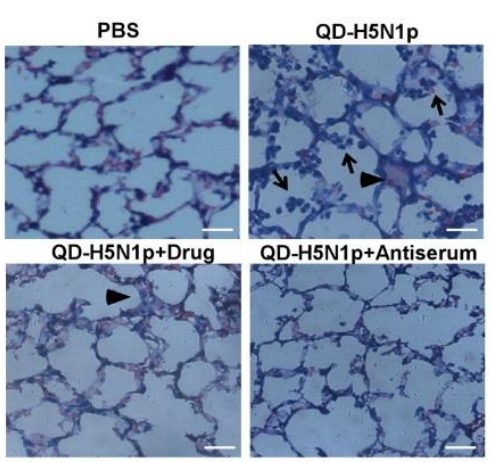

(c)

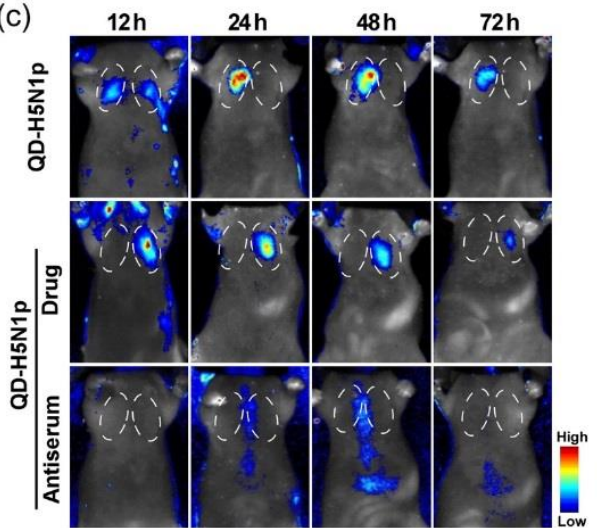

(e)

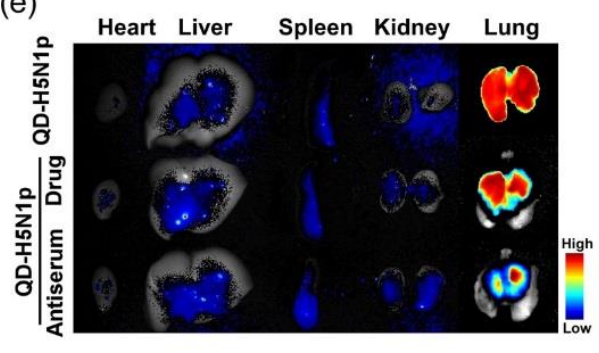

(b)

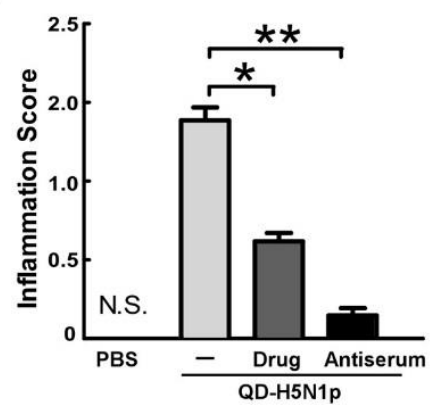

(d)

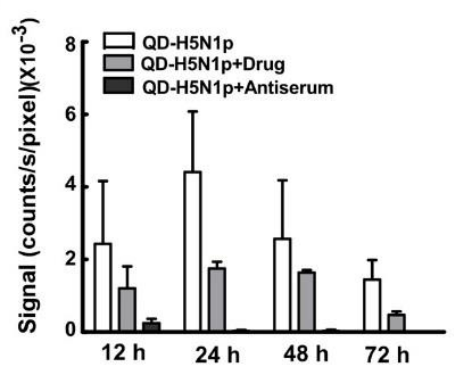

(f)

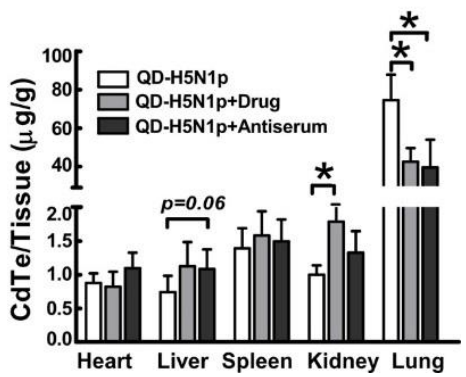

Figure 28. Effect of antiviral agents on the dynamics of respiratory QD-H5N1p infection in mice. Six week old female Balb/c mice were i.n. infected by PBS or QD-H5N1p \pm oseltamivir carboxylate (drug) or mouse antiserum against H5N1p (antiserum). (a,b) Histopathology of lung tissues on day 3 postinfection was assessed by the H\&E staining (a), followed by histopathology scoring (b). ( $\uparrow$ ) Infiltrated inflammatory cells; ( $\boldsymbol{\Delta}$ ) thickening of lung epithelium. Scale bar $=20 \mu \mathrm{m}$. (c,d) In vivo live imaging of mice at 12-72 h post-infection, and the fluorescent signals of circled regions. (e) Ex vivo fluorescent imaging of hearts, livers, spleens, kidneys, and lungs on day 3 post-infection. (f) ICP-OES analysis of cadmium concentration in different organs 3 days post-infection. Tissue cadmium concentration $(\mu \mathrm{g} / \mathrm{g})$ was calculated by normalizing the amount of cadmium to sample weight. Bars shown are mean $\pm \mathrm{SE}(n$ $=5$ ), and the differences among groups were determined using one-way ANOVA analysis; ${ }^{*} p<0.05$; $* * p<0.01$. [Reprinted with permission from Ref. 138 Copyright (2014) American Chemical Society]

\subsubsection{Lanthanide doped nanoparticles - upconverting nanoparticles, UCNPs}

Lanthanide-doped upconverting nanoparticles (UCNPs) - sometimes termed as upconverting nanophosphors - are capable of converting low energy (near infra-red) light into higher energy, visible light via sequential multi-photon absorption and energy transfer processes.[139,140] Their NIR excitation enable virtually autofluorescence-free imaging techniques with deeper tissue penetration. Moreover, these features are paired with low 
cytotoxicity, narrow emission bandwidth, highly photostability and last, but not least, NPs do not blink. Several bioimaging applications harvest the excellent photophysical properties of UCNPs even in challenging biological media such as blood, however, in combination with bioorthogonality surprisingly few records could be obtained.[141] This is somewhat unexpected, as excellent methods exist for the bioorthogonal modification of UCNPs.

A simple, but efficient method for the modification of hexagonal phase $\mathrm{NaYF}_{4}$ nanoparticles doped with $\mathrm{Yb}$ and $\mathrm{Er}$ or Tm was reported by Wolfbeis et al. to make these nanophosphors amenable to click chemistry.[142] Similar to other metal-oxide (hydroxide) surfaces UCNPs can easily be coated with silane reagents to form a hydrophobic silica shell around the particles. When tetraethoxyorthosilicate was applied simultaneously with either (3azidopropyl)triethoxysilane or prop-2-yn-1-yl (3-(triethoxysilyl)propyl)carbamate using a modified Stöber method azide or alkyne decorated silica coated UCNPs were obtained. Such clickable UCNPs were further modified by means of copper catalyzed azide-alkyne cycloaddition with biotin, maleimide or small organic fluorophore derivatives harboring complementary functions providing evidence for the versatility of this straightforward modification method. The groups of Wagenknecht and Wolfbeis gave an account of making highly functionalized DNA-UCNP constructs using similar azide decorated silica coated green $(550 \mathrm{~nm})$ and red $(660 \mathrm{~nm})$ emitting $\mathrm{NaYF}_{4}: \mathrm{Yb}, \mathrm{Er}$ UCNPs and alkyne modified oligonucleotides.[143] The obtained DNA-UCNP constructs were highly water soluble compared to plain UCNPs. They have tested the recognition abilities of these DNA-UCNPs in the presence of the counterstrand DNA sequence. Thermal dehybridization experiments using UV absorption together with duplex formation in the presence of ethidium-bromide confirmed that the conjugate can recognize its complementary DNA sequence (Figure 29). 


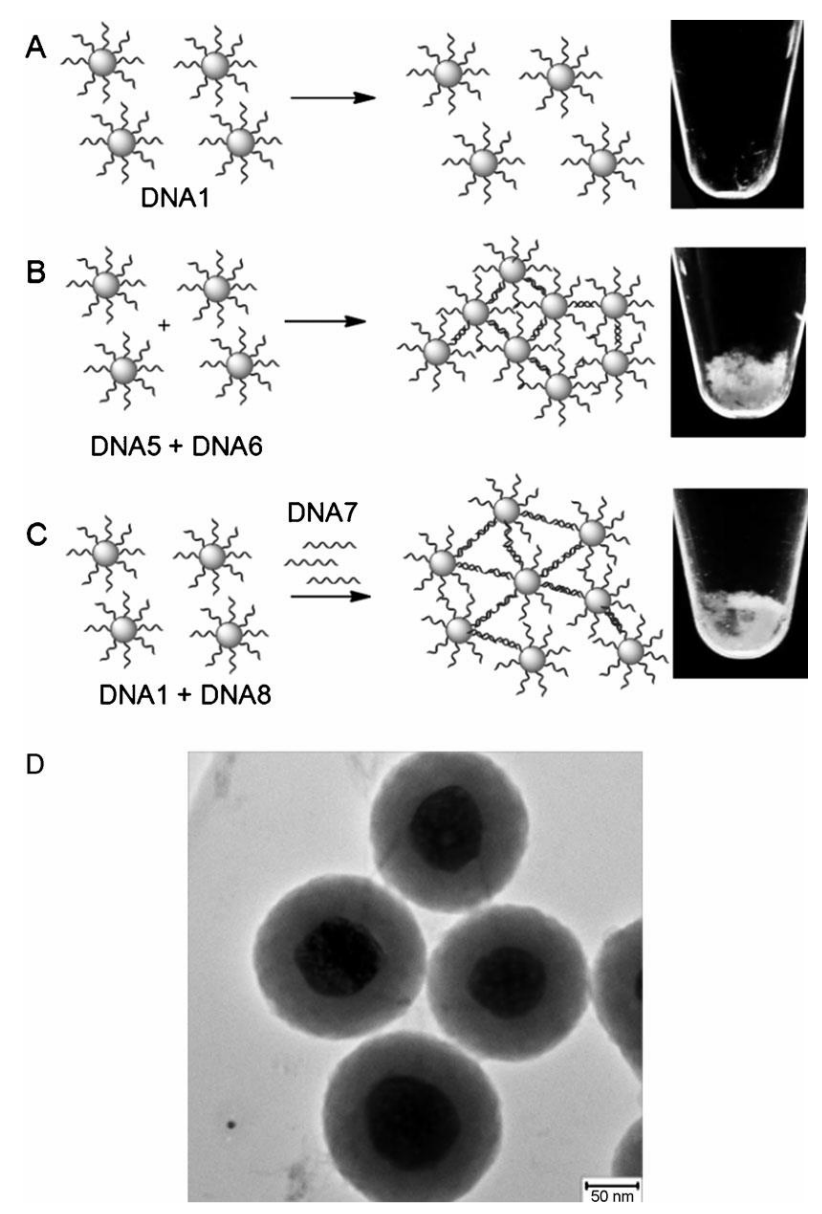

Figure 29. Aggregation of UCNP-DNA conjugates: A) Control with UCNP-DNA1 without cross-linker oligonucleotide. B) UCNP-DNA5+UCNP-DNA6. C) UCNP-DNA1, UCNP-DNA8 and DNA7. D) TEM Image of aggregate B. [Reprinted with permission from Ref. 143 Copyright: John Wiley and Sons]

The imaging applicability of DNA-UCNPs was tested in cells. Normal rat kidney cells were treated with the nanoparticle constructs and imaged using confocal microscopy equipped with an external $980 \mathrm{~nm}$ laser source. The cells ingested the particles and upon NIR excitation the upconverted emission colors could be seen without blinking or photobleaching. The authors also investigated the sequence selective aggregation properties of the constructs. When two DNA-UCNP constructs bearing complementary DNA strands were mixed aggregation of the particles could be observed. In a parallel experiments when two particle constructs decorated with non-complementary DNA sequences (DNA1 and DNA8) were mixed no aggregation could be observed. However, aggregation could be initiated when a cross-linker DNA sequence (DNA7) complementary with both DNA-UCNP constructs was added. These experiments confirmed that DNA-UCNP conjugates had retained recognition properties and are promising luminescent materials for bioanalytical applications ea. in DNA and RNA recognition applications. 
Branda and Baillie introduced an azide coated UCNP system that was further manipulated with alkyne derivatized photoactive dithienylethene (DTE) photoswitchable unit. In their report they used $\mathrm{NaYF}_{4}: \mathrm{Yb}$,Er $\left(20 \mathrm{~mol} \% \mathrm{Yb}^{3+}, 2 \mathrm{~mol} \% \mathrm{Er}^{3+}\right.$,). This UCNP has characteristic emission peaks in the green and the red region $(550$ and $660 \mathrm{~nm}$, respectively).[144] The original oleic acid capping ligands were replaced by azidopropylphosphonate ligands to afford azide functionalized particles. Copper catalyzed azide-alkyne cycloaddition reaction with an alkyne and PEG bearing DTE afforded DTEUCNP conjugates. The DTE motif can be reversibly toggled between an open and a closed form using UV and visible light as trigger. UV irradiation induces a photocyclization of the DTE affording a closed DTE that absorbs efficiently the green emission of the UCNPs either via energy transfer (FRET) or inner filter mechanism. Irradiation with visible light $(<460 \mathrm{~nm})$ induces a reverse photochemical reaction and leads to ring opening of the DTE. Upon ring opening the intensity of the UCNP green emission reinstates. This photomodulation could be carried out for several photochemical cycles using alternating UV and visible irradiation with minimal changes in the switchability (Figure 30).

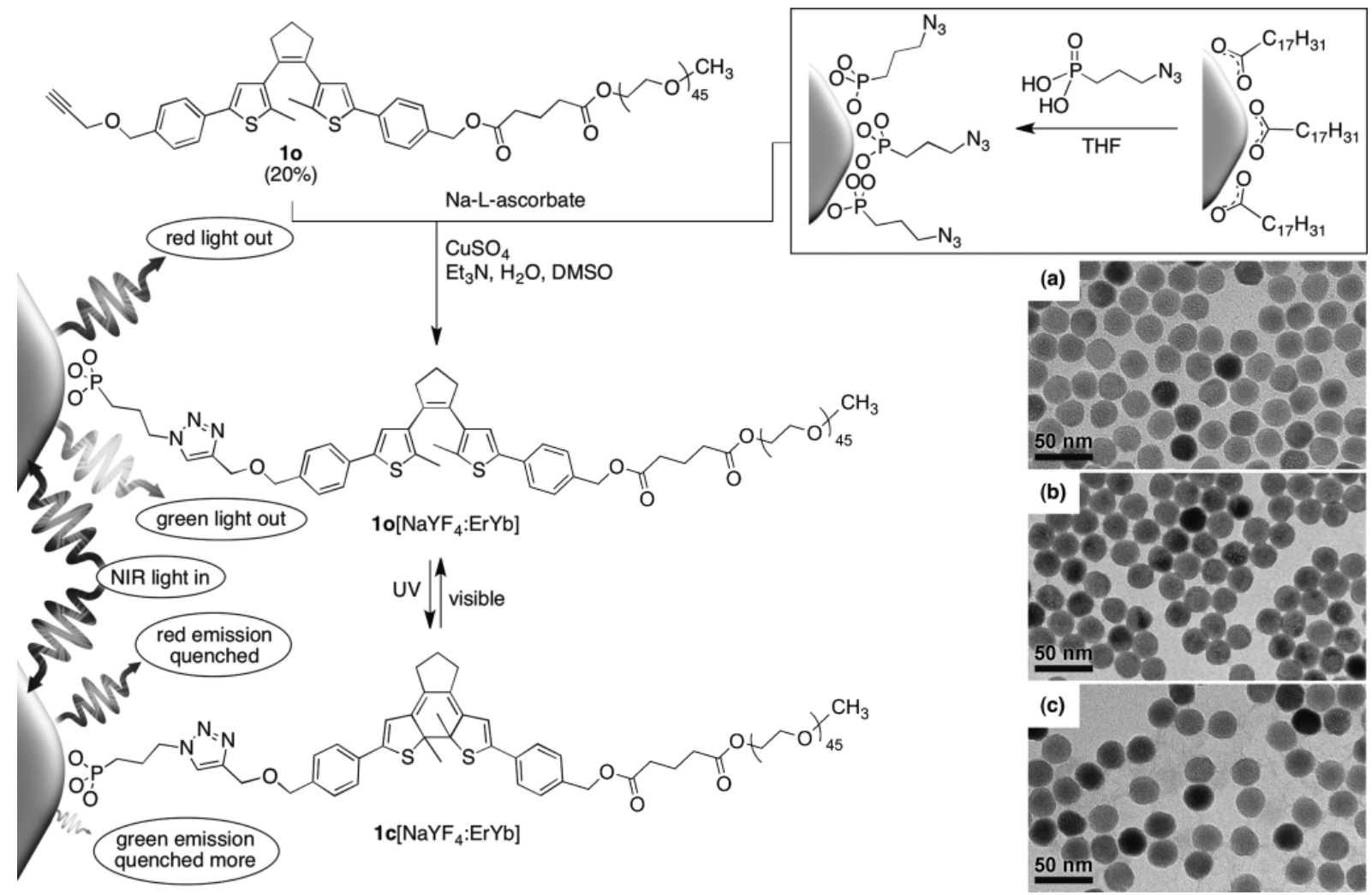

Figure 30. Synthesis of the photoresponsive hybrid system $\left(\mathbf{1 o}\left[\mathrm{NaYF}_{4}: \mathrm{ErYb}\right]\right)$ and a conceptual description of selective quenching of the emission from the nanoparticles by ring-closing the photoswitch. The images are TEM micrographs that show a) the oleate-coated nanoparticle starting material, b) the azide-coated nanoparticles, and c) the nanoparticles decorated with the ring-open form of the photoswitch $\left(\mathbf{1 o}\left[\mathrm{NaYF}_{4}: \mathrm{ErYb}\right]\right)$; this illustrates the uniform size and shape. [Reprinted with permission from Ref. 144 Copyright: John Wiley and Sons] 
The UCNP-DTE conjugate was successfully tested in nematodes as well. Moreover, no toxicity or sensitivity towards the constructs could be observed. Such photomodulated UCNPs have the advantage over caged fluorophores as their luminescence can be repeatedly cycled between the two states. Thus, these constructs are promising tools in super-resolution microscopy applications.

An elegant and smart approach for the functionalization of UCNPs was introduced by Haupt and Bui.[145] They took advantage of the nanolamp properties of UCNPs. In their respective work they used diversely functionalized (epoxyde, alkyne, benzamidine or carboxylic acid) acrylic acid derivatives as photopolymerizable monomers. Their method relied on the light emitted by the particles upon NIR excitation. In the presence of a photosensitizer the produced visible light induced photopolymerization of the monomeric species. Since the emission of the particles is weak the polymerization is confined to the close proximity of the particles resulting in the formation of a fine shell around the particles.

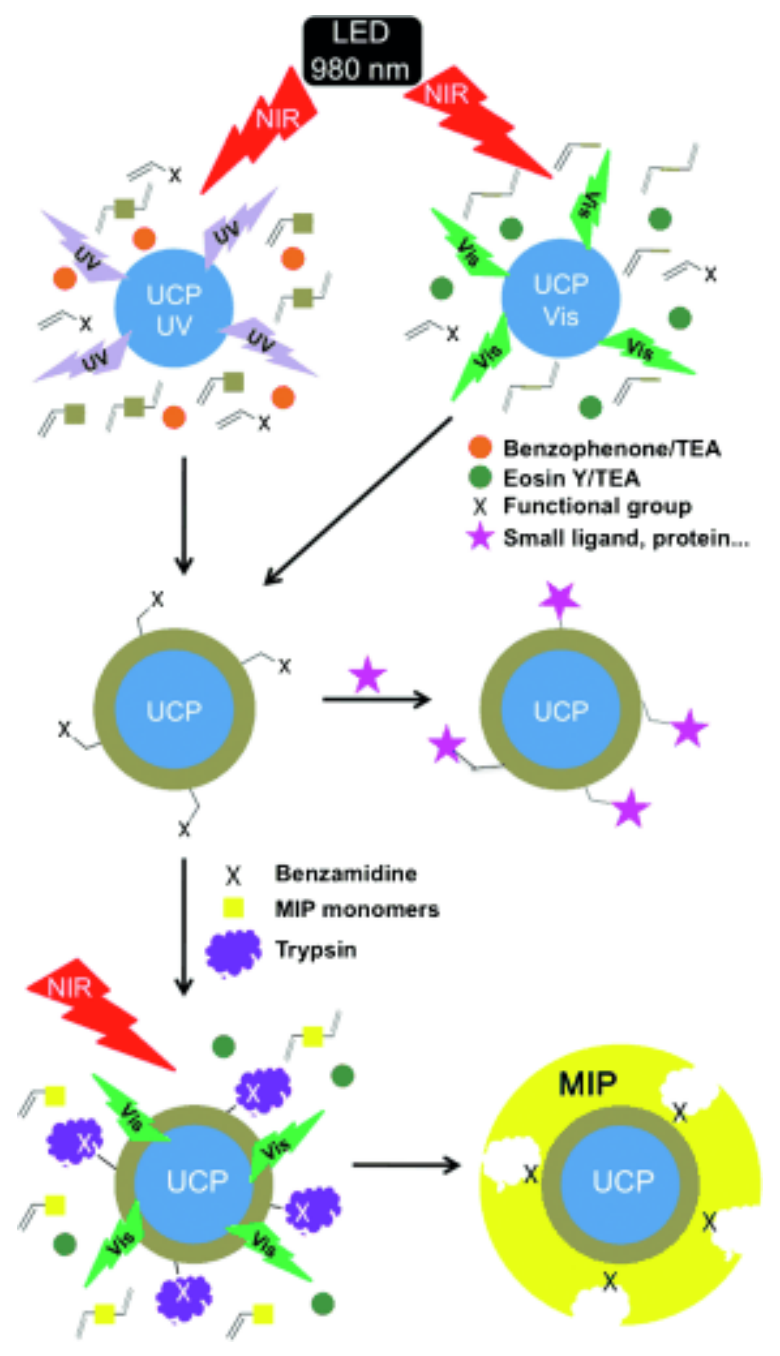

Figure 31. UV or visible light emitted from upconverting nanoparticles excited in the nearinfrared region $(980 \mathrm{~nm})$ is used to create a polymeric shell in situ around the particles by photopolymerization. Benzophenone and eosin Y are used as UV and visible initiators, respectively. The incorporation of functional monomers enables the subsequent attachment of small ligands, proteins, or other moieties. A second shell, for example, a molecularly imprinted polymer (MIP), can be synthesized by re-initiation in the presence of different monomers and a molecular template (trypsin). LED=light-emitting diode. [Reprinted with permission from Ref. 145 Copyright: John Wiley and Sons] 
The authors used two different UCNPs, a visible light emitter $\mathrm{NaYF}_{4}: \mathrm{Yb}, \mathrm{Er}$ (UCNP-Vis) and a UV emitter $\mathrm{Na}_{0.6} \mathrm{~K}_{0.4} \mathrm{YF}_{4}: \mathrm{Yb}, \mathrm{Tm}$ (UCNP-UV). They have tested the two UCNPs in the presence of different sensitizers and found that UCNP-Vis/eosine and UCNP-UV/benzophenone systems are ideal for shell formation processes (Figure 31). The shell thickness was dependent on the time allowed for polymerization, the concentration of monomers and sensitizers. Further modification of the core-shell particles was achieved using the functions incorporated through the polymerization process. For example, FITC-N $\mathrm{N}_{3}$ was used to fluorescently label the alkyne coated particles via $\mathrm{CuAAC}$. The platform can also serve as a basis of a second shell e.g. in the construction of molecularly imprinted polymers.

\subsubsection{Carbon allotropes, fluorescent nanodiamonds, FNDs}

Several nanosized carbon allotrope particle exist, however, herein we restrict our attention to a recently emerged allotrope, namely fluorescent nanodiamonds (FNDs) for their excellent luminescent properties and promising future applications.

Fluorescent nanodiamonds are luminescent, biocompatible nanoparticles between five and several hundred nanometers.[146,147] Their visible excitation results in a NIR emission band centered at around $700 \mathrm{~nm}$. Their emission that originates from nitrogen-vacancy centers is completely resistant to photobleaching or blinking, which allows their use in techniques (e.g. SRM) where large laser power is required. To enhance their dispersbility in water and to reduce their non-specific binding to proteins or to install further surface modification abilities, surface of FNDs needs to be modified as in the case of many other nanoparticulate systems. Cigler and co-workers reported on the development of a "translucent" shell around FNPs that leaves the photophysical characteristics of the nanodiamonds unaffected.[148,149] They utilized a modified Stöber method to form a thin silica shell using TEOS and 3-(trimetoxysilyl)propyl methacrylate. The terminal methacrylates served as a polymerizable platform that afforded "grafting from" coating for further functionalization. In their study they used poly[N-(2hydroxypropyl)methacrylamide] (poly(HPMA)) with a small amount of propargylacrylamide or 3-(azidopropyl)methacrylamide to afford a hydrophilic biocompatible coated FNDs ready for click conjugation that was resistant to protein adsorption. With this method they formed a 2-5 nm thick shell around the nanoparticles. The alkyne modified FNDs were further modified with several azide-derivatized compounds e.g. fluorogenic coumaryl-azide (Figure 10, 1) or a radiolabeled GGGRGDSGGGY-azide (RGD-azide) a vectoring molecule for tumor cell targeting. In a following work the same group has used a modified version of this robust method to construct a luminescent platform to image human prostate cancer cells. In this latter 
contribution the FNDs (ND1) were first coated with a thin silica shell using TEOS (ND2). This step was followed by shell growth using (3-aminopropyl)triethoxysilane (APTES) that enables further modification and crosslinking-agent bis(triethoxysilyl)ethane to improve the shell's resistance to hydrolysis (ND3). The amino-functionalized nanodiamonds were then modified with heterobifunctional PEG bearing N-hydroxysuccinimidyl and alkyne moieties (ND4). Finally, RGD-azide was installed via CuAAC chemistry to afford RGD bearing FNDs (ND5). In contrast to naked FNDs, coated nanodiamonds were found to be stable in in vitro tissue culture proteins.[147]

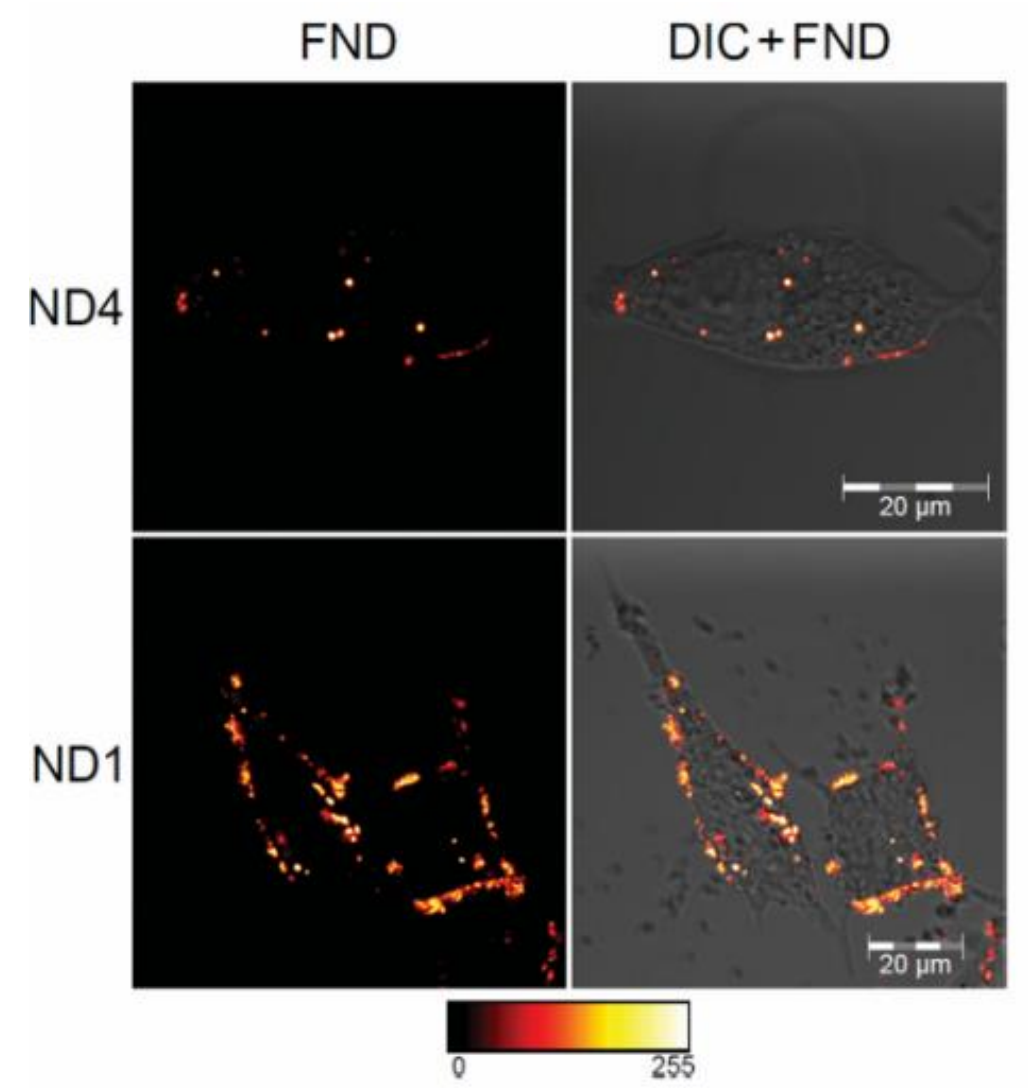

Figure 32. Confocal microscopy images of PEGylated aminosilica- coated (ND4) and noncoated (ND1) particles preincubated in PBS and internalized by LNCaP cells. The displayed images are fluorescence from NDs (FND) in false colors (left) and merged differential interference contrast (DIC) and FND fluorescence (right). FNDs were dispersed in PBS before adding to cells in medium (final concentration $200 \mu \mathrm{g} \mathrm{ml}^{-1}$ ). Cell were washed by PBS after one hour incubation, incubated for subsequent 23 hours and observed after fixation. Fluorescence of FND was collected by Zeiss LSM 780 at $639-758 \mathrm{~nm}$ upon excitation at $532 \mathrm{~nm}$. [Reprinted with permission from Ref. 148 Copyright: John Wiley and Sons]

The authors examined the differences between naked (ND1) and coated (ND4) nanoparticles in interaction with human prostate cancer cells. The particles were internalized without nonspecific cell-membrane adhesion. The naked FNDs however, showed much greater nonspecific affinity for cell surfaces, and aggregated inside cells (Figure 32). At the same time the 
colloidal behavior of ND4 particles was not affected providing evidence that such FNDconstructs are versatile platforms for imaging studies.

\subsubsection{Doped SiNPs}

Silica is a biocompatible and versatile material that can be readily modified with diverse chemical functions, including bioorthogonal moieties. As seen above, silica shell is often formed around inorganic NPs as a biocompatible shell. The size of silica nanoparticles that are most often formed using the Stöber method ranges between tens and hundred nanometers. SiNPs has the unique feature that they can be doped with a wide range of materials.[150] For example, SiNPs can host $10^{4}$ fluorescent organic dye molecules within 50-75 nm particles. Besides, the silica matrix enhances the photostability and the brightness of dopant organic dyes. Even a defined composition of different dyes can be doped at different concentrations so that can be fabricated to construct color-"barcoded" labels.

A method, suitable for the multiple functionalization of SiNPs was introduced by the Lin group.[151] Their silica platform was suited to incorporate fluorescent dyes, targeting moieties to recognize certain cancer cell-lines, and an anti-cancer drug. They have started their synthesis by forming $40 \mathrm{~nm}$ plain silica nanoparticles (HO@SiO $2 \mathbf{N P}$ ) by means of conventional Stöber method. Next a fluorescent shell was formed around these particles using APTES and Cy3-silane in a 100 to 1 ratio to afford amino-functionalized Cy3-doped NPs $\left(\mathbf{N H}_{2} @ \mathbf{C y 3 S i O} \mathbf{O}_{2} \mathbf{N P}\right)$. Next an amino-appending di-akyne, built on a lysine framework was incorporated using conventional activated ester coupling (di-alkyne@ $\mathbf{C y 3 S i O}_{2} \mathbf{N P}$ ). The dialkyne moiety included a cyclooctyne and a terminal alkyne function that allows orthogonal stepwise modification by means of sequential SPAAC and CuAAC chemistries, a concept introduced by Wolbeis and Kele.[152,153] The di-alkynylated NPs were then allowed to react with antitumor drug Paclitaxel-azide (PTX) using SPAAC, then with targeting ligand triantennary galactose-azide (TGal) in a CuAAC reaction to afford (TGal-PTX@ $\mathbf{C y 3 S i O} 2 \mathbf{N P}$ ). 


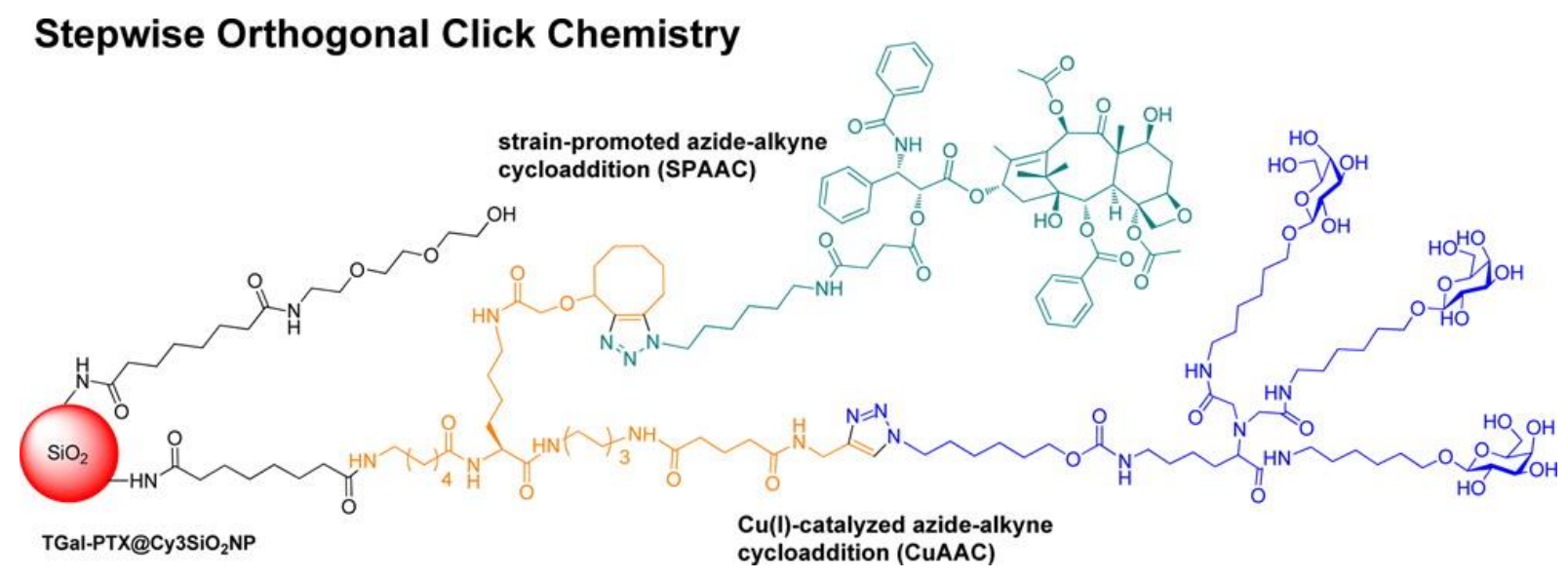

Figure 33. Schematic representation of trifunctionalized SiNPs. [Reprinted with permission from Ref. 151 Copyright (2013) American Chemical Society]

The resulting particles were efficiently functionalized suggesting that the applied bioorthogonal reactions are robust. The size of the particles were determined to be ca. $50 \mathrm{~nm}$, ideal for NPmediated cellular internalization. To evaluate the anticancer activity of the NPs HepG2 cells were treated with TGal-PTX@Cy3SiO 2 NP, TGal@ $\mathbf{C y 3 S i O}_{2} \mathbf{N P}$ and free PTX. The tubulin network of cells was visualized using DyLight 649-IgG to give purple color. The red color originates from the Cy3 dopants. LysoTracker Green DNS-26 was used to stain late endosomes and lysosomes green, while DAPI was used to label the nuclei (blue). Confocal microscopy images showed that PTX (Figure 34, 1b) and TGal-PTX@Cy3SiO 2 NP (Figure 34, 1c) cells have similar tubulin pattern indicating the microtubule inhibition effects of PTX. By contrast, TGal@Cy3SiO 2 NP treated cells showed the same uptake of NPs without the effects of PTX (Figure 34, 1d). The yellow color on the merged images (Figure 34, 5c and 5d) originates from co-localization of red and green fluorescence indicating that the NPs accumulate in late endosomes and lysosomes after endocytosis. Further, cell-proliferation studies revealed that the cytotoxicity of TGal@ $\mathbf{C y 3 S i O}_{2} \mathbf{N P s}$ is dose dependent. The authors anticipate that the presented di-alkyne platform provides a versatile modification method for future targeted drug delivery applications using nanoparticulate systems. 


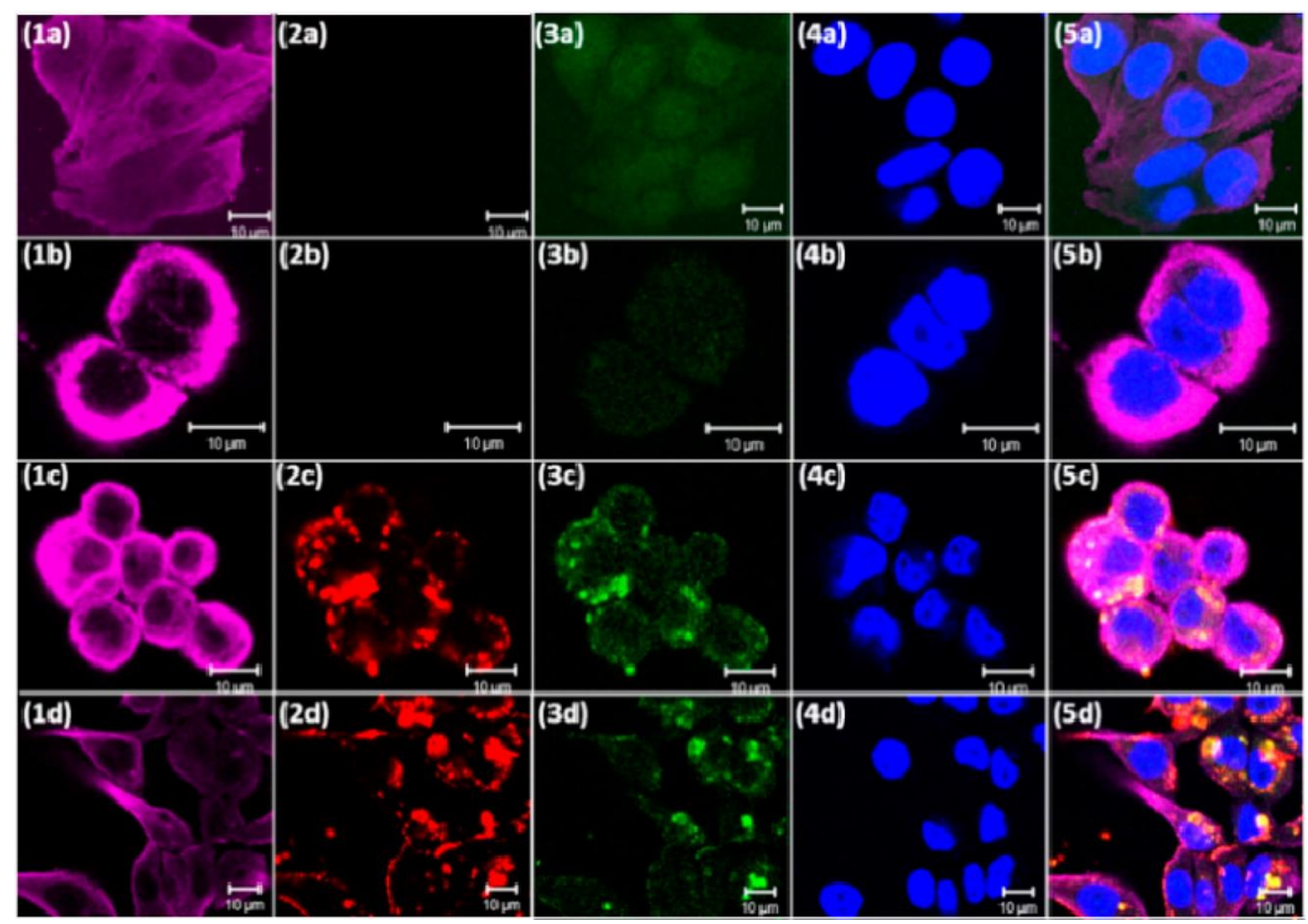

Figure 34. Confocal images of HepG2 cells treated with PTX (5.3 $\mu \mathrm{M}$ in $0.5 \mathrm{~mL}$ serum-free DMEM), TGal-PTX@Cy3SiO $2 \mathbf{N P}\left(100 \mu \mathrm{g} / \mathrm{mL}\right.$ in $0.5 \mathrm{~mL}$ serum-free DMEM), or TGal@Cy3SiO $\mathbf{S}_{2} \mathbf{N P}(100$ $\mu \mathrm{g} / \mathrm{mL}$ in $0.5 \mathrm{~mL}$ serum-free DMEM) for 2 days. Each horizontal row of images (a-d) represents: (a) control without added reagents as control, (b) PTX with 3.3\% DMSO as a positive control, (c) TGalPTX@ $\mathbf{C y}_{3} \mathrm{SiO}_{2} \mathbf{N P}$, and (d) TGal $@ \mathbf{C y}_{3} \mathbf{S i O}_{2} \mathbf{N P}$ as a negative control. The vertically arranged images (1-5) show: (1) purple color representing tubulin distribution; (2) red fluorescence arising from Cy3 dye on silicon oxide NP; (3) green fluorescence associated with LysoTracker Green DND-26 found within the endosomes and/or lysosomes; (4) cell nuclei stained with DAPI, which fluoresces blue; and (5) a merge of the images. The yellow fluorescence indicates that TGal-PTX@ $\mathbf{C y 3 S i O} \mathbf{S}_{2} \mathbf{N P}$ and TGal@ $\mathbf{C y 3 S i O}_{2} \mathbf{N P}$ colocalized with LysoTracker Green DND-26 in late endosomes and/or lysosomes. Scale bar: $10 \mu \mathrm{m}$. [Reprinted with permission from Ref. 151 Copyright (2013) American Chemical Society]

\subsubsection{Magnetofluorescent nanoparticles, MFNPs}

Weissleder and co-workers introduced a concept termed BOND for "bioorthogonal nanoparticle detection".[154,155] In their study they used magnetofluorescent nanoparticles (MFNPs) as markers allowing dual-channel detection. They started from an amine modified cross-linked iron-oxide (CLIO) magnetic core that was modified with amine reactive cyanine dye (VT680). 
BOND (bioorthogonal nanoparticle detection)

Magneto-fluorescent nanoparticle (MFNP)
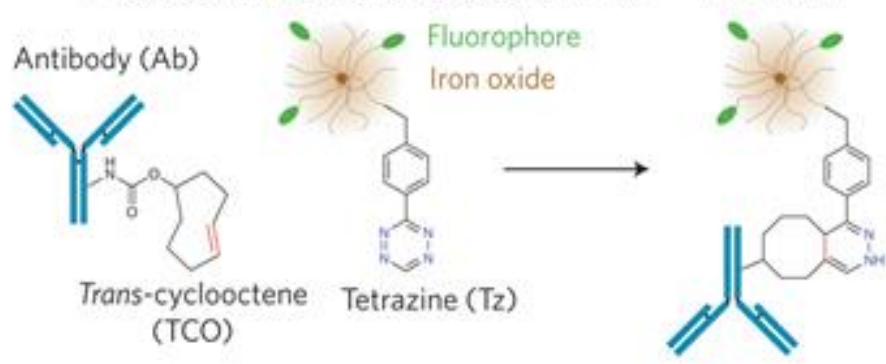

\section{One-step BOND (BOND-1)}
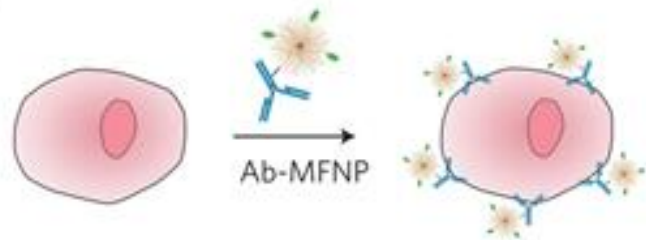

Two-step BOND (BOND-2)
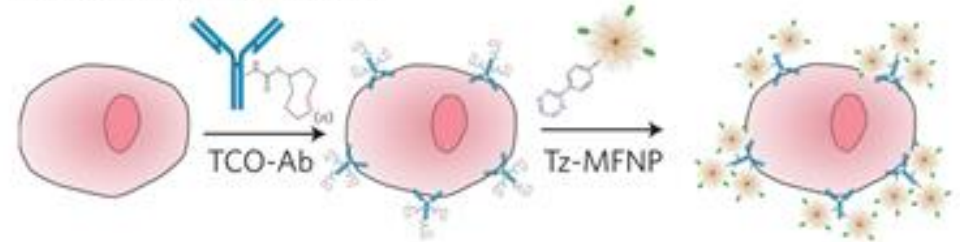

Figure 35. Top: Schematic showing the conjugation chemistry between antibody and nanoparticle. The diagram is a schematic and not to scale. Bottom: Application of BOND for one-step (direct) and twostep targeting of nanoparticles to cells. Note that the antibody and tetrazine are present in multiple copies per nanoparticle ( 2-3 antibodies, Ab; 84 tetrazine, Tz). [Reprinted partly from Ref. 154 by permission from Macmillan Publishers Ltd: Nature Nanotechnology, copyright (2010)]

These NP contained approximately 4.7 dye molecules per MFNP and $\sim 84$ available primary amine sites. The remaining amines were allowed to react with amine reactive tetrazine (TZNHS). Since no primary amine could be detected after the reaction the Tz valency was assumed to be 84 per particle. Parallel to this monoclonal antibody trastuzumab, which is used to clinically treat breast cancers expressing HER2, was modified with trans-cyclooctenes (TCOs) via amide bond formation through the lysine moieties of the antibody. Two methods were tested for targeting extracellular receptors on cancer cells. In one setting the MFNPs were directly modified with the TCO bearing antibodies via inverse electron demand Diels-Alder chemistry (BOND-1). In another setting they used a sequential approach where the cells were first treated with TCO-Abs then with Tz-MFNPs (BOND-2). The authors have explored the performance of BOND-1 and BOND-2 techniques and found that the nanoparticle binding to cells efficiency of BOND-2 was consistently higher by a factor of 10-15 due to binding amplification. This amplification was found to be similar to other two-step schemes, however, the small size of the 
bioorthogonal reagents allows for significantly degree of covalent tagging. Using this specific rapid and modular scheme, the same authors accounted on the staining of intracellular biomarkers. Using optimized fixation and permeabilization, the cells were treated with TCO modified anti-cytokeratin (CK) and anti-nuclear protein $\left(\mathrm{K}_{\mathrm{i}}-67\right)$ antibodies (Figure 36).[156] Subsequent treatment with Tz-MFNPs resulted in specific labelling of the respective proteins. Similarly to previous observations the two-step tagging scheme resulted in amplified signals in contrast to tagging with a directly labeled anti-CK-MFNP conjugate, which may be explained by the much smaller size of TZ-MFNPs ( $29 \mathrm{~nm})$ relative to immune-conjugates $(\sim 42 \mathrm{~nm})$.
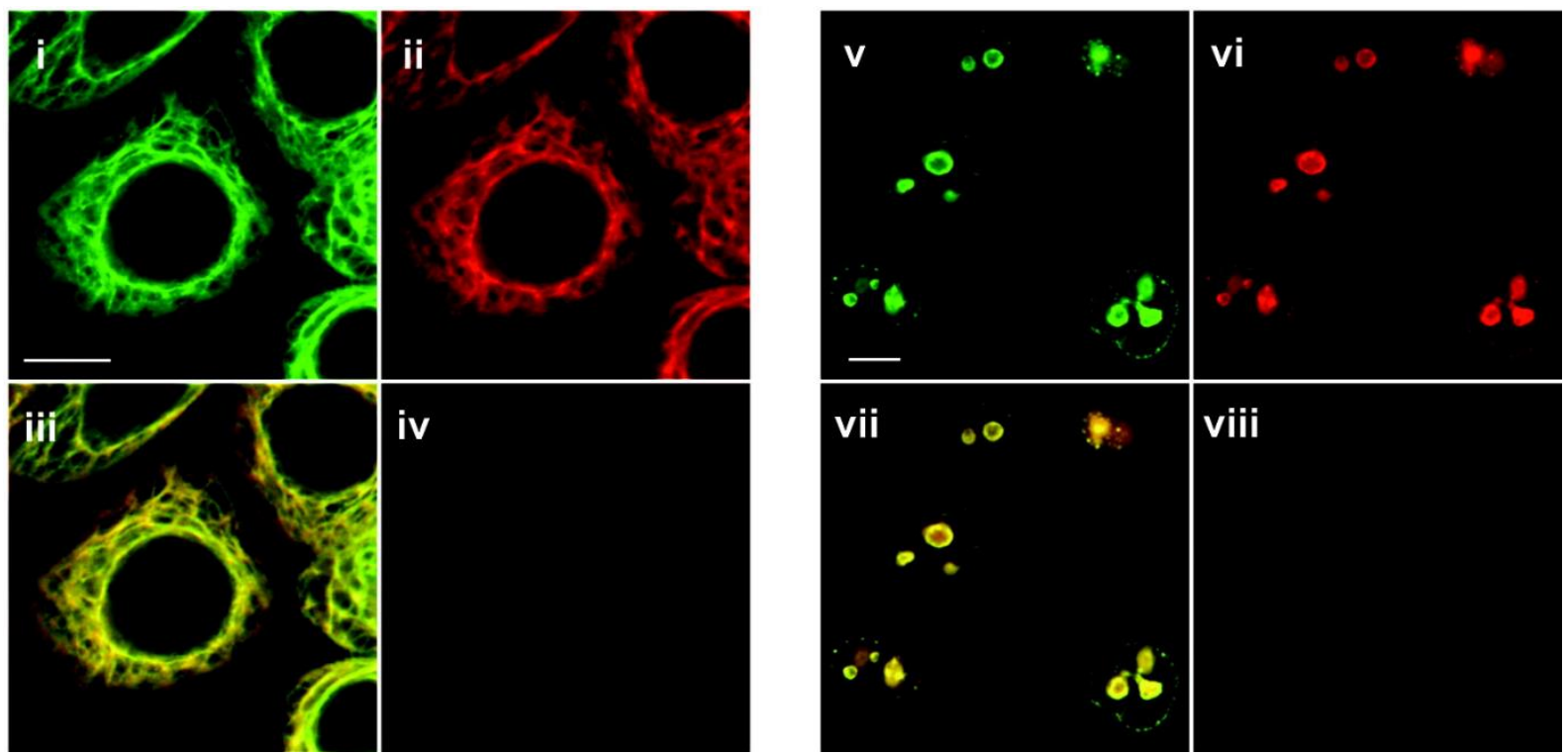

Figure 36. Confocal microscopy images of SK-BR-3 (i-iv) and PANC-1 (v-viii) cells targeted for CK and $K_{\mathrm{i}}-67$, respectively. In both cases, antibodies were labeled with both TCO (3-4 per antibody) and AlexaFluor-488 fluorescent dye. Following MFNP labeling, images were captured at 488 (antibody, pseudocolored green, i and v) and 680 (MFNP, pseudocolored red, ii and vi) nm emission. Merged images reveal excellent correlation between the two signals (iii and vii). Controls determined using a nonbinding, TCO-modified control antibody were negative (iv and viii). The scale bars in (i) and (v) represent $10 \mu \mathrm{m}$. [Reprinted with permission from Ref. 156 Copyright (2011) American Chemical Society]

Moreover, the dual-channel detection features enabled magnetic resonance imaging of MFNP tagged proteins. Since biological samples exhibit minimal intrinsic magnetic background magnetic detection is possible even in optically obscure samples.

\subsubsection{Semiconducting polymer dots (PDots)}

PDots are a new class of ultrabright and non-toxic luminescent nanoprobes that consist of $p$ conjugated semiconducting polymeric materials.[157,158,159] They are able to exhibit strong fluorescence, which can be described in terms of semiconductor band theory. For biological 
applications, the surface chemistry of the Pdots need to be addressed. Unlike its inorganic counterpart, QDs, the luminescence of PDots is not affected by the presence of metal ions, thus their use in $\mathrm{CuAAC}$ conjugation schemes is obvious. Chiu et al. presented a versatile approach, where semiconducting, highly fluorescent poly[(9,9-dioctylfluorenyl-2,7-diyl)-co-(1,4-benzo$\{2,1$, 3$\}$-thiadiazole)] (PFBT) polymer was functionalized with poly(styrene-co-maleic anhydride) (PSMA).[160] Coprecipitation of PFBT and a small amount of PSMA resulted in PDots bear carboxylic groups on their surface, which presents an easily modifiable platform for further conjugations. The PDots were modified using amino functionalized ethylene glycol azide or alkyne to afford clickable PDots in the $15 \mathrm{~nm}$ size range. These clickable luminescent PDots were used to image newly synthesized proteins in MCF-7 cells. The cells were metabolically labeled with ManNAz to render surface glycans clickable. Azide-bearing cellsurface gylcans were then successfully labeled with alkyne-PDots using CuAAC chemistry (Figure 37).

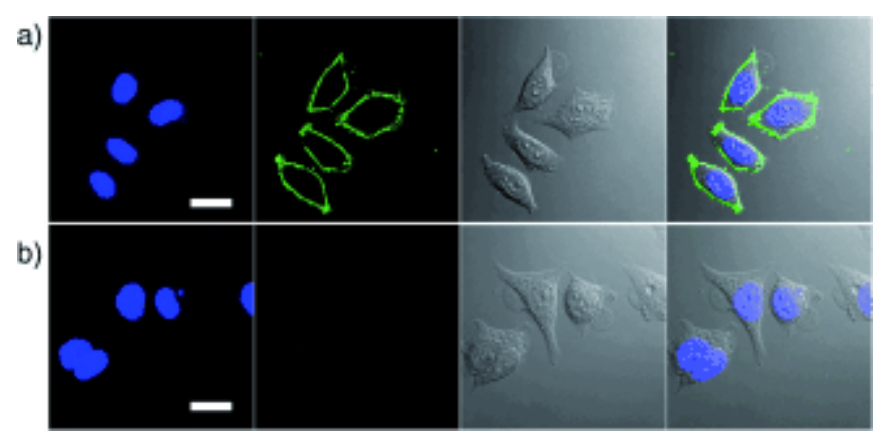

Figure 37. Fluorescence imaging of glycoproteins in GalNAz-treated MCF-7 cells tagged with Pdotalkyne probes. a) Positive Pdot labeling in the presence of copper(I). b) Negative control for Pdot labeling carried out under identical conditions as in (a) but in the absence of copper(I). The left four panels show fluorescence images; green fluorescence is from Pdots and blue fluorescence is from the nuclear stain Hoechst 34580. The right four panels show Nomarski (DIC) and combined DIC and fluorescence images. Scale bars: $20 \mu \mathrm{m}$. [Reprinted with permission from Ref. 160 Copyright: John Wiley and Sons]

\subsubsection{Liposomes}

Amongst the various methods for the targeted delivery of drugs, liposomes are particularly advantageous.[132,161,162] Besides their enhanced permeability and retention (EPR) effects, coating the surface of liposomes with targeting moieties such as antibodies, proteins, polysaccharides etc. can further increase liposome-based drug accumulation in certain celllines.[163] Bioorthogonal chemical approaches are ideal to ensure the correct orientation of such targeting elements. In their account Kim and co-workers has modified PEGylated nanosized liposomes to image azidosialic acid modified cancer cells in vivo.[164] 1,2distearoyl-sn-glycero-3-phosphoethanolamine-N-[amino(polyethylene glycol)2000] (DSPE- 
PEG- $\mathrm{NH}_{2}$ ) was modified with a dibenzocyclooctyne (DBCO) through amide bond formation (DBCO-PEG-DSPE). Parallelly, 1,2-dipalmitoyl-sn-glycero-3-phosphoethanolamine (DPPE) was modified with Cy5 by similar means. DBCO-liposomes (DBCO-lipo) were synthesized by mixing DPPC : cholesterol : DBCO-PEG-DSPE : Cy5-DPPE in a 54.5: 35: 10: 0.5 molar ratio. The resulting fluorescent nanoparticles were $\sim 75 \mathrm{~nm}$ sized, ready for further conjugation via SPAAC chemistry. Xenograft mice models bearing two tumors (A549 tumor) in both sides of the flank region were intratumorally injected with ManNAz at one side. The resulting xenograft models had tumor cells expressing azido-sialates in their surface glycans at one side and normal sialates on the untreated side. Once the tumors reached $10 \mathrm{~nm}$ diameter they were given DBCOlipo intravenously. Non-invasive near infra-red imaging of mice showed specific labeling of the azide expressing tumors. In contrast, mice treated with liposomes lacking the cyclooctynes (PEG-lipo) showed no difference in fluorescence intensity in the tumors with or without azidosialate (Figure 38). In combination with other orthogonal chemistries installation of other elements (targeting, drug, etc.) is also possible.

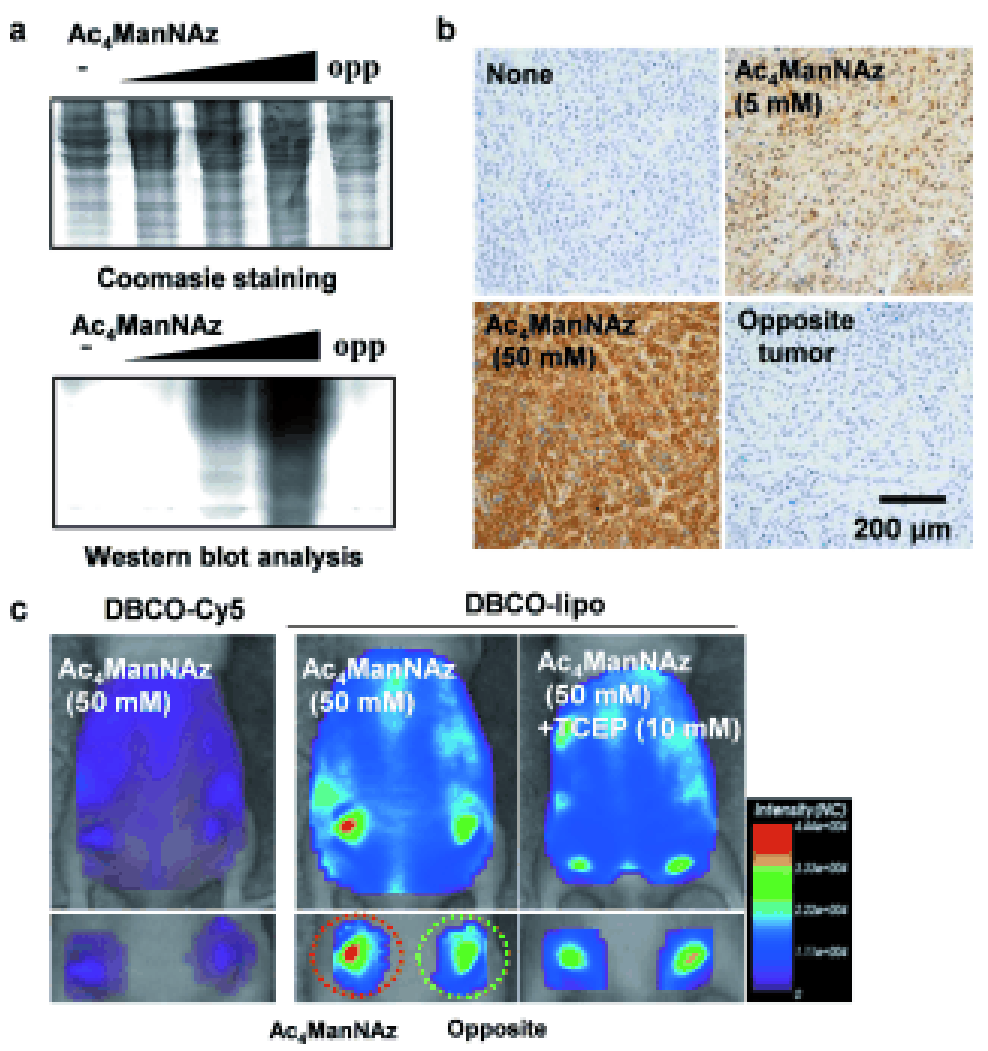

Figure 38. In vivo tumor-targeting of DBCO-lipo in tumor-bearing mice models. a) Coomassie staining and western blot analysis of $\mathrm{Ac}_{4} \mathrm{ManNAz}$-treated tumor tissues; opp=opposite (control) tumor. b) Histological staining of Ac 4 ManNAz-treated tumor tissues using phosphine-FLAG and FLAG-HRP. c) Whole body biodistribution of DBCO-lipo in $\mathrm{Ac}_{4}$ ManNAz-treated tumor-bearing mice. (left: $\mathrm{Ac}_{4} \mathrm{ManNAz-treated,} \mathrm{right:} \mathrm{saline-treated).} \mathrm{[Reprinted} \mathrm{with} \mathrm{permission} \mathrm{from} \mathrm{Ref.} 164$ Copyright: John Wiley and Sons] 


\section{Summary and outlook}

Fluorescent imaging techniques progressed considerably, lately. In the past years we could witness breakage of conceptual and experimental limits in optical microscopy, efforts that were acknowledged by Nobel-prizes in 2008 and 2014. These developments brought us much closer to the understanding of molecular processes inside live organisms. These hardware developments, however, could not have been fully harvested without developments in conjugation techniques. The need for selective installation of signaling units i.e. fluorophores onto biologically relevant targets triggered the exploration of new ways that could be employed even in in vivo labeling schemes. Not a surprise then that the last decade has brought considerable progress in the field of covalent conjugation techniques and led to the development of bioorthogonal chemistry.

In vivo fluorescent labeling schemes has probably benefited the most from developments in bioorthogonal ligation reactions. These biocompatible and selective chemical transformations in combination with advanced molecular biology techniques e.g. genetic encoding of non-canonical amino acids allow selective and site-specific fluorescent modulation and subsequent tracking of biologically relevant species. In this review we attempted to give an overview of the state-of-the-art of bioorthogonally applicable fluorescent labels of various kind. These bioorthogonalized fluorescent or fluorogenic small organics or luminescent nanoparticles can be applied to tag selected biological targets harboring the appropriate - complementary chemical reporter. Although the fluorescent labels listed here are suitable to fulfill the given specific needs, there are many aspects that still could be improved. For example, being orthogonal reactions SPAAC and CuAAC chemistries or certain SPAAC and SPIEDAC reactions allow dual labeling schemes, multicolor imaging schemes require more diverse tagging. For this more development of more orthogonal reactions are required.

Although the existing bioorthogonal reactions would allow selective labeling of intracellular structures most bioorthogonal tagging schemes are employed in the tagging of exctracellular targets such as receptors or glycans. For intracellular, specific in vivo tagging schemes non-toxic, membrane-permeable, bioorthogonally applicable labels are needed. Furthermore, super-resolution techniques require such probes also to be bright and photostable with minimal background signal. As a consequence, a special attention should be devoted to the development of small, membrane-permeable reagents with bright fluorogenic properties that allow biomolecule- and site-specific labeling of selected structures.

Another promising field in bioorthogonal fluorescent probes is the development of nanoparticulate systems that allow multimodal imaging (e.g. NIR, PET, MRI etc.) that could 
also serve as platforms for targeting elements and cargos for drugs at the same time. Design elements of such multi-functionalized nanoparticles also involves the use of multiple orthogonal chemistries for the installation of different modules.

Briefly concluding, existing and newly developed bioorthogonal fluorescent probes can bring us closer to a more comprehensive understanding of living matter. Seeing the whole picture more clearly can help us understand the essence of biomolecular processes and design more efficient drugs e.g. for the treatment of specific tumors.

\section{Acknowledgements}

This work was supported by grants from the Hungarian Academy of Sciences (Lendület, LP2013-55/2013) and the Hungarian Scientific Research Fund (NN-110214). The authors wish to thank Mr. Ádám Eördög for the design of the graphical contents. Competing interests: The authors have declared that no competing interests exist.

\section{References}

[1] Saxon E, Bertozzi C. R. 2000 Cell Surface Engineering by a Modified Staudinger Reaction Science 287 2007-10

[2] Sletten E M and Bertozzi C R 2009 Bioorthogonal chemistry: fishing for selectivity in a sea of functionality Angew. Chem. Int. Ed. Engl. 48 6974-98

[3] Patterson D M, Nazarova L A and Prescher J A 2014 Finding the right (bioorthogonal) chemistry ACS Chem. Biol. 9 592-605

[4] Sletten E M and Bertozzi C R 2011 From mechanism to mouse: a tale of two bioorthogonal reactions Acc. Chem. Res. 44 666-76

[5] Jewett J C and Bertozzi C R $2010 \mathrm{Cu}$-free click cycloaddition reactions in chemical biology Chem. Soc. Rev. 39 1272-9

[6] Chang P V, Prescher J A, Sletten E M, Baskin J M, Miller I A, Agard N J, Lo A and Bertozzi C R 2010 Copper-free click chemistry in living animals Proc. Natl. Acad. Sci. U.S.A. 107 1821-6

[7] Ramil C P and Lin Q 2013 Bioorthogonal chemistry: strategies and recent developments Chem. Commun. 49 11007-22

[8] Tinnefeld P, Eggeling C and Hell S W 2015 Far-Field Optical Nanoscopy (Berlin: Springer)

[9] Schilling C I, Jung N, Biskup M, Schepers U and Bräse S 2011 Bioconjugation via azide-Staudinger ligation: an overview Chem. Soc. Rev. 40 4840-71

[10] van Berkel S S, van Eldijk M B and van Hest J C M 2011 Staudinger ligation as a method for bioconjugation Angew. Chem. Int. Ed. Engl. 50 8806-27

[11] Lin F L, Hoyt H M, van Halbeek H, Bergman R G and Bertozzi C R 2005 Mechanistic Investigation of the Staudinger Ligation J. Am. Chem. Soc. 127 2686-95

[12] Yu Z, Ohulchanskyy T Y, An P, Prasad P N and Lin Q 2013 Fluorogenic, two-photontriggered photoclick chemistry in live mammalian cells J. Am. Chem. Soc. 135 16766-9 
[13] An P, Yu Z and Lin Q 2013 Design and synthesis of laser-activatable tetrazoles for a fast and fluorogenic red-emitting 1,3-dipolar cycloaddition reaction Org. Lett. 15 54969

[14] Song W, Wang Y, Qu J, Madden M M and Lin Q 2008 A photoinducible 1,3-dipolar cycloaddition reaction for rapid, selective modification of tetrazole-containing proteins Angew. Chem. Int. Ed. 47 2832-5

[15] Ramil C P and Lin Q 2014 Photoclick chemistry: a fluorogenic light-triggered in vivo ligation reaction Curr. Opin. Chem. Biol. 21 89-95

[16] Yu Z, Ho L Y, Wang Z and Lin Q 2011 Discovery of new photoactivatable diaryltetrazoles for photoclick chemistry via "scaffold hopping" Bioorg. Med. Chem. Lett. 21 5033-6

[17] Debets M F, van der Doelen C W J, Rutjes F P J T and van Delft F L 2010 Azide: a unique dipole for metal-free bioorthogonal ligations ChemBioChem 11 1168-84

[18] Rostovtsev V V, Green L G, Fokin V V and Sharpless K B 2002 A stepwise Huisgen cycloaddition process: copper(I)-catalyzed regioselective "ligation" of azides and terminal alkynes Angew. Chem. Int. Ed. 41 2596-9

[19] Tornøe C W, Christensen C and Meldal M 2002 Peptidotriazoles on Solid Phase: [1,2,3]-Triazoles by Regiospecific Copper(I)-Catalyzed 1,3-Dipolar Cycloadditions of Terminal Alkynes to Azides J. Org. Chem. 67 3057-64

[20] Rodionov V O, Presolski S I, Díaz D D, Fokin V V and Finn M G 2007 LigandAccelerated Cu-Catalyzed Azide-Alkyne Cycloaddition: A Mechanistic Report J. Am. Chem. Soc. 129 12705-12

[21] del Amo D S, Wang W, Jiang H, Besanceney C, Yan A C, Levy M, Liu Y, Marlow F L and Wu P 2010 Biocompatible Copper(I) Catalysts for in Vivo Imaging of Glycans $J$. Am. Chem. Soc. 132 16893-9

[22] Baskin J M, Prescher J A, Laughlin S T, Agard N J, Chang P V, Miller I A, Lo A, Codelli J A and Bertozzi C R 2007 Copper-free click chemistry for dynamic in vivo imaging Proc. Natl. Acad. Sci. U.S.A. 104 16793-7

[23] Debets M F, van Berkel S S, Dommerholt J, Dirks A J, Rutjes F P J T and van Delft F L 2011 Bioconjugation with Strained Alkenes and Alkynes Acc. Chem. Res. 44 805-15

[24] Jewett J C, Sletten E M and Bertozzi C R 2010 Rapid Cu-Free Click Chemistry with Readily Synthesized Biarylazacyclooctynones J. Am. Chem. Soc. 132 3688-90

[25] Ning X, Guo J, Wolfert M A and Boons G-J 2008 Visualizing Metabolically Labeled Glycoconjugates of Living Cells by Copper-Free and Fast Huisgen Cycloadditions Angew. Chem. Int. Ed. 120 2285-7

[26] Debets M F, van Berkel S S, Schoffelen S, Rutjes F P J T, van Hest J C M and van Delft F L 2010 Aza-dibenzocyclooctynes for fast and efficient enzyme PEGylation via copper-free (3+2) cycloaddition Chem. Commun. 46 97-99

[27] Dommerholt J, Schmidt S, Temming R, Hendriks L J A, Rutjes F P J T, van Hest J C M, Lefeber D J, Friedl P and van Delft F L 2010 Readily Accessible Bicyclononynes for Bioorthogonal Labeling and Three-Dimensional Imaging of Living Cells Angew. Chem. Int. Ed. Engl. 49 9422-25

[28] Varga B R, Kállay M, Hegyi K, Béni S and Kele P 2012 A non-fluorinated monobenzocyclooctyne for rapid copper-free click reactions Chem. Eur. J. 18 822-8

[29] Knall A-C and Slugovc C 2013 Inverse electron demand Diels-Alder (iEDDA)-initiated conjugation: a (high) potential click chemistry scheme. Chem. Soc. Rev. 42 5131-42

[30] Blackman M L, Royzen M and Fox J M 2008 Tetrazine Ligation: Fast Bioconjugation Based on Inverse-Electron-Demand Diels-Alder Reactivity J. Am. Chem. Soc. 130 13518-19 
[31] Devaraj N K, Weissleder R and Hilderbrand S A 2008 Tetrazine-Based Cycloadditions: Application to Pretargeted Live Cell Imaging Bioconjugate Chem. 19 2297-99

[32] Cserép G B, Demeter O, Bätzner E, Kállay M, Wagenknecht H-A and Kele P 2015 Synthesis and Evaluation of Nicotinic Acid Derived Tetrazines for Bioorthogonal Labeling Synthesis doi: 10.1055/s-0034-1380721

[33] Karver M R, Weissleder R and Hilderbrand S A 2012 Bioorthogonal Reaction Pairs Enable Simultaneous, Selective, Multi-Target Imaging Angew. Chem. Int. Ed. 51 92022

[34] Nikić I, Plass T, Schraidt O, Szymański J, Briggs J A G, Schultz C and Lemke E A 2014 Minimal tags for rapid dual-color live-cell labeling and super-resolution microscopy Angew. Chem. Int. Ed. Engl. 53 2245-9

[35] Beatty K E 2011 Chemical strategies for tagging and imaging the proteome Mol. BioSyst. 7 2360-67

[36] Yi L, Sun H, Wu Y-W, Triola G, Waldmann H and Goody R S 2010 A highly efficient strategy for modification of proteins at the $\mathrm{C}$ terminus Angew. Chem. Int. Ed. Engl. 49 9417-21

[37] Gilmore J M, Scheck R A, Esser-Kahn A P, Joshi N S and Francis M B 2006 N-terminal protein modification through a biomimetic transamination reaction Angew. Chem. Int. Ed. Engl. 45 5307-11

[38] Dixon H B F 1964 Transamination of peptides Biochem. J. 92 661-6

[39] Stephanopoulos N and Francis M B 2011 Choosing an effective protein bioconjugation strategy Nat. Chem. Biol. 7 876-84

[40] Morales-Sanfrutos J, Lopez-Jaramillo J, Ortega-Muñoz M, Megia-Fernandez A, PerezBalderas F, Hernandez-Mateo F and Santoyo-Gonzalez F 2010 Vinyl sulfone: a versatile function for simple bioconjugation and immobilization Org. Biomol. Chem. 8 667-75

[41] Cserép G B, Baranyai Zs, Komáromy D, Horváti K, Bősze Sz and Kele P 2014 Fluorogenic tagging of peptides via Cys residues using thiol-specific vinyl sulfone affinity tags Tetrahedron 70 5961-65

[42] Tilley S D and Francis M B 2006 Tyrosine-selective protein alkylation using piallylpalladium complexes J. Am. Chem. Soc. 128 1080-1

[43] Cserép G B, Herner A, Wolfbeis O S and Kele P 2013 Tyrosine specific sequential labeling of proteins Bioorg. Med. Chem. Lett. 23 5776-8

[44] Zhang G, Zheng S, Liu H and Chen P R 2015 Illuminating biological processes through site-specific protein labeling Chem. Soc. Rev. 44 3405-17

[45] Rashidian M, Kumarapperuma S C, Gabrielse K, Fegan A, Wagner C R and Distefano M D 2013 Simultaneous dual protein labeling using a triorthogonal reagent. J. Am. Chem. Soc. 135 16388-96

[46] Los G V, Encell L P, McDougall M G, Hartzell D D, Karassina N, Zimprich C, Wood M G, Learish R, Ohana R F, Urh M, Simpson D, Mendez J, Zimmerman K, Otto P, Vidugiris G, Zhu J, Darzins A, Klaubert D H, Bulleit R F and Wood K V 2008 HaloTag: a novel protein labeling technology for cell imaging and protein analysis. ACS Chem. Biol. 3 373-82

[47] Lang K and Chin J W 2014 Cellular incorporation of unnatural amino acids and bioorthogonal labeling of proteins Chem. Rev. 114 4764-806

[48] Grammel M and Hang H C 2013 Chemical reporters for biological discovery Nat. Chem. Biol. 9 475-84

[49] Ngo J T and Tirrell D A 2011 Noncanonical amino acids in the interrogation of cellular protein synthesis Acc. Chem. Res. 44 677-85 
[50] Laughlin S T, Baskin J M, Amacher S L and Bertozzi C R 2008 In vivo imaging of membrane-associated glycans in developing zebrafish Science 320 664-7

[51] Hang H C, Wilson J P and Charron G 2011 Bioorthogonal chemical reporters for analyzing protein lipidation and lipid trafficking Acc. Chem. Res. 44 699-708

[52] Kostiuk M A, Corvi M M, Keller B O, Plummer G, Prescher J A, Hangauer M J, Bertozzi C R, Rajaiah G, Falck J R and Berthiaume L G 2008 Identification of palmitoylated mitochondrial proteins using a bio-orthogonal azido-palmitate analogue FASEB J. 22 721-32

[53] Dean K M and Palmer A E 2014 Advances in fluorescence labeling strategies for dynamic cellular imaging Nat. Chem. Biol. $10512-23$

[54] Wolfbeis O S 2015 An overview of nanoparticles commonly used in fluorescent bioimaging Chem. Soc. Rev. doi: 10.1039/c4cs00392f

[55] Speers A E, Adam G C and Cravatt B F 2003 Activity-Based Protein Profiling in Vivo Using a Copper(I)-Catalyzed Azide-Alkyne [3+2] Cycloaddition J. Am. Chem. Soc. 125 4686-7

[56] Speers A E and Cravatt B F 2004 Profiling Enzyme Activities In Vivo Using Click Chemistry Methods Chem. Biol. 11 535-46

[57] Wright A T and Cravatt B F 2007 Chemical Proteomic Probes for Profiling Cytochrome P450 Activities and Drug Interactions In Vivo Chem. Biol. 14 1043-1051

[58] Seo T S, Li Z, Ruparel H and Ju J 2003 Click Chemistry to Construct Fluorescent Oligonucleotides for DNA Sequencing J. Org. Chem. 68 609-12

[59] Li X, Fang T and Boons G-J 2014 Preparation of Well-Defined Antibody-Drug Conjugates through Glycan Remodeling and Strain-Promoted Azide-Alkyne Cycloadditions Angew. Chem. 126 7307-10

[60] Shao F, Weissleder R and Hilderbrand S A 2008 Monofunctional carbocyanine dyes for bio- and bioorthogonal conjugation Bioconjugate Chem. 19 2487-91

[61] Sawa M, Hsu T-L, Itoh T, Sugiyama M, Hanson S R, Vogt P K and Wong C-H 2006 Glycoproteomic probes for fluorescent imaging of fucosylated glycans in vivo Proc. Natl. Acad. Sci. U.S.A. 103 12371-6

[62] Tsou L K, Zhang M M and Hang H C 2009 Clickable fluorescent dyes for multimodal bioorthogonal imaging Org. Biomol. Chem. 7 5055-8

[63] Lukinavičius G, Umezawa K, Olivier N, Honigmann A, Yang G, Plass T, Mueller V, Reymond L, Corrêa I R Jr, Luo Z-G, Schultz C, Lemke E A, Heppenstall P, Eggeling C, Manley S and Johnsson K 2013 A near-infrared fluorophore for live-cell superresolution microscopy of cellular proteins Nat. Chem. 5 132-9

[64] Yang K S, Budin G, Reiner T, Vinegoni C and Weissleder R 2012 Bioorthogonal Imaging of Aurora Kinase A in Live Cells Angew. Chem. Int. Ed. 51 6598-6603

[65] Fischer G M, Jüngst C, Isomäki-Krondahl M, Gauss D, Möller H M, Daltrozzo E and Zumbusch A 2010 Asymmetric PPCys: Strongly fluorescing NIR labels Chem. Commun. 46 5289-91

[66] Zhou M, Zhang X, Bai M, Shen D, Xu B, Kao J, Ge X and Achilefu S 2013 Click reaction-mediated functionalization of near-infrared pyrrolopyrrole cyanine dyes for biological imaging applications $R S C A d v .36756-8$

[67] Nagy K, Orbán E, Bősze Sz and Kele P 2010 Clickable Long-Wave "Mega-Stokes" Fluorophores for Orthogonal Chemoselective Labeling of Cells Chem. Asian. J. 5 7737

[68] Cserép G B, Enyedi K N, Demeter A, Mező G and Kele P 2013 NIR Mega-Stokes Fluorophores for Bioorthogonal Labeling and Energy Transfer Systems-An Efficient Quencher for Daunomycin Chem. Asian. J. 8 494-502 
[69] Stubinitzky C, Cserép G B, Bätzner E, Kele P and Wagenknecht H-A 2014 2'Deoxyuridine conjugated with a reactive monobenzocyclooctyne as a DNA building block for copper-free click-type postsynthetic modification of DNA Chem. Commun. 50 11218-21

[70] Kiick K L, Saxon E, Tirrell D A and Bertozzi C R 2002 Incorporation of azides into recombinant proteins for chemoselective modification by the Staudinger ligation Proc. Natl. Acad. Sci. U.S.A. 99 19-24

[71] Wang Q, Chan T R, Hilgraf R, Fokin V V, Sharpless K B and Finn M G 2003 Bioconjugation by Copper(I)-Catalyzed Azide-Alkyne [3 + 2] Cycloaddition J. Am. Chem. Soc. 125 3192-3

[72] Sivakumar K, Xie F, Cash B M, Long S, Barnhill H N and Wang Q 2004 A Fluorogenic 1,3-Dipolar Cycloaddition Reaction of 3-Azidocoumarins and Acetylenes Org. Lett. 6 4603-6

[73] Herner A, Nikić I, Kállay M, Lemke E A and Kele P 2013 A new family of bioorthogonally applicable fluorogenic labels Org. Biomol. Chem. 11 3297-306

[74] Urano Y, Kamiya M, Kanda K, Ueno T, Hirose K and Nagano T 2005 Evolution of Fluorescein as a Platform for Finely Tunable Fluorescence Probes J. Am. Chem. Soc. 127 4888-94

[75] Goonewardena S N, Leroueil P R, Gemborys C, Tahiliani P, Emery S, Baker J R Jr., Zong H 2013 Fluorogenic 'click-on' dendrimer reporter for rapid profiling of cell proliferation Bioorg. Med. Chem. Lett. 23 2230-3

[76] Dirksen A, Madsen M, Iacono G D, Matin M J, Bacica M, Stanković N, Callans S and Bhat A 2014 Parallel Synthesis and Screening of Peptide Conjugates Bioconjugate Chem. 25 1052-60

[77] Xie F, Sivakumar K, Zeng Q, Bruckman M A, Hodges B and Wang Q 2008 A fluorogenic 'click' reaction of azidoanthracene derivatives Tetrahedron 64 2906-14

[78] Seela F and Pujari S S 2010 Azide-Alkyne "Click" Conjugation of 8-Aza-7deazaadenine-DNA: Synthesis, Duplex Stability, and Fluorogenic Dye Labeling Bioconjugate Chem. 21 1629-41

[79] Pujari S S, Ingale S A and Seela F 2014 High-Density Functionalization and CrossLinking of DNA: "Click" and "Bis-Click" Cycloadditions Performed on Alkynylated Oligonucleotides with Fluorogenic Anthracene Azides Bioconjugate Chem. 25 1855-70

[80] Koide Y, Urano Y, Hanaoka K, Terai T and Nagano T 2011 Evolution of Group 14 Rhodamines as Platforms for Near-Infrared Fluorescence Probes Utilizing Photoinduced Electron Transfer ACS Chem. Biol. 6 600-8

[81] Shieh P, Hangauer M J and Bertozzi C R 2012 Fluorogenic Azidofluoresceins for Biological Imaging J. Am. Chem. Soc. 134 17428-31

[82] Shieh P, Siegrist M S, Cullen A J and Bertozzi C R 2014 Imaging bacterial peptidoglycan with near-infrared fluorogenic azide probes Proc. Natl. Acad. Sci. U.S.A. $1115456-61$

[83] Shieh P, Dien V T, Beahm B J, Castellano J M, Wyss-Coray T and Bertozzi C R 2015 CalFluors: A universal motif for fluorogenic azide probes across the visible spectrum $J$. Am. Chem. Soc. 137 7145-51

[84] Staros J V, Bayley H, Standring D N and Knowles J R 1978 Reduction of Aryl Azides by Thiols: Implications for the Use of Photoaffinity Reagents Biochem. Bioph. Res. Co. 80 568-72

[85] Shie J-J, Liu Y-C, Lee Y-M, Lim C, Fang J-M and Wong C-H 2014 An Azido-BODIPY Probe for Glycosylation: Initiation of Strong Fluorescence upon Triazole Formation $J$. Am. Chem. Soc. 136 9953-61 
[86] Wang C, Xie F, Suthiwangcharoen N, Sun J and Wang Q 2012 Tuning the optical properties of BODIPY dye through $\mathrm{Cu}(\mathrm{I})$ catalyzed azide-alkyne cycloaddition (CuAAC) reaction Sci. China 55 125-30

[87] Chauhan D P, Saha T, Lahiri M, Talukdar P 2014 BODIPY based 'click on' fluorogenic dyes: application in live cell imaging Tetrahedron Lett. 55 244-7

[88] Kamaruddin M A, Ung P, Hossain M I, Jarasrassamee B, O’Malley W, Thompson P, Scanlon D, Cheng H-C, Graham B 2011 A facile, click chemistry-based approach to assembling fluorescent chemosensors for protein tyrosine kinases Bioorg. Med. Chem. Lett. 21 329-31

[89] Hörner A, Volz D, Hagendorn T, Fürniss D, Greb L, Rönicke F, Nieger M, Schepersc $\mathrm{U}$ and Bräse S 2014 Switchable fluorescence by click reaction of a novel azidocarbazole dye $R S C A d v .4$ 11528-34

[90] Herner A, Girona G E, Nikić I, Kállay M, Lemke E A and Kele P 2014 New Generation of Bioorthogonally Applicable Fluorogenic Dyes with Visible Excitations and Large Stokes Shifts Bioconjugate Chem. 25 1370-4

[91] Zhou Z and Fahrni C J 2004 A Fluorogenic Probe for the Copper(I)-Catalyzed AzideAlkyne Ligation Reaction: Modulation of the Fluorescence Emission via ${ }^{3}\left(\mathrm{n}, \pi^{*}\right)-{ }^{1}\left(\pi, \pi^{*}\right)$ Inversion J. Am. Chem. Soc. 126 8862-3

[92] Jewett J C and Bertozzi C R 2011 Synthesis of a Fluorogenic Cyclooctyne Activated by Cu-Free Click Chemistry Org. Lett. 13 5937-9

[93] Friscourt F, Fahrni C J and Boons G-J 2012 A Fluorogenic Probe for the Catalyst-Free Detection of Azide-Tagged Molecules J. Am. Chem. Soc. 134 18809-15

[94] Lemieux G A, de Graffenried C L and Bertozzi C R 2003 A Fluorogenic Dye Activated by the Staudinger Ligation J. Am. Chem. Soc. 125 4708-9

[95] Azoulay M, Tuffin G, Sallem W and Florent J-C 2006 A new drug-release method using the Staudinger ligation Bioorg. Med. Chem. Lett. 16 3147-9

[96] Tsao M-L, Tian F and Schultz P G 2005 Selective Staudinger Modification of Proteins Containing $p$-Azidophenylalanine ChemBioChem 6 2147-9

[97] Saxon E, Armstrong J I and Bertozzi C R 2000 A "Traceless" Staudinger Ligation for the Chemoselective Synthesis of Amide Bonds Org. Lett. 2 2141-3

[98] Hangauer M J and Bertozzi C R 2008 A FRET-Based Fluorogenic Phosphine for LiveCell Imaging with the Staudinger Ligation Angew. Chem. Int. Ed. 47 2394-7

[99] Cohen A S, Dubikovskaya E A, Rush J S and Bertozzi C R 2010 Real-Time Bioluminescence Imaging of Glycans on Live Cells J. Am. Chem. Soc. 132 8563-5

[100] Furukawa K, Abe H, Hibino K, Sako Y, Tsuneda S and Ito Y 2009 Reduction-Triggered Fluorescent Amplification Probe for the Detection of Endogenous RNAs in Living Human Cells Bioconjugate Chem. 20 1026-36

[101] Pianowski Z, Gorska K, Oswald L, Merten C A and Winssinger N 2009 Imaging of mRNA in Live Cells Using Nucleic Acid-Templated Reduction of Azidorhodamine Probes J. Am. Chem. Soc. 131 6492-7

[102] Clovis J S, Eckell A, Huisgen R and Sustmann R 1967 Der Nachweis des freien Diphenylnitrilimins als Zwischenstufe bei Cycloadditionen Chem. Ber. 100 60-70

[103] An P, Yu Z and Lin Q 2013 Design of oligothiophene-based tetrazoles for lasertriggered photoclick chemistry in living cells Chem. Commun. 49 9920-2

[104] Yu Z, Pan Y, Wang Z, Wang J and Lin Q 2012 Genetically Encoded Cyclopropene Directs Rapid, Photoclick-Chemistry-Mediated Protein Labeling in Mammalian Cells Angew. Chem. Int. Ed. 51 10600-4

[105] Yu Z, Ho L Y and Lin Q 2011 Rapid, Photoactivatable Turn-On Fluorescent Probes Based on an Intramolecular Photoclick Reaction J. Am. Chem. Soc. 133 11912-5 
[106] Devaraj N K, Hilderbrand S, Upadhyay R, Mazitschek R and Weissleder R 2010 Bioorthogonal Turn-On Probes for Imaging Small Molecules inside Living Cells Angew. Chem. Int. Ed. 49 2869-72

[107] Pyka A M, Domnick C, Braun F and Kath-Schorr S 2014 Diels-Alder Cycloadditions on Synthetic RNA in Mammalian Cells Bioconjugate Chem. 25 1438-43

[108] Asare-Okai P N, Agustin E, Fabris D and Royzen M 2014 Site-specific fluorescence labelling of RNA using bio-orthogonal reaction of trans-cyclooctene and tetrazine Chem. Commun. 50 7844-7

[109] Holstein J M, Stummer D and Rentmeister A 2015 Enzymatic modification of 5' -capped RNA with a 4-vinylbenzyl group provides a platform for photoclick and inverse electron-demand Diels-Alder reaction Chem. Sci. 6 1362-9

[110] Lang K, Davis L, Wallace S, Mahesh M, Cox D J, Blackman M L, Fox J M and Chin J W 2012 Genetic Encoding of Bicyclononynes and trans-Cyclooctenes for Site-Specific Protein Labeling in Vitro and in Live Mammalian Cells via Rapid Fluorogenic Diels-Alder Reactions J. Am. Chem. Soc. 134 10317-20

[111] Lang K, Davis L, Torres-Kolbus J, Chou C, Deiters A and Chin J W 2012 Genetically encoded norbornene directs site-specific cellular protein labelling via a rapid bioorthogonal reaction Nat. Chem. 4 298-304

[112] Liu D S, Tangpeerachaikul A, Selvaraj R, Taylor M T, Fox J M and Ting A Y 2012 Diels-Alder Cycloaddition for Fluorophore Targeting to Specific Proteins inside Living Cells J. Am. Chem. Soc. 134 792-5

[113] Yang J, Šečkutė J, Cole C M and Devaraj N K 2012 Live-Cell Imaging of Cyclopropene Tags with Fluorogenic Tetrazine Cycloadditions Angew. Chem. Int. Ed. 51 7476-9

[114] Jiao G-S, Thoresen L H and Burgess K 2003 Fluorescent, Through-Bond Energy Transfer Cassettes for Labeling Multiple Biological Molecules in One Experiment $J$. Am. Chem. Soc. 125 14668-9

[115] Wan C-W, Burghart A, Chen J, Bergström F, Johansson L B-Å, Wolford M F, Kim T G, Topp M R, Hochstrasser R M and Burgess K 2003 Anthracene-BODIPY Cassettes: Syntheses and Energy Transfer Chem. Eur. J. 9 4430-41

[116] Carlson J C T, Meimetis L G, Hilderbrand S A and Weissleder R 2013 BODIPYTetrazine Derivatives as Superbright Bioorthogonal Turn-on Probes Angew. Chem. Int. Ed. 52 6917-20

[117] Wieczorek A, Buckup T and Wombacher R 2014 Rigid tetrazine fluorophore conjugates with fluorogenic properties in the inverse electron demand Diels-Alder reaction Org. Biomol. Chem. 12 4177-85

[118] Wu H, Cisneros B T, Cole C M and Devaraj N K 2014 Bioorthogonal TetrazineMediated Transfer Reactions Facilitate Reaction Turnover in Nucleic Acid-Templated Detection of MicroRNA J. Am. Chem. Soc. 136 17942-5

[119] Wu H, Yang J, Šeškute J and Devaraj N K 2014 In Situ Synthesis of Alkenyl Tetrazines for Highly Fluorogenic Bioorthogonal Live-Cell Imaging Probes Angew. Chem. Int. Ed. 53 5805-9

[120] Meimetis L G, Carlson J C T, Giedt R J, Kohler R H and Weissleder R 2014 Ultrafluorogenic Coumarin-Tetrazine Probes for Real-Time Biological Imaging Angew. Chem. Int. Ed. 53 7531-4

[121] Madani F, Lind J, Damberg P, Adams S R, Tsien R Y and Gräslund A O 2009 Hairpin Structure of a Biarsenical-Tetracysteine Motif Determined by NMR Spectroscopy $J$. Am. Chem. Soc. 131 4613-5

[122] Griffin B A, Adams S R, Tsien R Y 1998 Specific Covalent Labeling of Recombinant Protein Molecules Inside Live Cells Science 281 269-72 
[123] Adams S R, Campbell R E, Gross L A, Martin B R, Walkup G K, Yao Y, Llopis J and Tsien R Y 2002 New Biarsenical Ligands and Tetracysteine Motifs for Protein Labeling in Vitro and in Vivo: Synthesis and Biological Applications J. Am. Chem. Soc. 124 6063-76

[124] Hoffmann C, Gaietta G, Zürn A, Adams S R, Terrillon S, Ellisman M H, Tsien R Y and Lohse M J 2010 Fluorescent labeling of tetracysteine-tagged proteins in intact cells Nat. Protoc. 5 1666-77

[125] Cao H, Xiong Y, Wang T, Chen B, Squier T C and Mayer M U 2007 A Red Cy3-Based Biarsenical Fluorescent Probe Targeted to a Complementary Binding Peptide J. Am. Chem. Soc. 129 8672-3

[126] Fu N, Xiong Y, and Squier T C 2012 Synthesis of a Targeted Biarsenical Cy3-Cy5 Affinity Probe for Super-resolution Fluorescence Imaging J. Am. Chem. Soc. 134 18530-3

[127] Alexander S C and Schepartz A 2014 Interactions of AsCy3 with Cysteine-Rich Peptides Org. Lett. 16 3824-7

[128] Halo T L, Appelbaum J, Hobert E M, Balkin D M, and Schepartz A 2009 Selective Recognition of Protein Tetraserine Motifs with a Cell-Permeable, Pro-fluorescent Bisboronic Acid J. Am. Chem. Soc. 131 438-9

[129] Girouard S, Houle M-H, Grandbois A, Keillor J W and Michnick S W 2005 Synthesis and Characterization of Dimaleimide Fluorogens Designed for Specific Labeling of Proteins J. Am. Chem. Soc. 127 559-66

[130] Guy J, Caron K, Dufresne S, Michnick S W, Skene W G and Keillor J W 2007 Convergent Preparation and Photophysical Characterization of Dimaleimide Dansyl Fluorogens: Elucidation of the Maleimide Fluorescence Quenching Mechanism J. Am. Chem. Soc. 129 11969-77

[131] Chen Y, Clouthier C M, Tsao K, Strmiskova M, Lachance H and Keillor J W 2014 Coumarin-Based Fluorogenic Probes for No-Wash Protein Labeling Angew. Chem. Int. Ed. 53 13785-8

[132] Feldborg L N, Jølck R I and Andresen T L 2012 Quantitative evaluation of bioorthogonal chemistries for surface functionalization of nanoparticles Bioconjugate Chem. 23 2444-50

[133] Murray C B, Norris D J and Bawendi M G 1993 Synthesis and characterization of nearly monodisperse $\mathrm{CdE}$ ( $\mathrm{E}=$ sulfur, selenium, tellurium) semiconductor nanocrystallites $J$. Am. Chem. Soc. 115 8706-15

[134] Medintz I L, Uyeda H T, Goldman E R and Mattoussi H 2005 Quantum dot bioconjugates for imaging, labelling and sensing Nat Mater 4 435-46

[135] Bernardin A, Cazet A, Guyon L, Delannoy P, Vinet F, Bonnaffé D and Texier I 2010 Copper-free click chemistry for highly luminescent quantum dot conjugates: application to in vivo metabolic imaging Bioconjug. Chem. 21 583-8

[136] Han H-S, Devaraj N K, Lee J, Hilderbrand S A, Weissleder R and Bawendi M G 2010 Development of a bioorthogonal and highly efficient conjugation method for quantum dots using tetrazine-norbornene cycloaddition J. Am. Chem. Soc. 132 7838-9

[137] Han H-S, Niemeyer E, Huang Y, Kamoun W S, Martin J D, Bhaumik J, Chen Y, Roberge S, Cui J, Martin M R, Fukumura D, Jain R K, Bawendi M G and Duda D G 2015 Quantum dot/antibody conjugates for in vivo cytometric imaging in mice Proc. Natl. Acad. Sci. U.S.A. 112 1350-5

[138] Pan H, Zhang P, Gao D, Zhang Y, Li P, Liu L, Wang C, Wang H, Ma Y and Cai L 2014 Noninvasive visualization of respiratory viral infection using bioorthogonal conjugated near-infrared-emitting quantum dots ACS Nano 8 5468-77 
[139] Auzel F 2004 Upconversion and anti-Stokes processes with $\mathrm{f}$ and $\mathrm{d}$ ions in solids Chem. Rev. 104 139-74

[140] Wang F and Liu X 2009 Recent advances in the chemistry of lanthanide-doped upconversion nanocrystals Chem. Soc. Rev. 38 976-89

[141] Mader H S, Kele P, Saleh S M and Wolfbeis O S 2010 Upconverting luminescent nanoparticles for use in bioconjugation and bioimaging Curr. Opin. Chem. Biol. $14582-$ 96

[142] Mader H S, Link M, Achatz D E, Uhlmann K, Li X and Wolfbeis O S 2010 SurfaceModified Upconverting Microparticles and Nanoparticles for Use in Click Chemistries Chem. Eur. J. 16 5416-24

[143] Rubner M M, Achatz D E, Mader H S, Stolwijk J A, Wegener J, Harms G S, Wolfbeis O S and Wagenknecht H-A 2012 DNA "Nanolamps": "Clicked" DNA Conjugates with Photon Upconverting Nanoparticles as Highly Emissive Biomaterial ChemPlusChem 77 129-34

[144] Boyer J-C, Carling C-J, Chua S Y, Wilson D, Johnsen B, Baillie D and Branda N R 2012 Photomodulation of Fluorescent Upconverting Nanoparticle Markers in Live Organisms by Using Molecular Switches Chem. Eur. J. 18 3122-6

[145] Beyazit S, Ambrosini S, Marchyk N, Palo E, Kale V, Soukka T, Tse Sum Bui B and Haupt K 2014 Versatile Synthetic Strategy for Coating Upconverting Nanoparticles with Polymer Shells through Localized Photopolymerization by Using the Particles as Internal Light Sources Angew. Chem. Int. Ed. 53 8919-23

[146] Faklaris O, Joshi V, Irinopoulou T, Tauc P, Sennour M, Girard H, Gesset C, Arnault J-C, Thorel A, Boudou J-P, Curmi P A and Treussart F 2009 Photoluminescent Diamond Nanoparticles for Cell Labeling: Study of the Uptake Mechanism in Mammalian Cells ACS Nano 3 3955-62

[147] Schrand A M, Huang H, Carlson C, Schlager J J, Ōsawa E, Hussain S M and Dai L 2007 Are diamond nanoparticles cytotoxic? J. Phys. Chem. B 111 2-7

[148] Rehor I, Slegerova J, Kucka J, Proks V, Petrakova V, Adam M-P, Treussart F, Turner S, Bals S, Sacha P, Ledvina M, Wen A M, Steinmetz N F and Cigler P 2014 Fluorescent Nanodiamonds Embedded in Biocompatible Translucent Shells Small 10 1106-15

[149] Rehor I, Mackova H, Filippov S K, Kucka J, Proks V, Slegerova J, Turner S, van Tendeloo G, Ledvina M, Hruby M and Cigler P 2014 Fluorescent Nanodiamonds with Bioorthogonally Reactive Protein-Resistant Polymeric Coatings ChemPlusChem 79 214

[150] Mader H, Li X, Saleh S, Link M, Kele P, and Wolfbeis O S 2008 Fluorescent silica nanoparticles Ann. N. Y. Acad. Sci. 1130 218-23

[151] Lai C-H, Chang T-C, Chuang Y-J, Tzou D-L and Lin C-C 2013 Stepwise orthogonal click chemistry toward fabrication of paclitaxel/galactose functionalized fluorescent nanoparticles for HepG2 cell targeting and delivery Bioconjugate Chem. 24 1698-709

[152] Kele P, Mező G, Achatz D and Wolfbeis O S 2009 Dual labeling of biomolecules by using click chemistry: a sequential approach Angew. Chem. Int. Ed. 48 344-7

[153] Achatz D E, Mező G, Kele P and Wolfbeis O S 2009 Probing the activity of matrix metalloproteinase II with a sequentially click-labeled silica nanoparticle FRET probe ChemBioChem 10 2316-20

[154] Haun J B, Devaraj N K, Hilderbrand S A, Lee H and Weissleder R 2010 Bioorthogonal chemistry amplifies nanoparticle binding and enhances the sensitivity of cell detection Nat. Nanotechnol. 5 660-5

[155] Chung H J, Castro C M, Im H, Lee H and Weissleder R 2013 A magneto-DNA nanoparticle system for rapid detection and phenotyping of bacteria Nat. Nanotechnol. 8 369-75 
[156] Haun J B, Devaraj N K, Marinelli B S, Lee H and Weissleder R 2011 Probing intracellular biomarkers and mediators of cell activation using nanosensors and bioorthogonal chemistry ACS Nano 5 3204-13

[157] Wu C, Szymanski C, Cain Z and McNeill J 2007 Conjugated polymer dots for multiphoton fluorescence imaging J. Am. Chem. Soc. 129 12904-5

[158] Wu C, Bull B, Szymanski C, Christensen K and McNeill J 2008 Multicolor conjugated polymer dots for biological fluorescence imaging ACS Nano 2 2415-23

[159] Moon J H, McDaniel W, MacLean P and Hancock L F 2007 Live-Cell-Permeable Poly(p-phenylene ethynylene) Angew. Chem. Int. Ed. 46 8223-25

[160] Wu C, Jin Y, Schneider T, Burnham D R, Smith P B and Chiu D T 2010 Ultrabright and Bioorthogonal Labeling of Cellular Targets Using Semiconducting Polymer Dots and Click Chemistry Angew. Chem. Int. Ed. 49 9436-40

[161] Petersen A L, Hansen A E, Gabizon A and Andresen T L 2012 Liposome imaging agents in personalized medicine Adv. Drug Deliv. Rev. 64 1417-35

[162] Phillips M A, Gran M L and Peppas N A 2010 Targeted nanodelivery of drugs and diagnostics Nano Today 5 143-59

[163] Maeda H, Wu J, Sawa T, Matsumura Y and Hori K 2000 Tumor vascular permeability and the EPR effect in macromolecular therapeutics: a review J. Control Release 65271 84

[164] Koo H, Lee S, Na J H, Kim S H, Hahn S K, Choi K, Kwon I C, Jeong S Y and Kim K 2012 Bioorthogonal copper-free click chemistry in vivo for tumor-targeted delivery of nanoparticles Angew. Chem. Int. Ed. 51 11836-40 